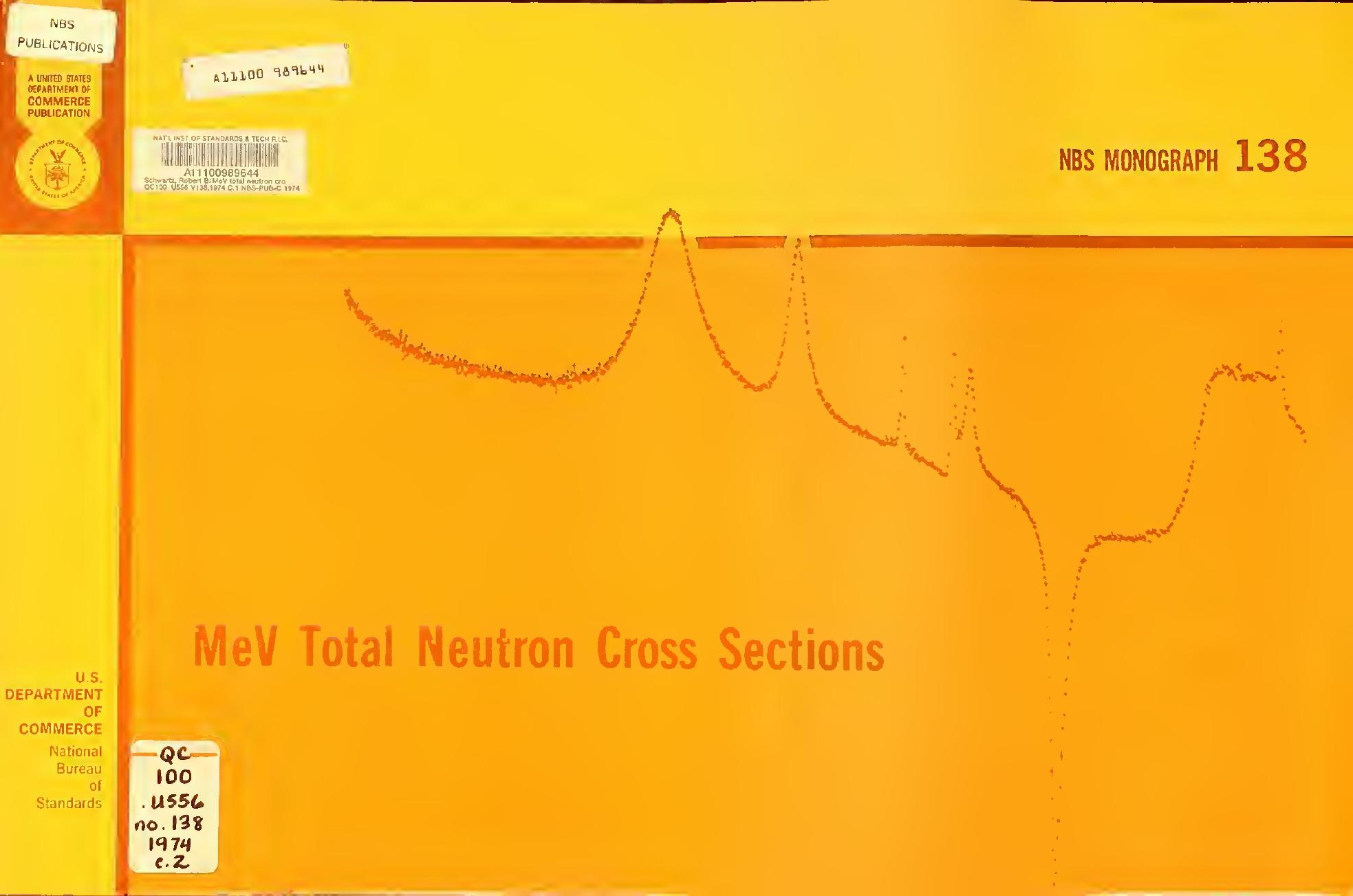


The Nulionat Eureat of Standards' was established by an act of Congress March 3, 1901 The flurene's ovcralt goal is to sirengthen and advance the Nation's sciense and lechnolog and taciltuste their effective application for public henefit. To this end, the Buseau conducts revesich and provides: (1) a basis for the Nathon's physical measurement system, (2) scientific and lechnological servees for industry and governmenl, (3) a technical basis for equity in trade, and (t) Iechnical servites to promote rablic safety. The Bureau consists of the Institute for the Institule for Corrinster Sciences and Technology, and the Office for Applicd Technology,

THE INSTITUTE FOR BASIC STANDARDS provides the eentral tasis within the United States of a complete and consistent syvtem of physical messurement; coordinates that systern with measurement systems of other natons, and furnishes essential services leading to ace urate and inthrtm shysseal micasurements thuoughoul the Nation's scientific community, industry. and commerce. The Inctitute consists of a Center for Radiation Research, an Office of Meas-

Appled Mathemalics - Elecricily - Mechanics - Hent - Optical Physics - Nuclear

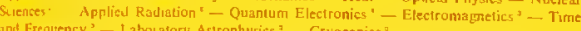
aboutory Adrophysic ${ }^{7}$ - Cryogenic

IHE INSTITUTE FOR MATERIALS RESEARCH conducls materials nescarch leading to improwed methods of meaturetrent, standards, and data on the properties of well-characterized udvisory and reseorch serviees to othe, educational ansifututions, and Government; provides distiklutes standard teferense materials. The Institute consists of the Office of Standard Reference Matc ials and the following divisons:

Analynizal Chernistiy - Polymers - Metallurgy - Inorganic Muterials - Reacior Radiation - Physical Chernistry.

THE IASTITUTE FOR APPLIED TECHNOLOGY provides technical services to promot the noe of avalable techrology and to facilitale technological innovation in industry and Iechnologreal standates wath public and privale organizations leading to the development of

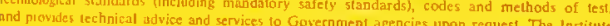

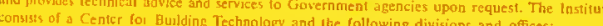
Tects

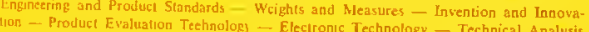
- Mteasurerrent Engineering - SIructures, Materials, and Life Satety" Enstronnen! " - Technical Evaluation and Application " - Fire Teehnology. Building

THE NSTITUTE FOR COMPUTER SCIENCES AND TECHNOLOGY cONdUELS research and provides lechnical services designed to ajd Government agencies in improving cost effec. liveness in the conduct of therr programs through the selection, acquisiuon, and effective

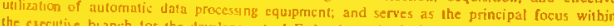
colipment. equipmitnt. techniques, and computer languages. The Insiltute consists of the following

Cornputer Services Systerns and Soltwarc - Computer Systems Eneineering - Informa. tritholosy

THE OFHICE FOR INLORMATION PROGRAMS Rromotes OPLImuE dissemination and accessibulity of scientific informution generated withis NBS and other agencies of the Federal Governenent: promoles the development of the National Standard Reference Data System and Me systcrn of informalion analysis centers dealing with the broader aspects of the National

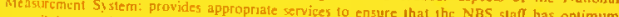
atwessititly to the xicntine unformation of the world. The Office consists of the following rganizaliosal units $x$ Office of Standard Reference Data - Offece of Information Activitits - Office of Technical
Publicalions - Litrary Offece ol International Relations.

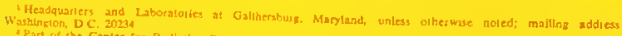

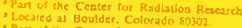

"Pari as the Cenler for Buildua Tecthentor 


\section{MeV Total Neutron Cross Sections}

Robert B. Schwartz, Roald A. Schrack, and H. Thompson Heaton, II

Nuclear Sciences Division

Institute for Basic Standard

National Bureau of Standards

Washington, D.C. 20234

mo

Mcniarich no. 13

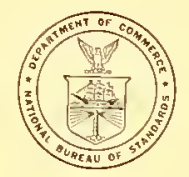

U.S. DEPARTMENT OF COMMERCE, Frederick B, Dent, Secretory

NATIONAL BUREAU OF STANDARDS, Richard W. Raberts, Director

Issued January 1974 
Library of Congress Catalog Number: 73-600276

National Bureau of Standards Monograph 138

Nat Bur, Stond, (US.), Monour. 138, 160 prages (Jan. 1974) CODEN: NBSMAG

US, GOVERYMIENT PRINTING OFFICE

WASHINGTON:

For sale by the Supcrintcrdent of Documenty, U.S. Covernment Printing Offec, Washington, D.C. 20402

(Order by SD Calaloz No, C13,44-138). Price $\$ 3.60$ 


\section{Contents}

CROSS SECTION CURVES

1. Introduction.

Page

Curves..

1

\section{APPENDIX - EXPERIMENTAL TECHNIQUES}

A1. Experimental Arrangement.

烈

Accelerator ............................................... A A

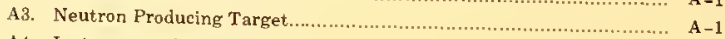

A4. Instrumentation............................. A-2

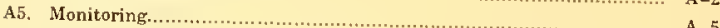

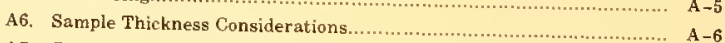

A7. Corrections to the Data

A8. Summary

A9. Referention A 7

R 



\section{MeV Total Neutron Cross Sections*}

\section{Robert B. Schwartz, Roald A. Schrack, and H. Thompson Heaton, II}

This report is a compilation of the MeV neutron total cross section dat a meagured at the Nationa Bureau of Standards over the past several years. The measurements generally span the energy in eleme plete details of the separated isotopes $=U$,

Key words: MeV neutrons; neutron time-of-fight; neutron total cross sections.

\section{Introduction}

This report is a compilation of the MeV Total Neutron Cross Section data measured at the U.S. National Bureau of Standards. The neutron time-of-flight method used for the measurements, with the NBS electron linear accelerator as the pulse neutron source. The measurements were made over the energy range 0.5 to pulse (in some cases, only to $15 \mathrm{MeV}$ ). Except for the uranium and plutonium measurements were made on the nat urally occurring isotopiches, the in question. In each case, the data are presented in the for of and logrithme presented in the form of graphs, both linear and logarithmic. Descriptive notes are also included for each element, giving details cerning the samples

Most of these data have not as yet been formally published. In most cases, however, the dat a have been presented orally at various meetings of the American American Phys talks.

Details of the experimental technique are given in the appendix.

1.1. Quality of Data

A. Energy Resolution

At low energies the resolution is largely determined by the neutron detector thickness $(12.7 \mathrm{~cm})$; at high energies the electronic response function plays the dominant role. For our $40 \mathrm{~m}$ flight path, the resolution varies from $0.2 \mathrm{~ns} / \mathrm{m}$ at $500 \mathrm{keV}$ to $0.08 \mathrm{~ns} / \mathrm{m}$ at $15 \mathrm{MeV}$. The resolution as a function to $0.08 \mathrm{~ns} / \mathrm{m}$ at

"This work was supported in part by the U.S. Deferse Nuclear Agerey, Waghington, D.c. 20305.
B. Energy Scale Uneertainty

The energy scale uncertainty is $0.04 \mathrm{~ns} / \mathrm{m}$. There is excellent agreement between our energy assignments and, for example, the precision neutron energy determinations of Davis and Noda (Nucl. Phys. A134, 361 (1969))

\section{Absolute Aceuracy}

The absolute accuracy of the data is estimated to be within \pm 1 percent. This estimate is based largely on the excellent $(<1 \%)$ internal consistency of data taken with different sample thicknesses, and under different experimental conditions, as well as the excellent $(<1 \%$ ) agreement between our hydrogen data (Schwartz et al. Phys. Letters $30 \mathrm{~B}, 36(1969)$ ) and previously measured values, as represented by al. shape-independent effective range theory. Detgiled comparisons between our tat and those from other laboratories will be Diven in later pulications, we simply state here that such state here that such comparisons have generally shown good agreement consistent with our estimated 1 percent accuracy.

D. Statistical Precision

The statistical errors are generally 1 percent to 2 percent per point, but somewhat poorer at the extreme high and low energy regions of our data. In any case, the sta tistical errors are indicated by the usual vertical lines at every tenth point on our curves, except in cases where the error bars are smaller than the points.

\subsection{Experimental Technique}

A brief account of our experimental setup has been given previously (R. B. Schwartz, H. T. Heaton II, and R. A. Schrack, Proc. Symposium Neutron Standards and Flux Normalization, AEC Conf-701002, Argonne, Illinois, p. 377 (October 21 $1970)$ ). This description is brought up to date, and further details given, in the appendix. 



\section{HYDROGEN}

\section{Sample material: $\quad$ polyethylene $\left(\mathrm{CH}_{z}\right) \mathrm{x}$}

open: high-purity carbon

Sample diameter: $\quad 12.7 \mathrm{~cm}$

Sample thickness: $\quad 18.3 \mathrm{~cm}$

$n=1.438$ atoms/barn of hydrogen

Analysis: polyethylene: stochastic ratio of hydrogen to carbon within 0.04 percent of theoretical value

carbon: Volatile and nonvolatile contamination less than 0.01 percent

Literature Reference: R. B. Schwartz, R. A. Schrack, and H. T. Heaton II, Physics Letters 30B, 36 (1969); also, Proc Symp. Neutron Standards and Flux Normalization, AEC CONF-701002, Argonne, Illinois, p. 57 (Oct. 21, 1970)

Comments: Equality of carbon atoms/barn in the carbon and polyethylene samples can be seen from the absence of structure in the are large peaks in the carbon cross section (e.e., $2.1 \mathrm{MeV}$ ), but there are no net fluctuations. 


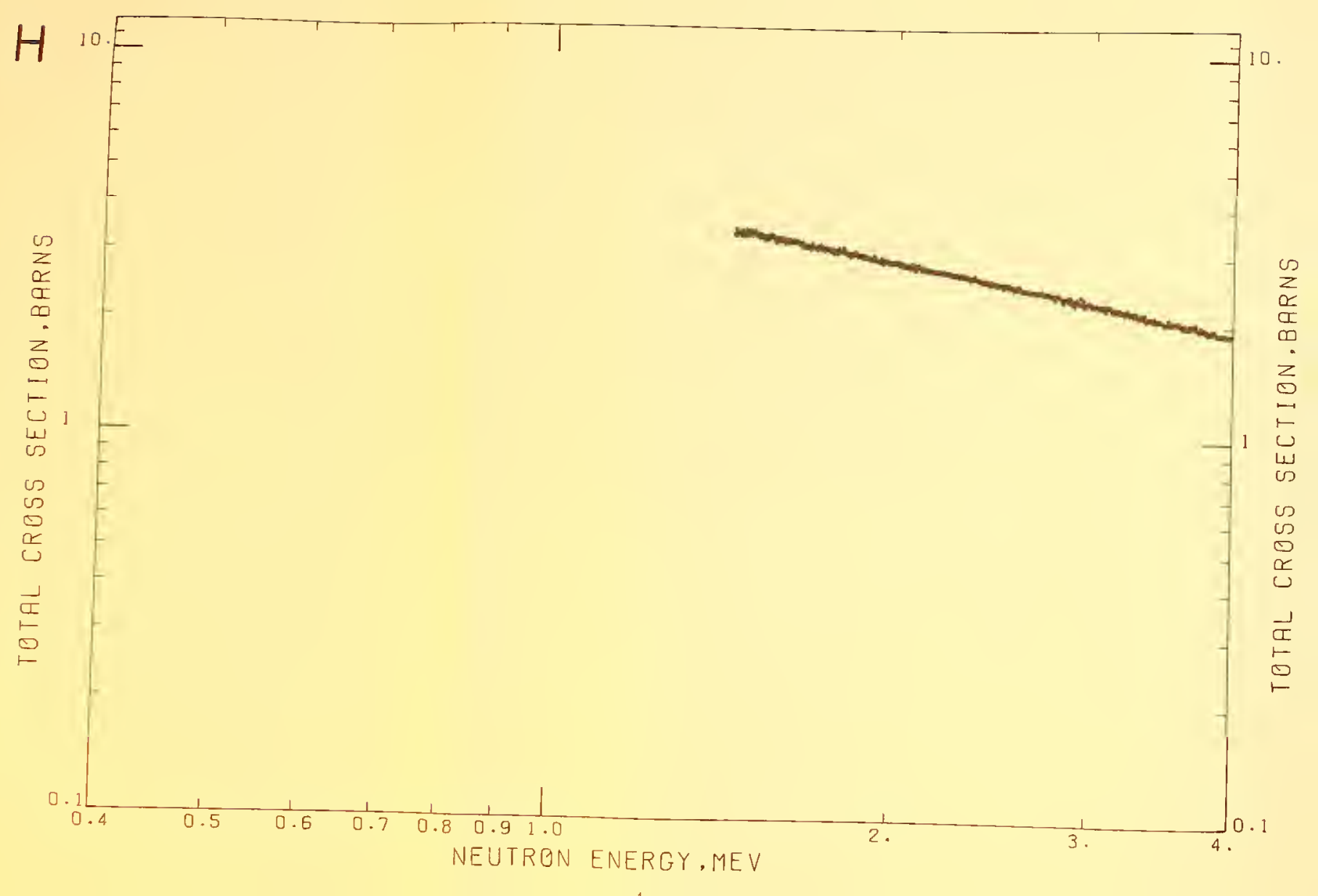




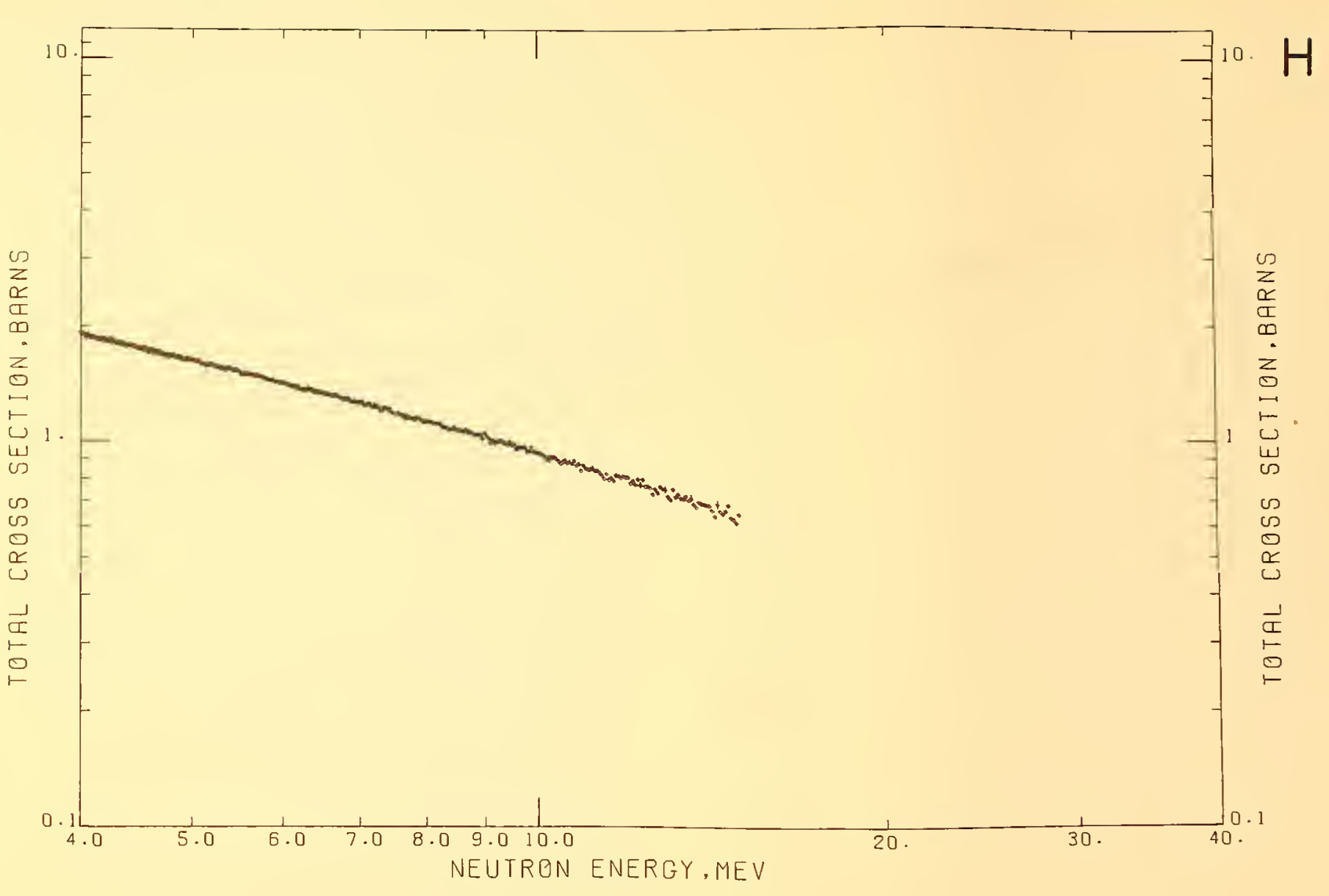




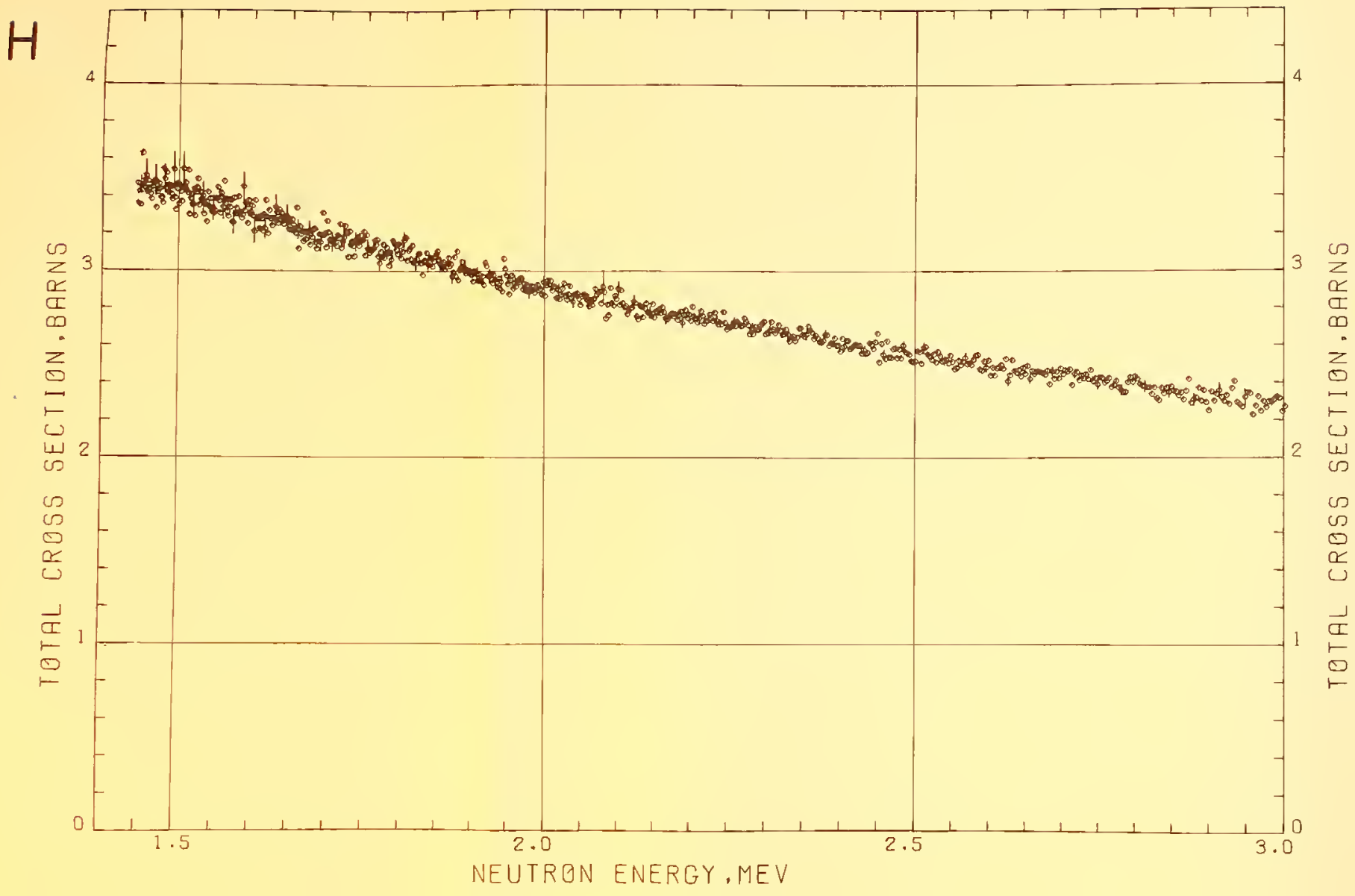




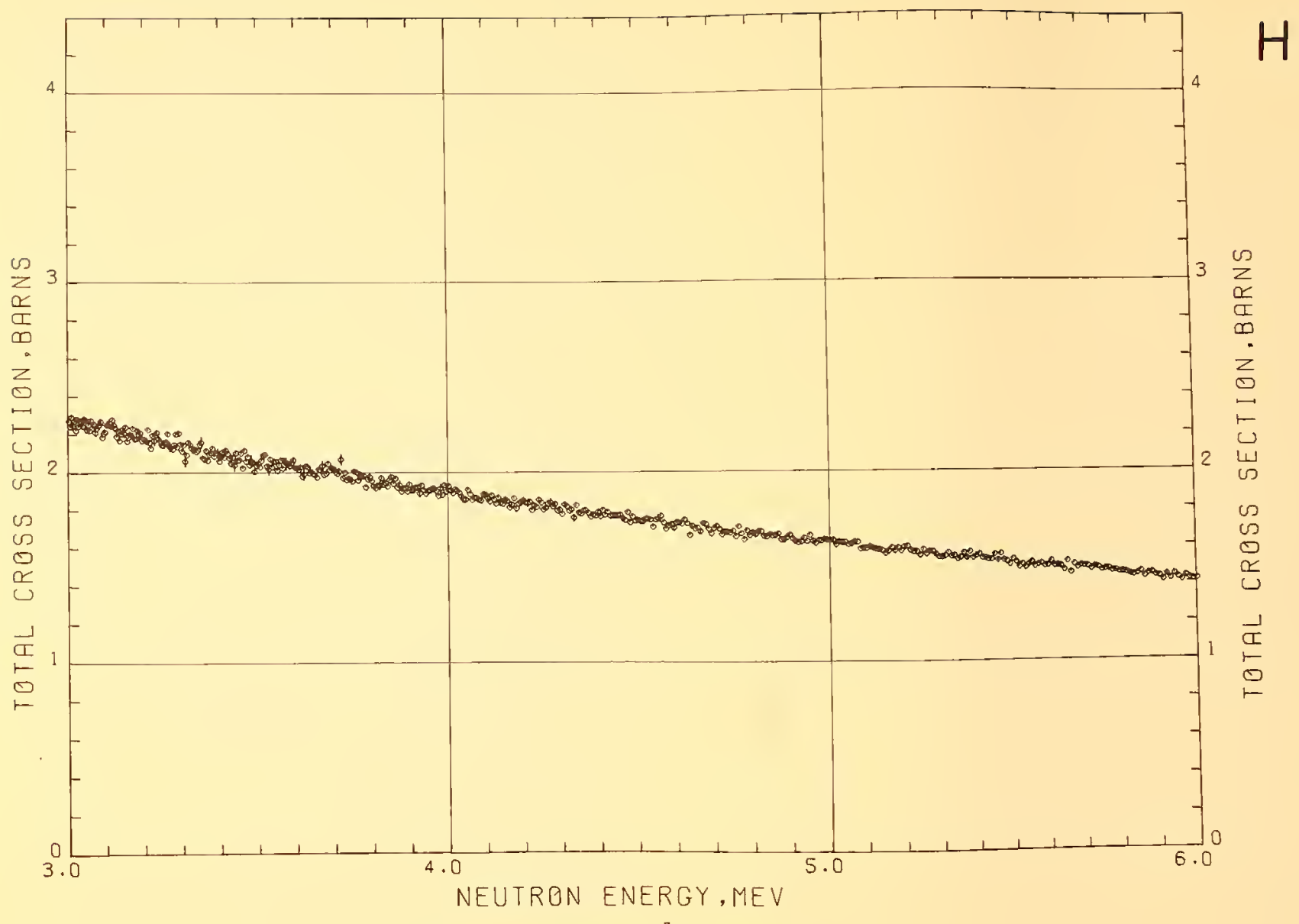




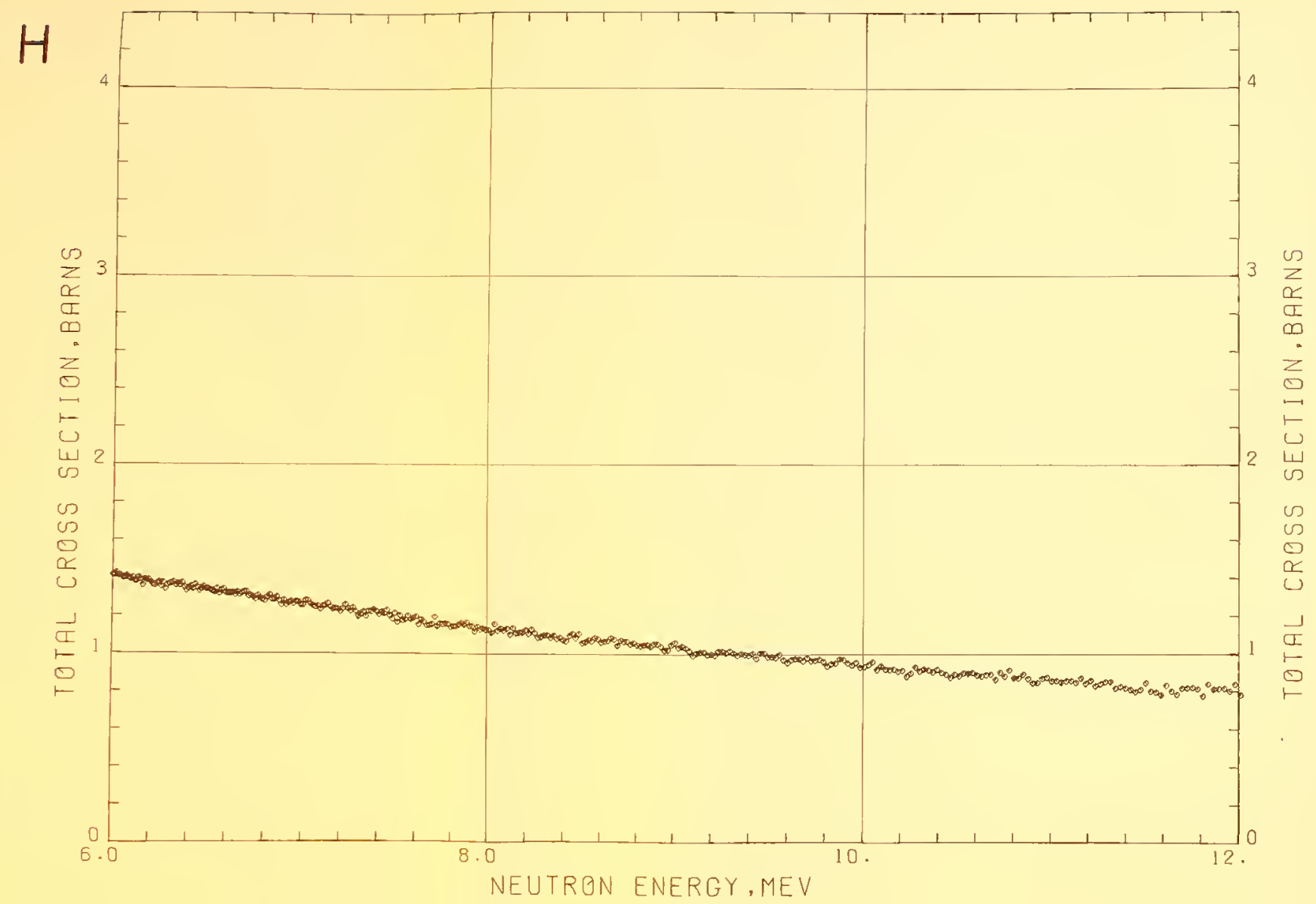




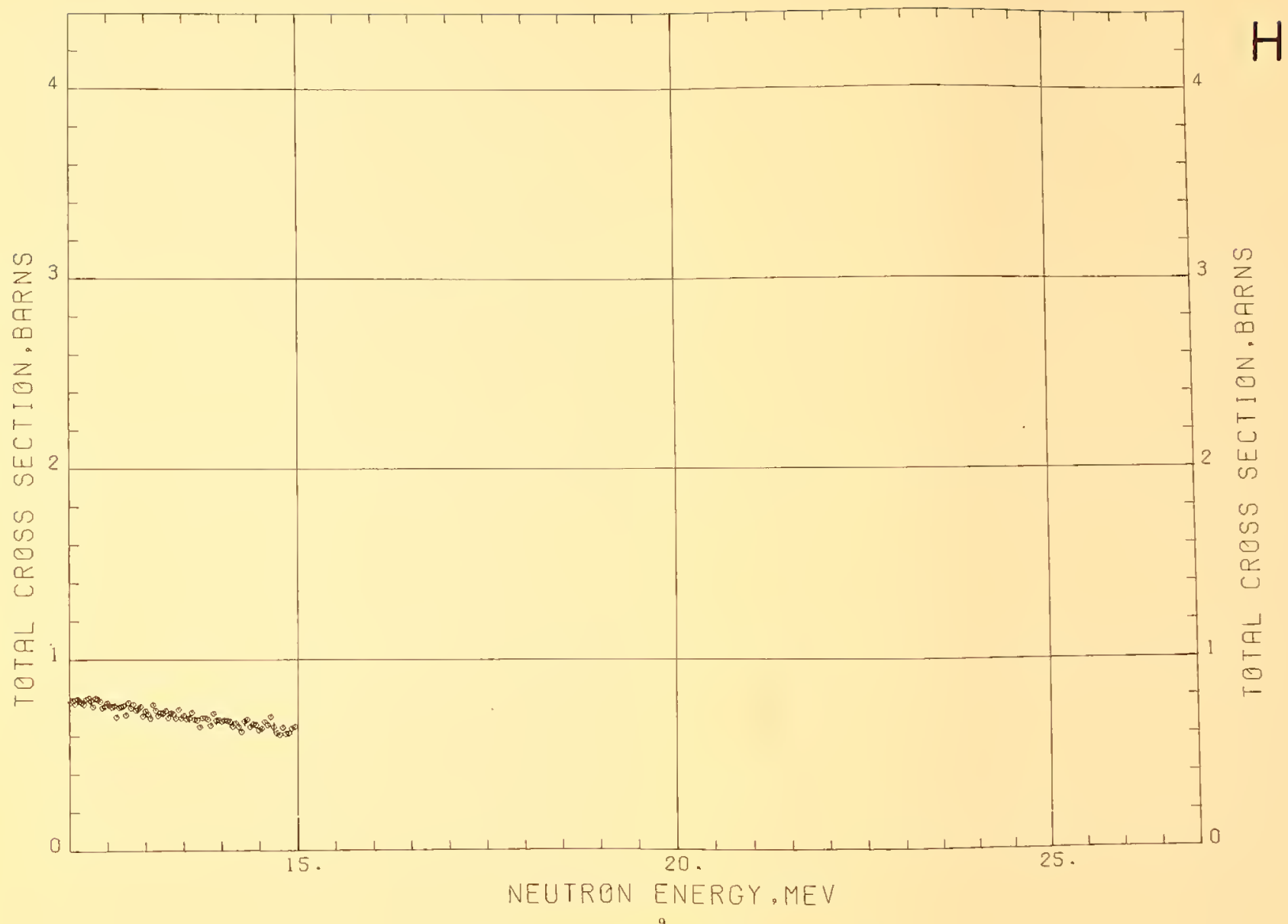


0 


\section{BERYLLIUM}

Sample Material: metallic beryllium

Sample Diameter: $\quad 12.7 \mathrm{~cm}$

Sample Thicknesses: $\quad 3.3 \mathrm{~cm} ; n=0.4069 \mathrm{atomg} / \mathrm{barn}$

$7.65 \mathrm{~cm} ; n=0.9447$

Analysis: $>99.39$ percent beryllium

principal impurity: $<0,6$ percent oxygen

Literature Reference: R. A. Schrack, R. B. Schwartz, and H. T. Heaton II, Bull. Am. Phys. Soc. 16, 495 (1971), 


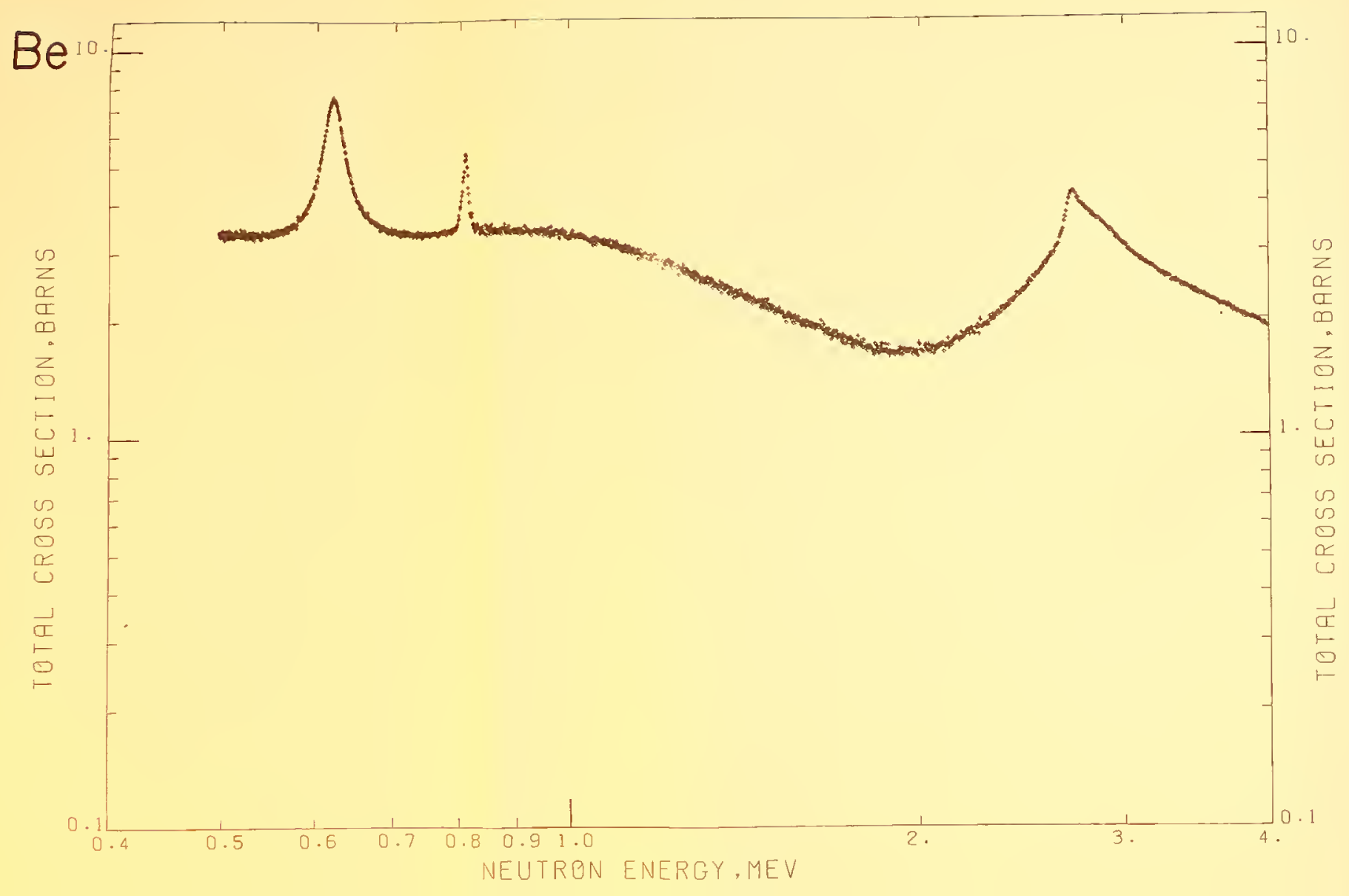




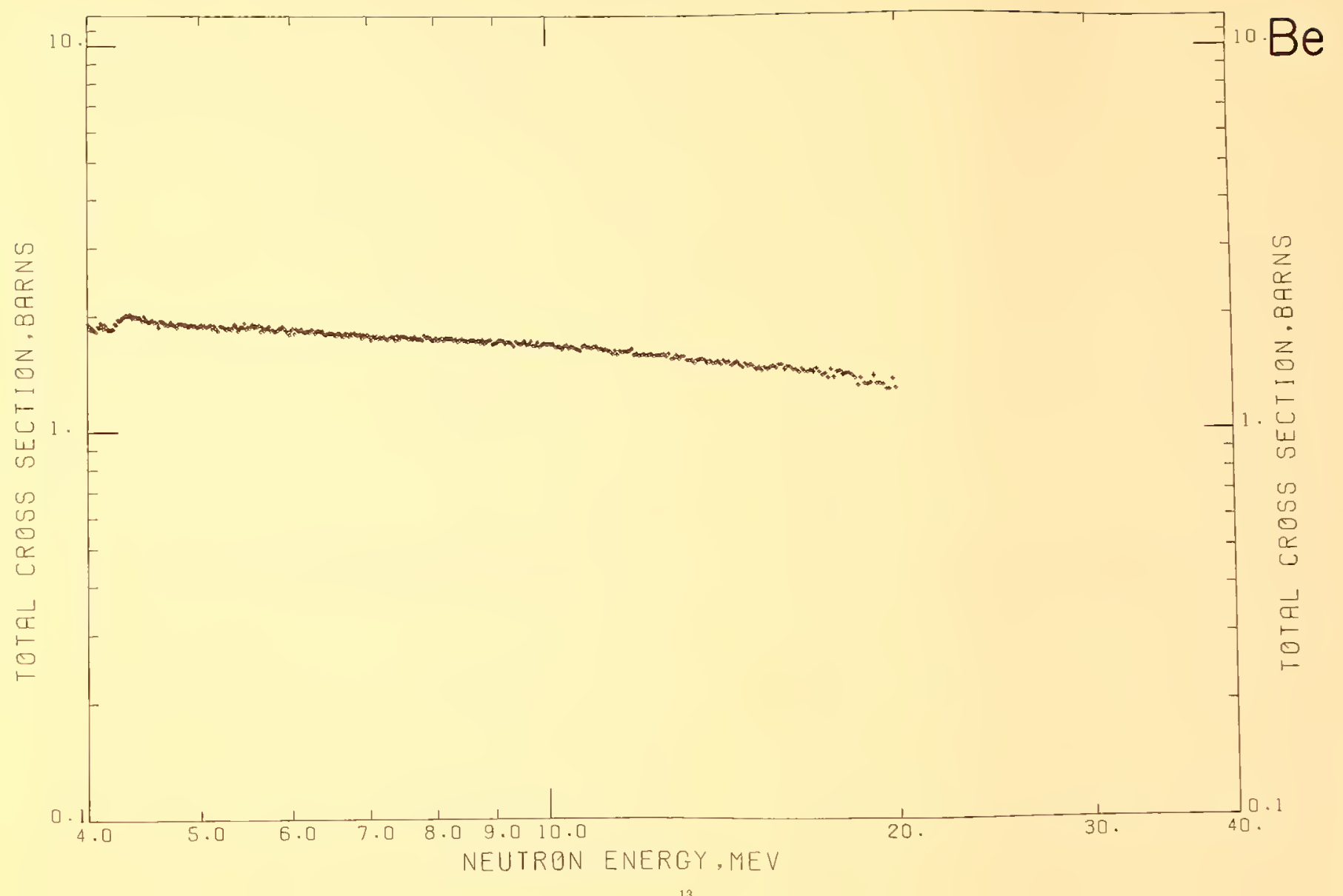




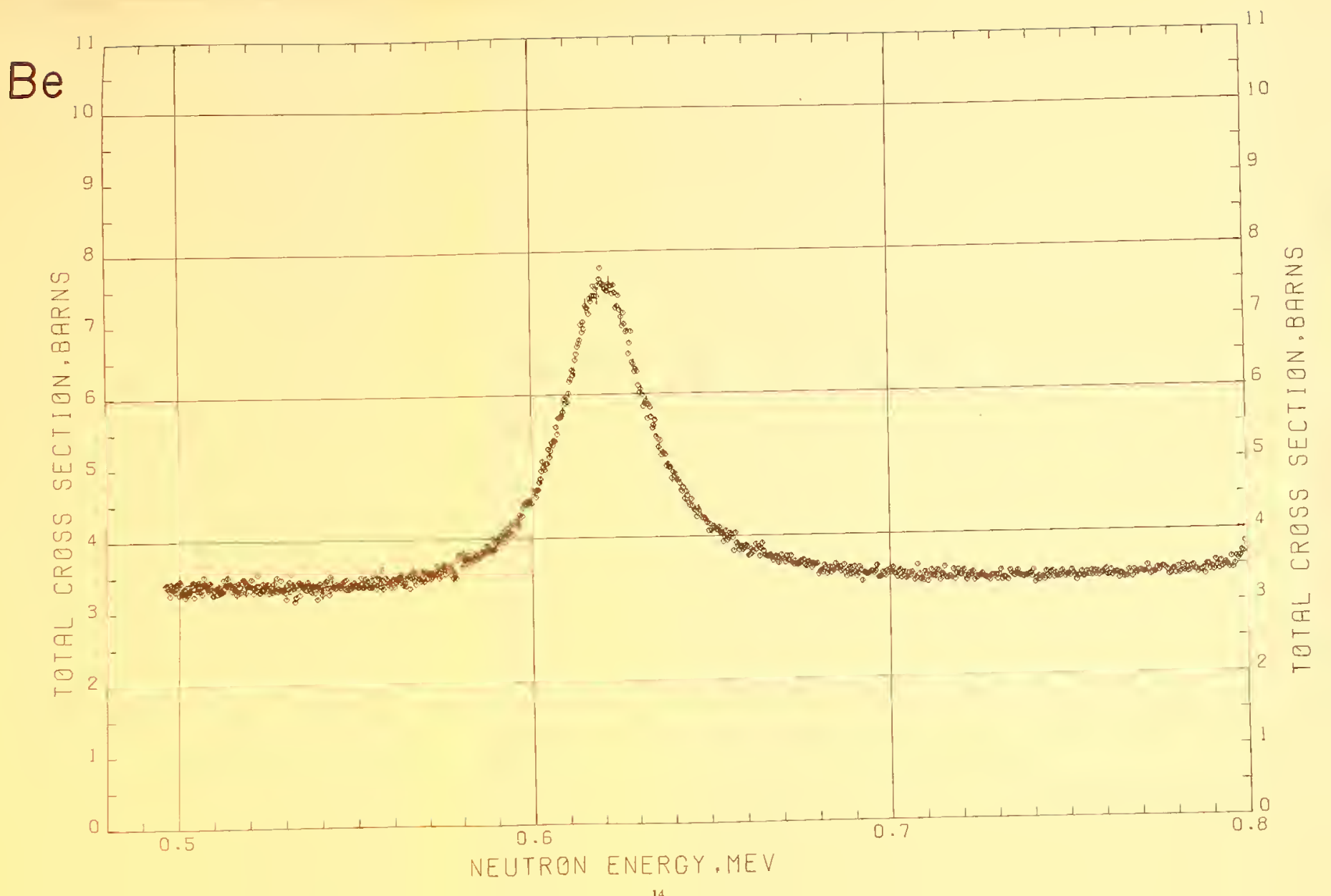




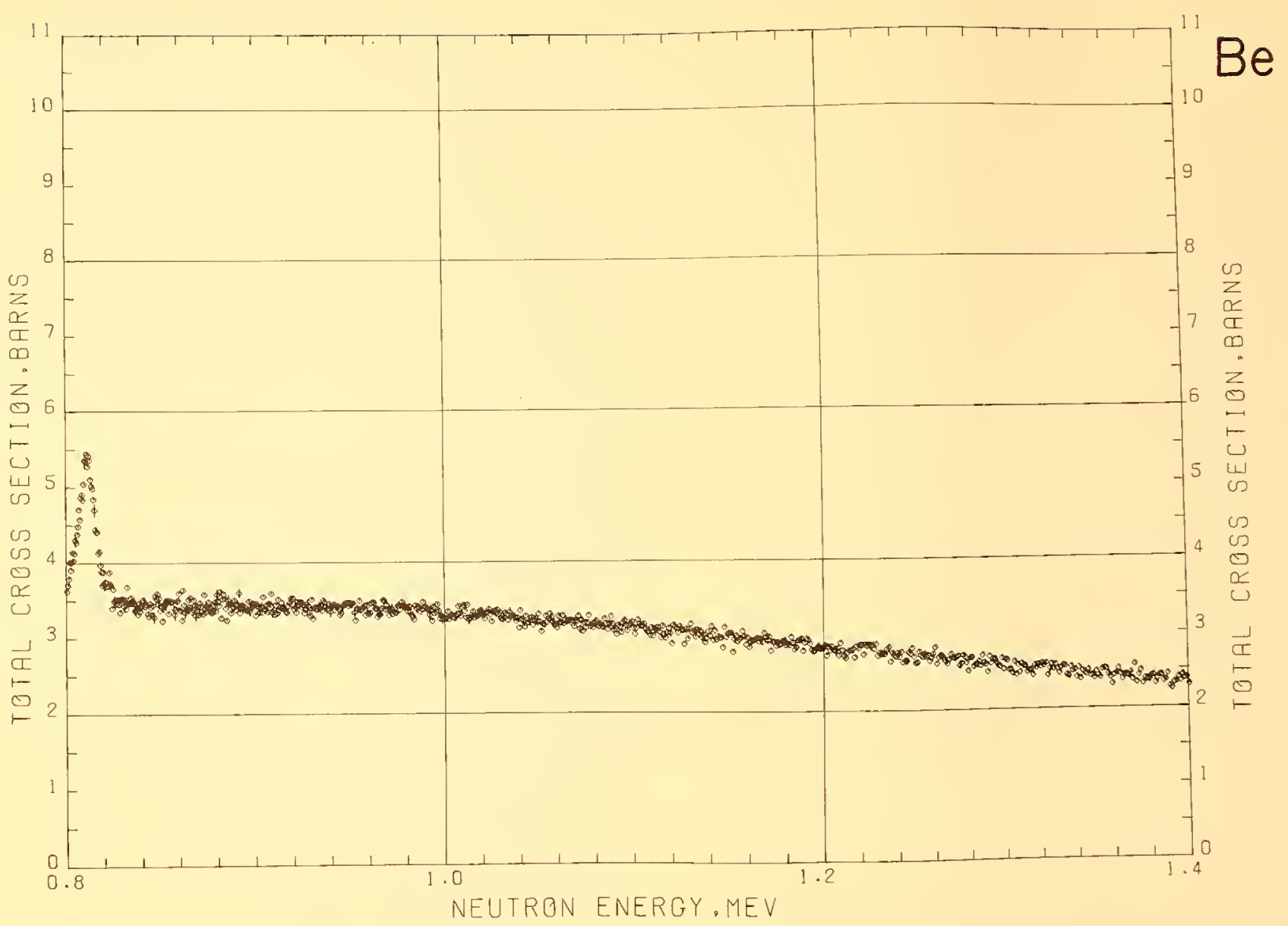




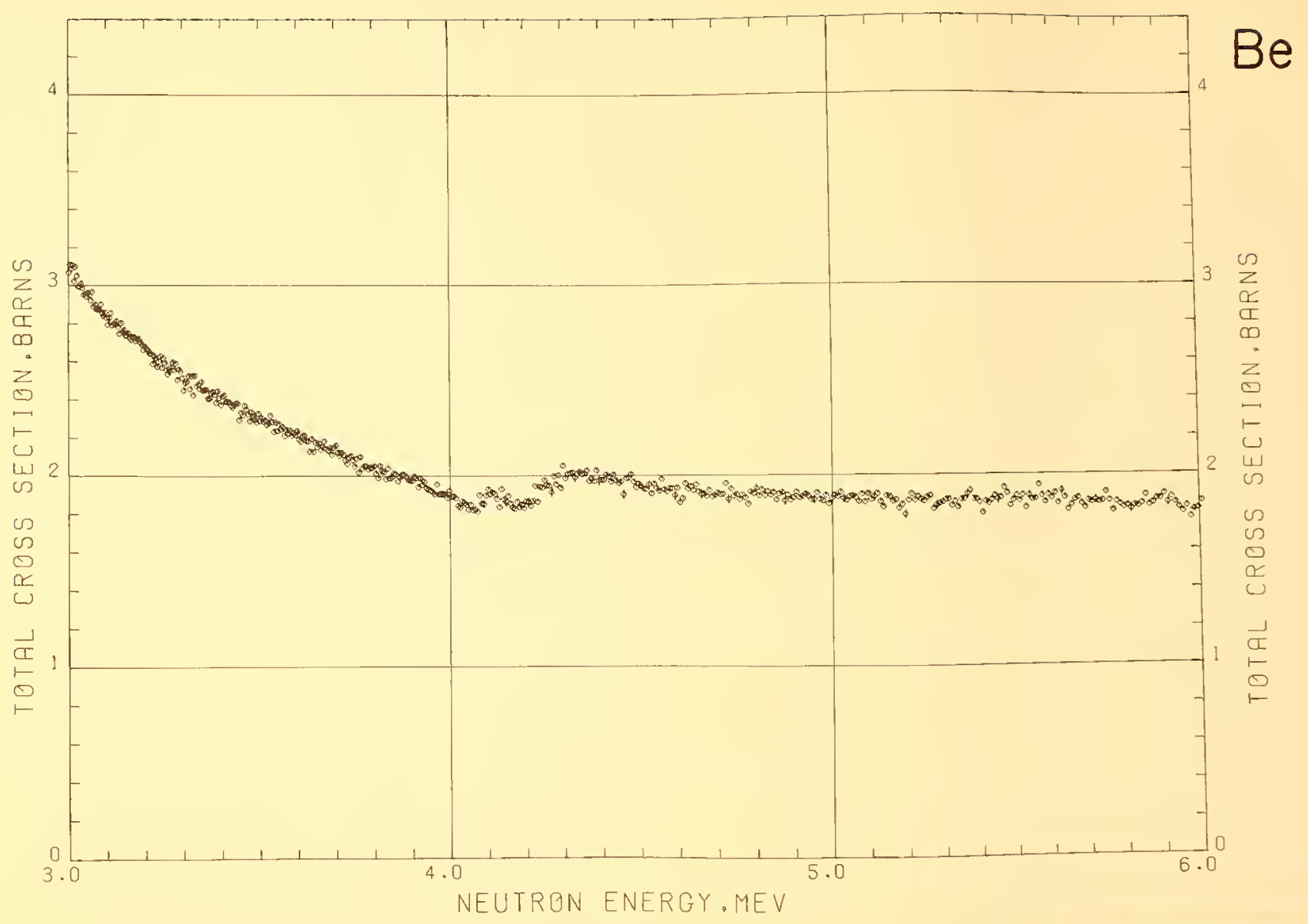




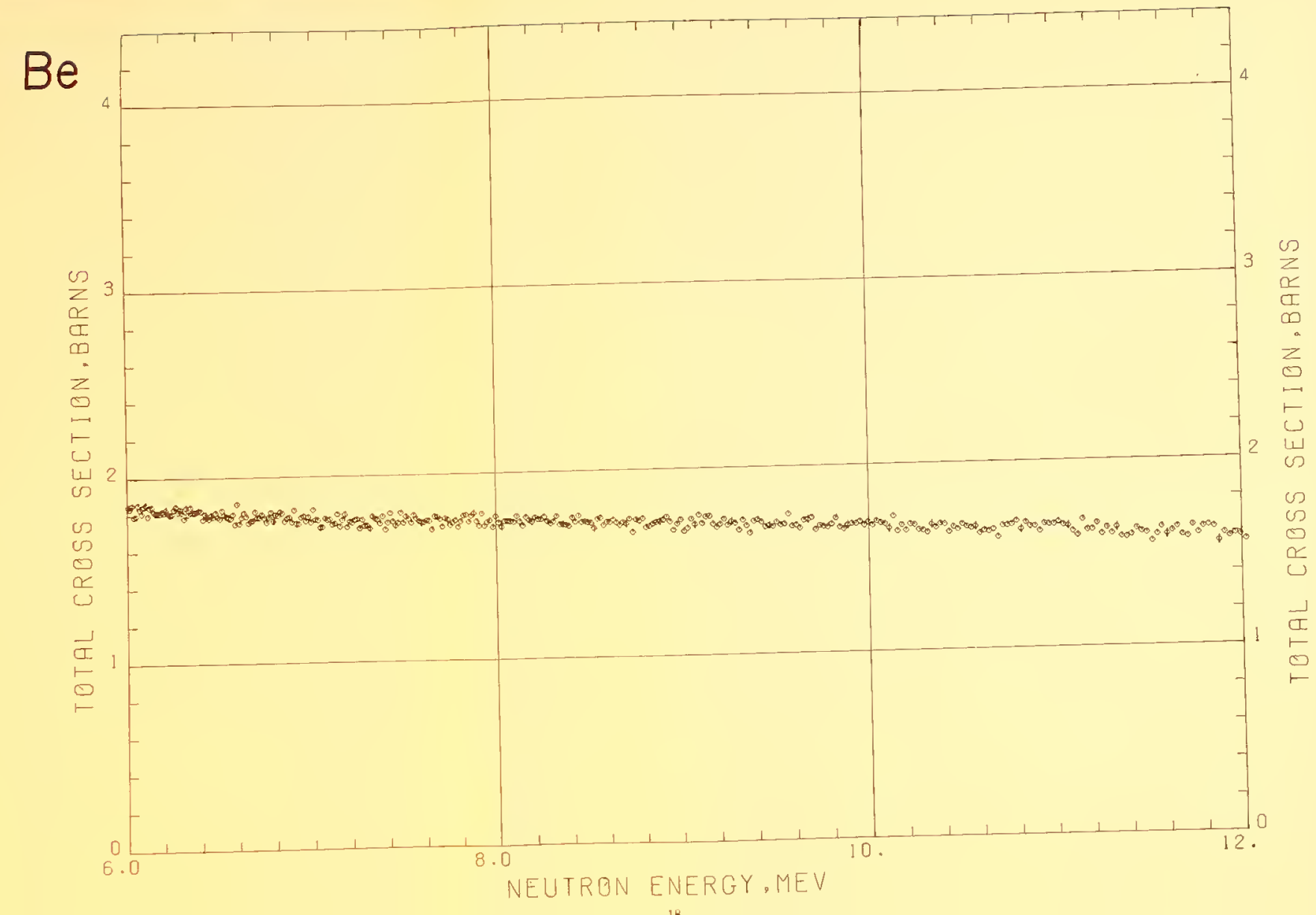




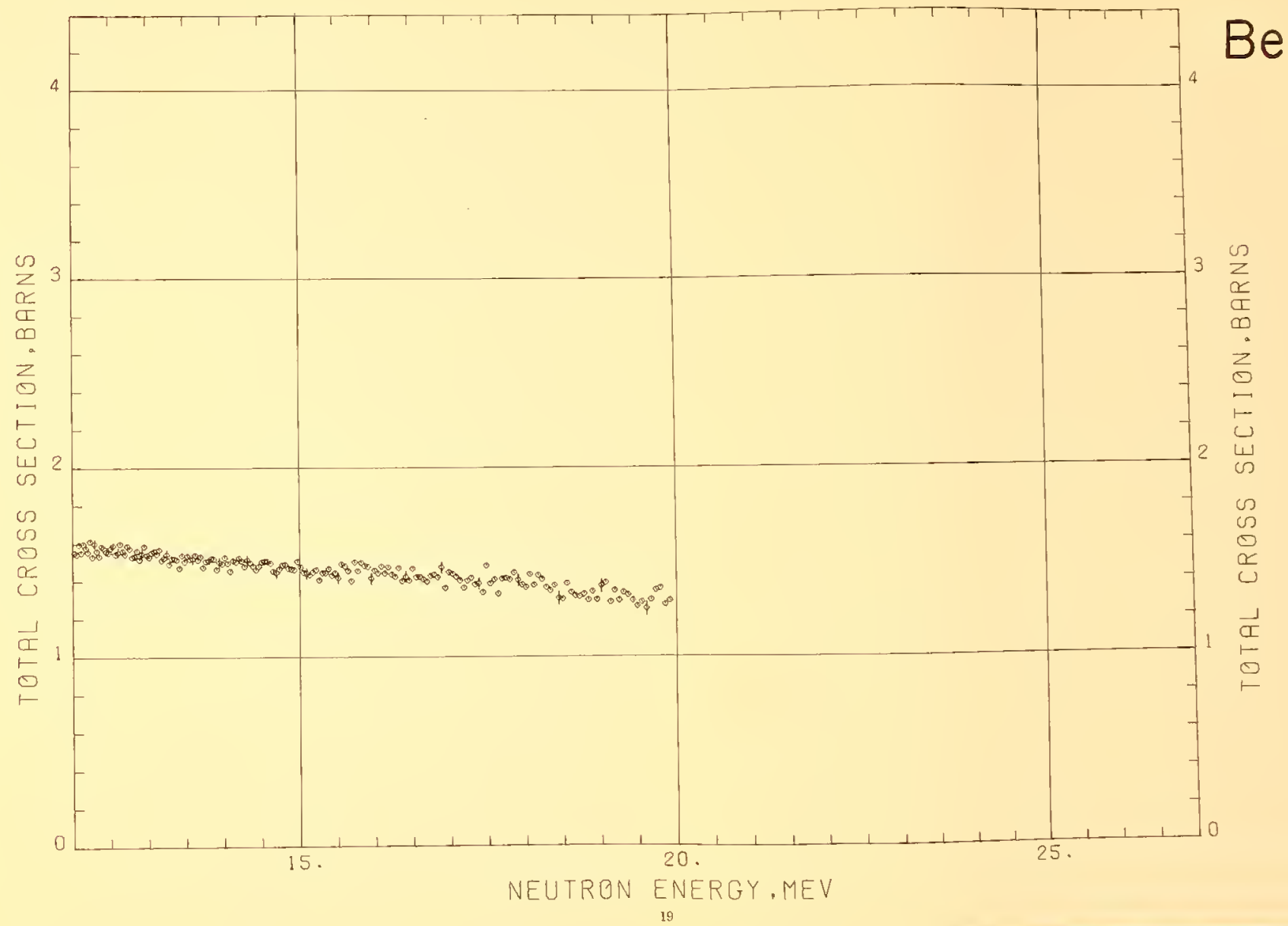





\section{CARBON}

\section{Sample Material: pressed graphite}

Sample Diameter: $\quad 12.7 \mathrm{~cm} ; 5.08 \mathrm{~cm}$.

Sample Thickness: $\quad 5.08 \mathrm{~cm} n=0.4803$ atoms/barn

$10.16 \mathrm{~cm} n=0.9557$ atoms/barn

$17.78 \mathrm{~cm} n=1.6750$ atoms/barn

Analysis: volatile components $<.01$ percent

nonvolatile components $<.01$ percent

Literature Reference: $\quad$ R. B. Schwartz, H. T. Heaton II, and R. A. Schrack, Bull. Am. Phys. Soc. 15, 567 (1970).

Comments: Density fluctuations within a sample are less than 1 percent. There was no evidence of absorption of impurities on exposure to air. 


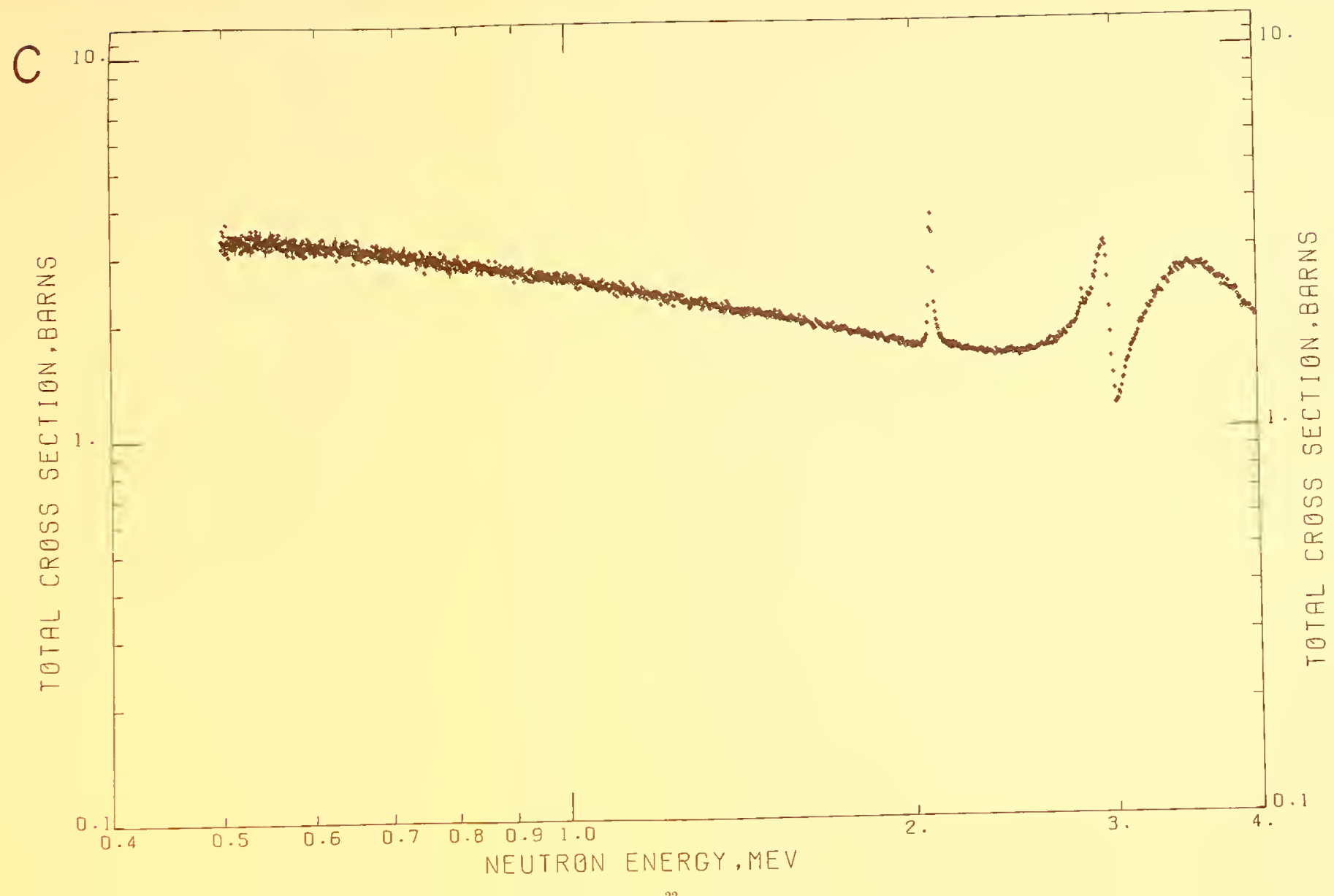




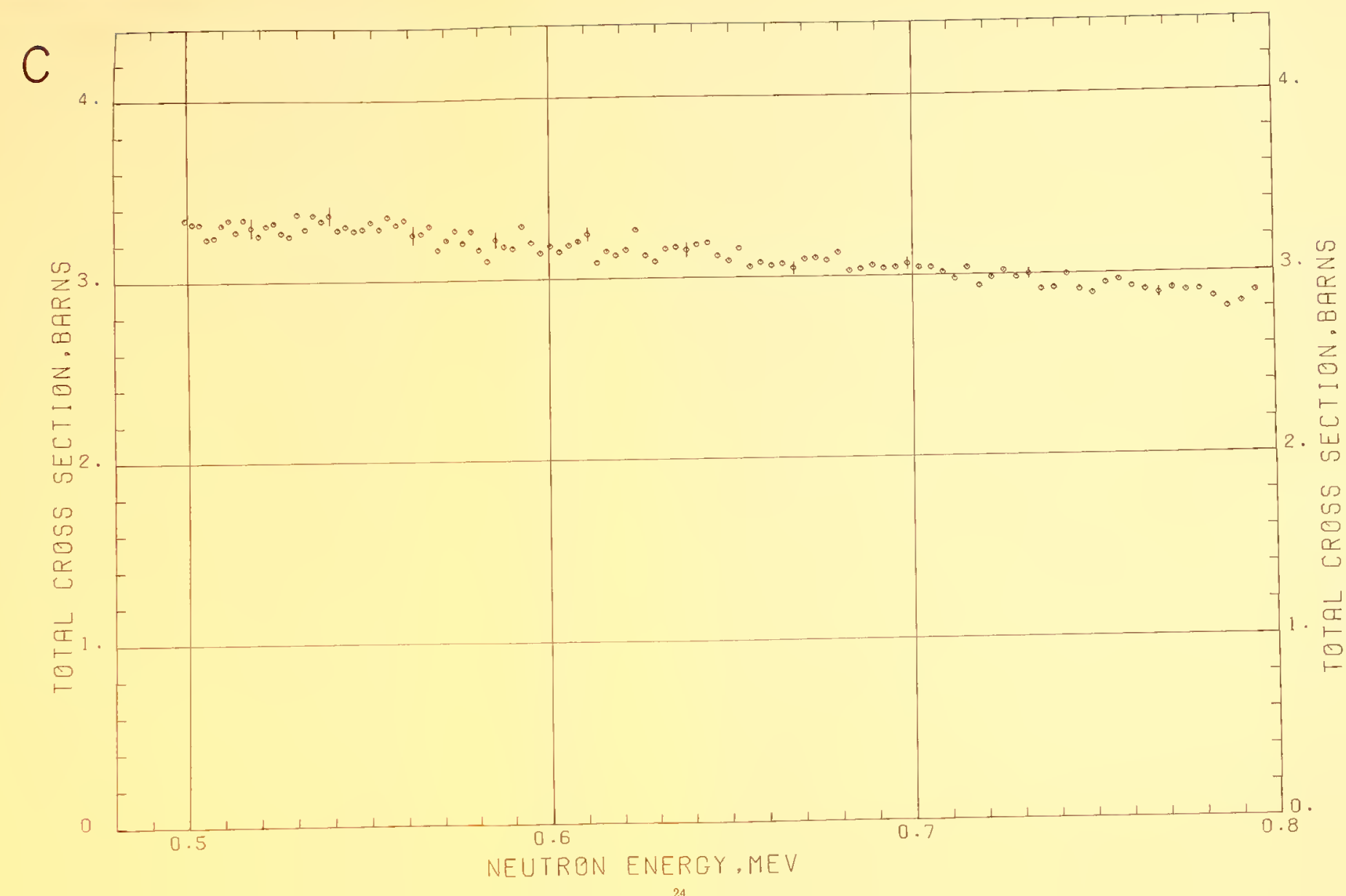




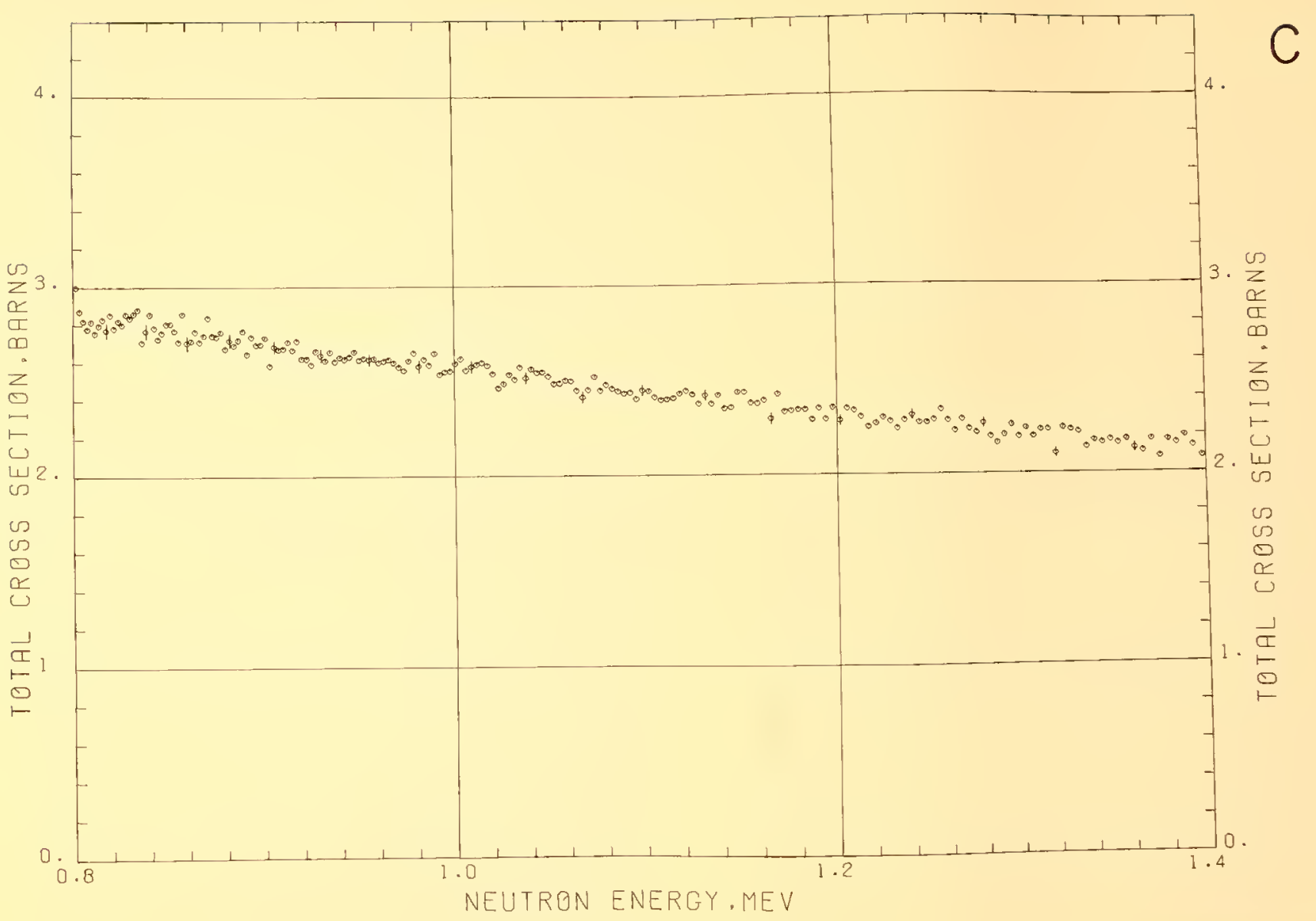




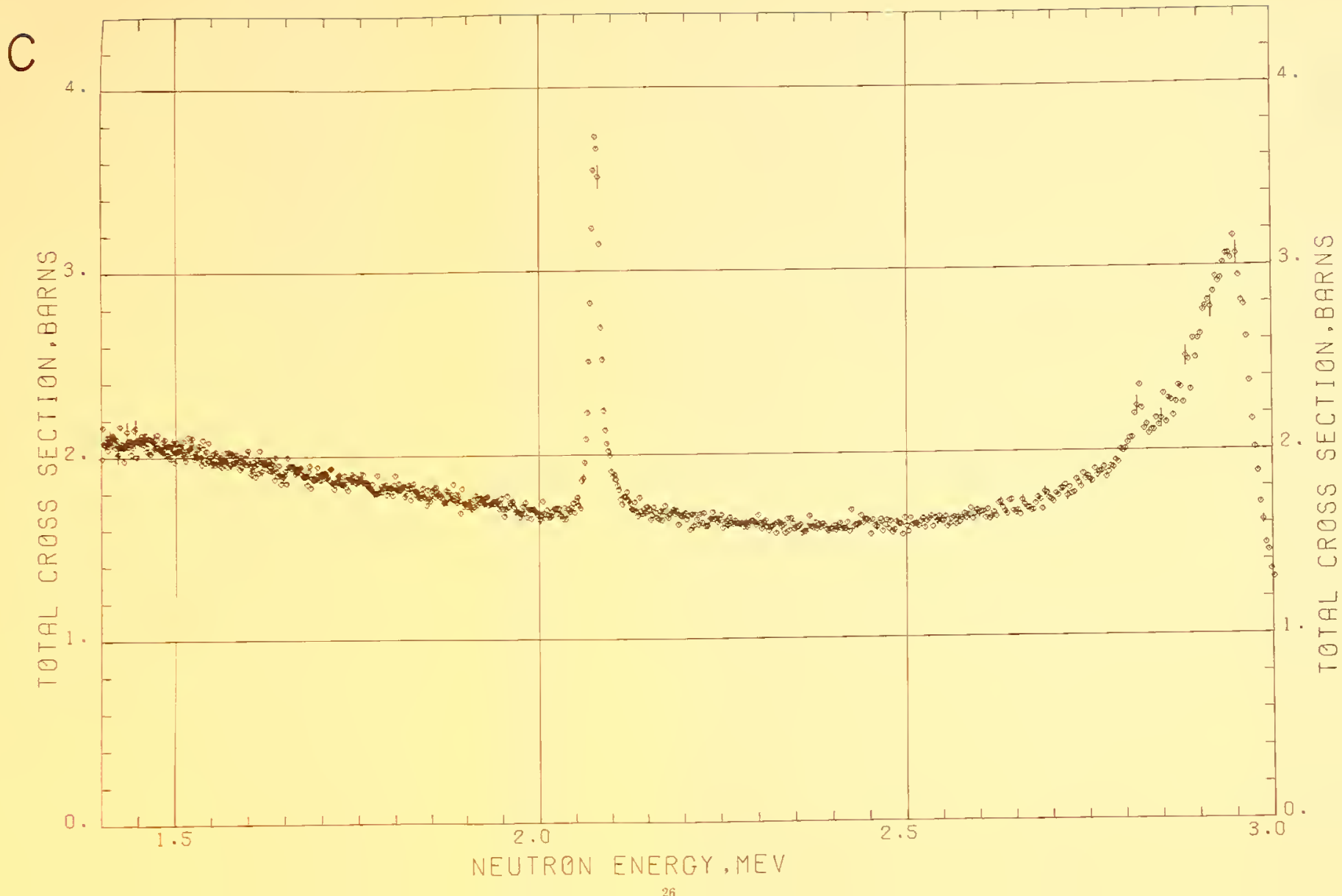




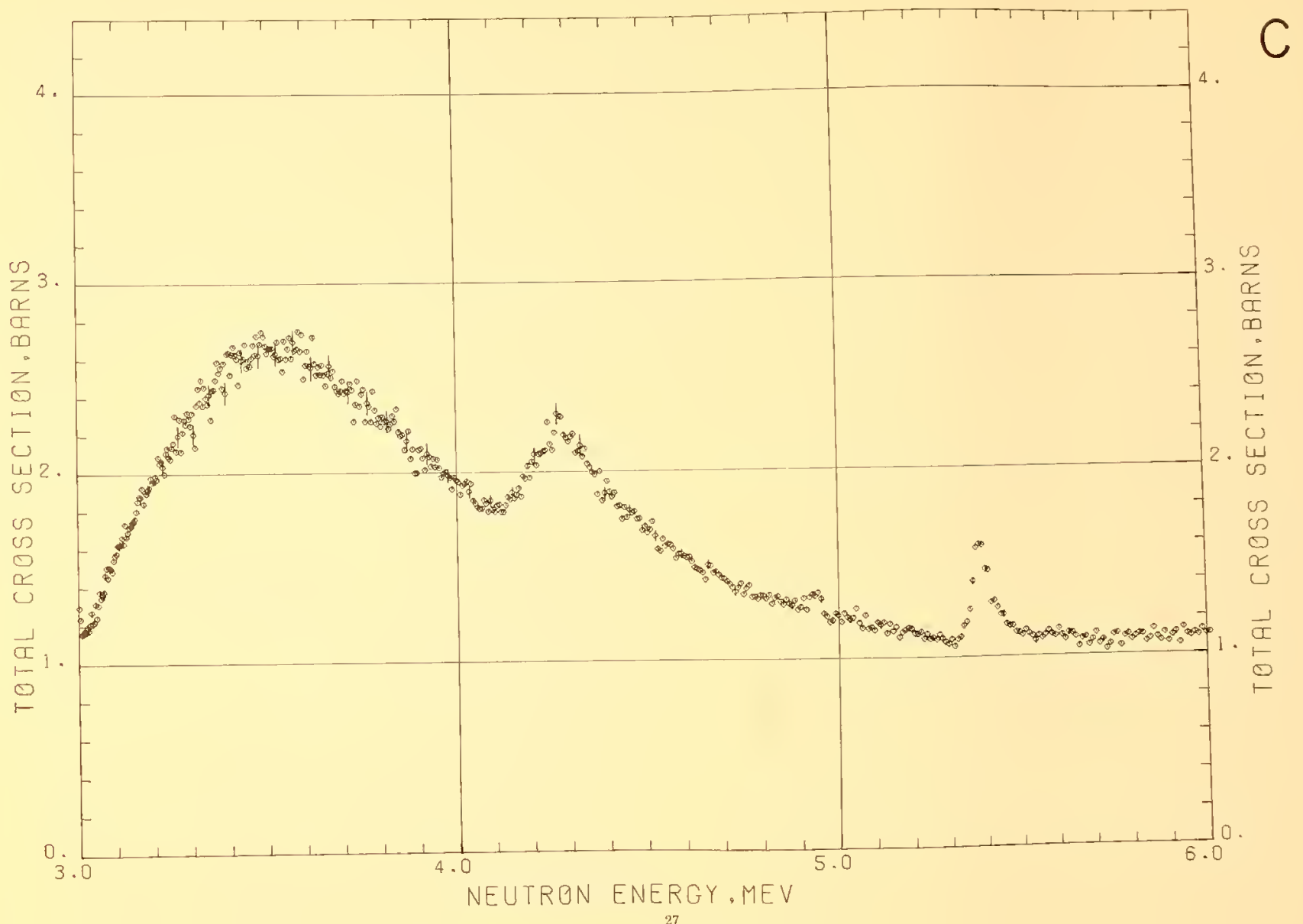




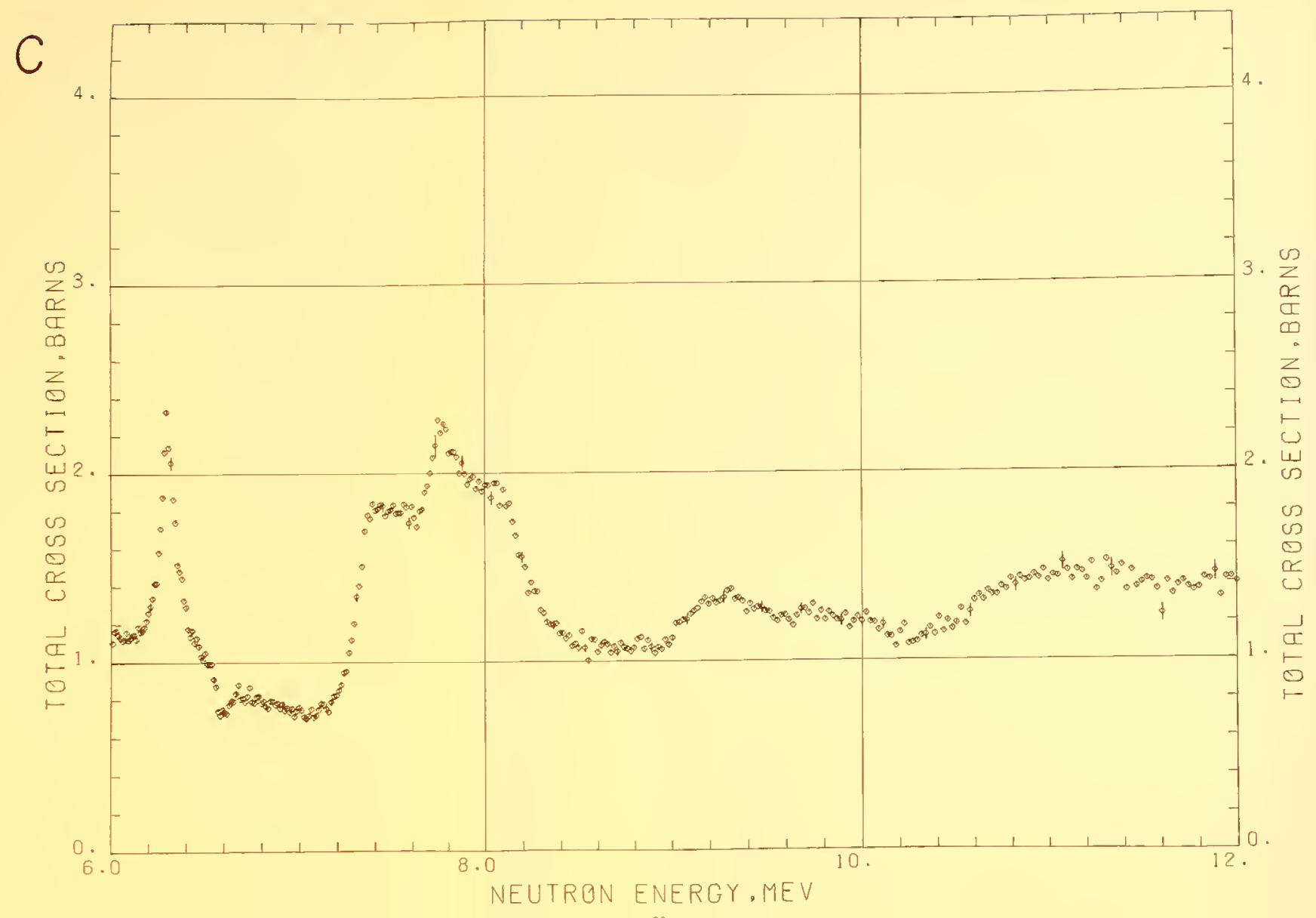




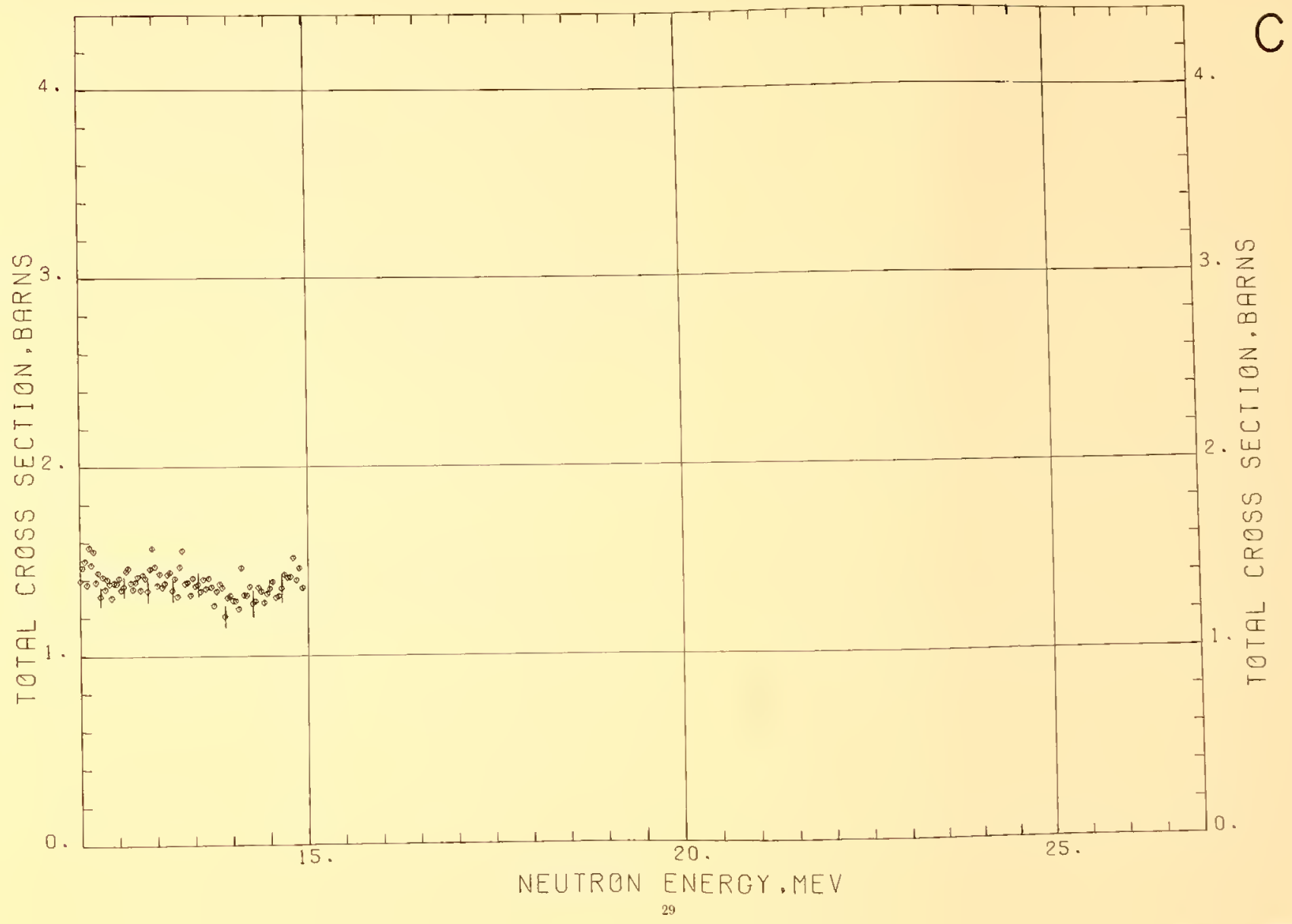





\section{NITROGEN}

Sample Material: liquid nitrogen

Sample Diameter: $12.7 \mathrm{~cm}$

Sample Thickness: $27.9 \mathrm{~cm}, n=0.9684$ atoms/barn

$13.5 \mathrm{~cm}, n=0.4683$

Literature Reference: H. T. Heaton II, R. B. Schwartz, and R. A. Schrack, Bull. Am. Phys. Soc, 15, 568 (1970).

Comments: Special dewars were constructed with end windows of known thickness of pyrex. Open runs were made whe nitrogen cross section was also obtained by runwith duplicates of the end windows in the beam. The nitrogen of melamine with $n=0.6756$ ning melamine $\left(\mathrm{CH}_{2} \mathrm{~N}_{2}\right)$ against polyethylene $\left(\mathrm{CH}_{1}\right)$. A powdered sample of mame number of atoms of $\mathrm{C}$ atoms/barn of nitrogen was run against a sample of polyethe ne having the same number of atom

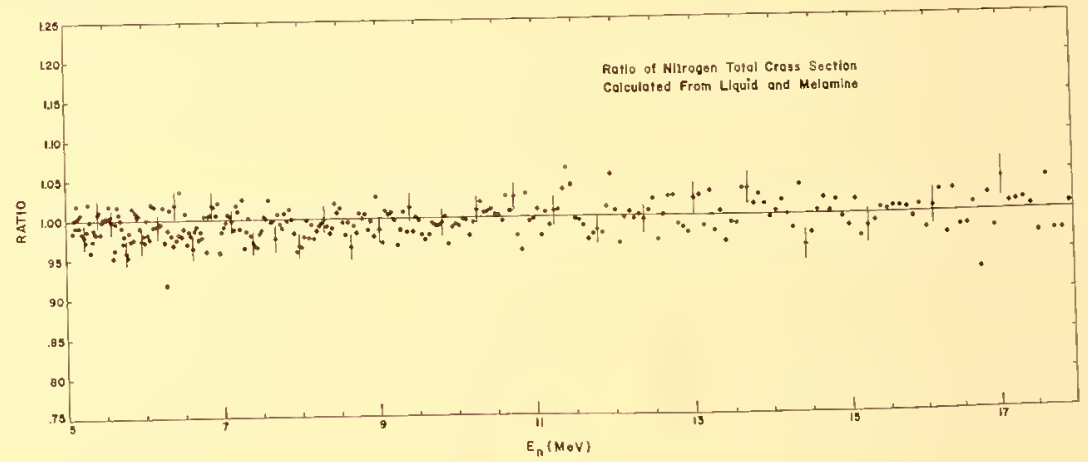

Fgure A 


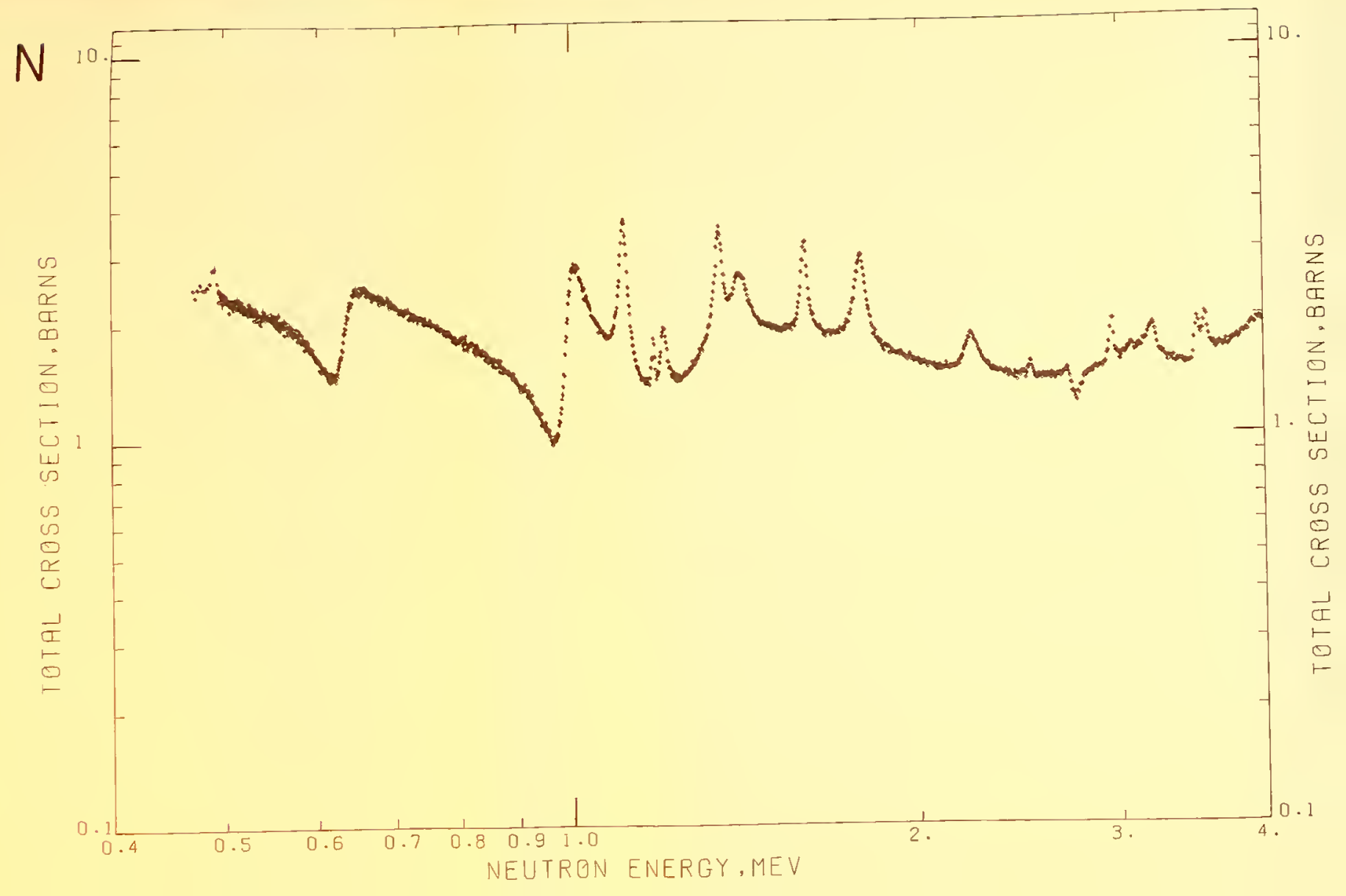




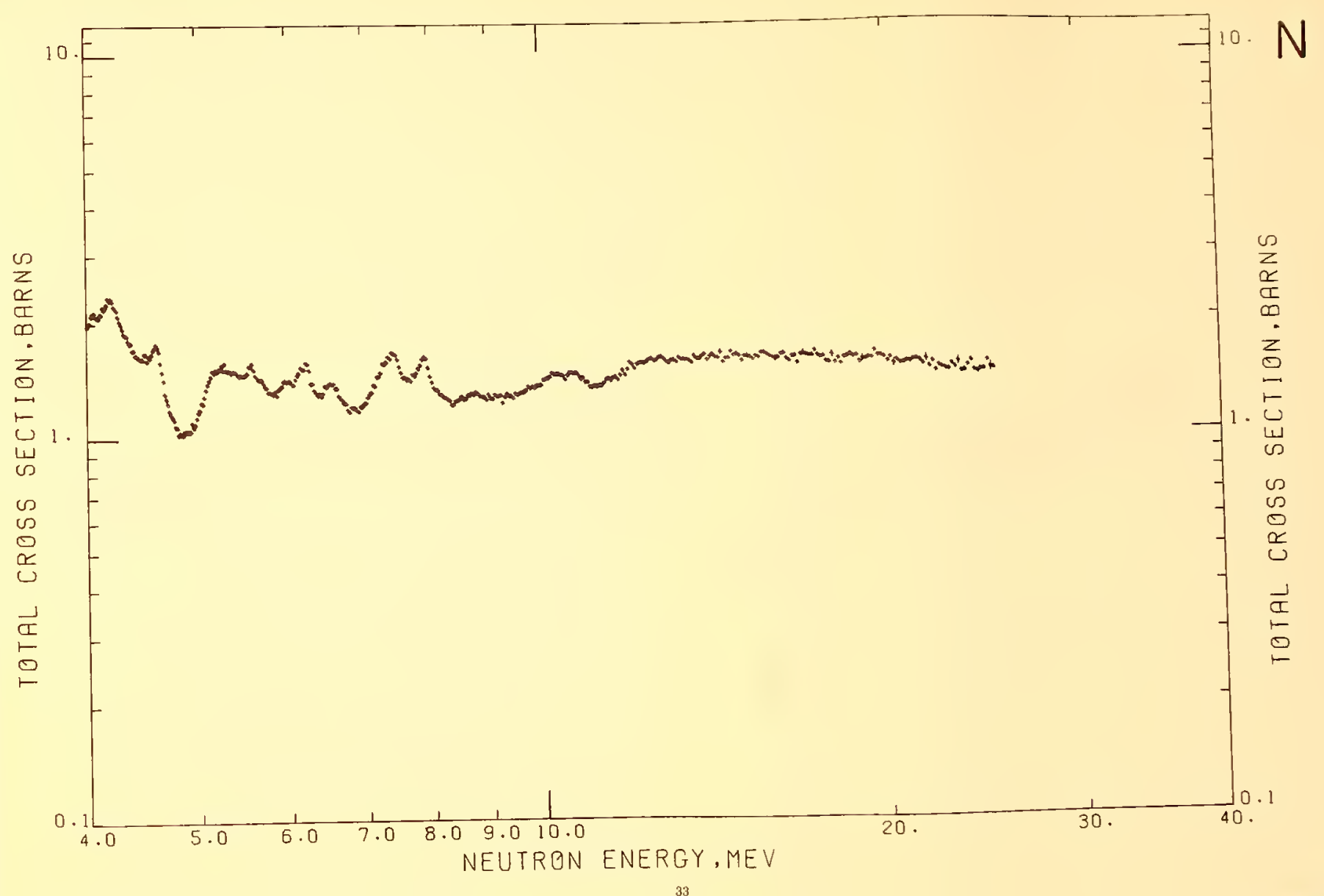




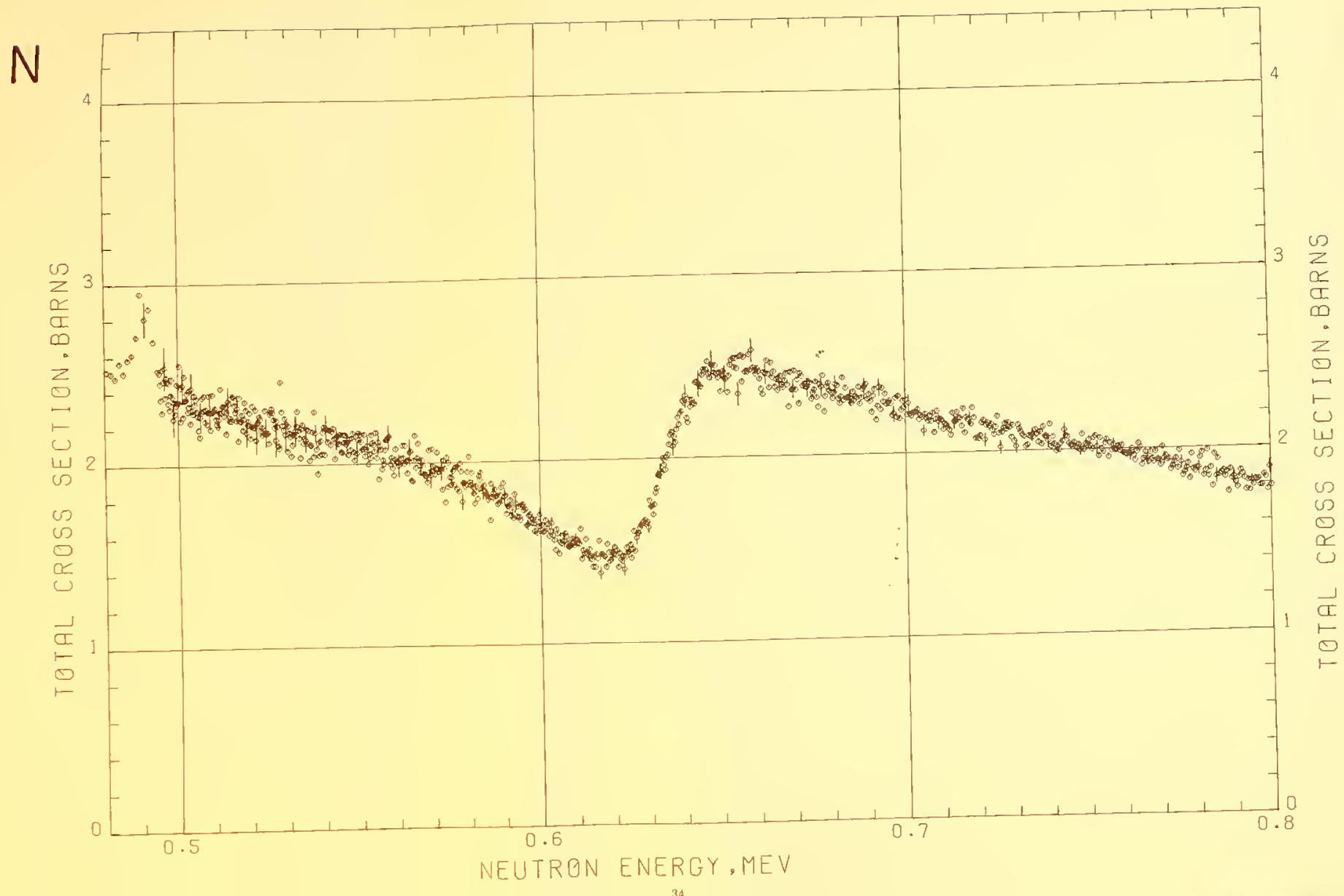




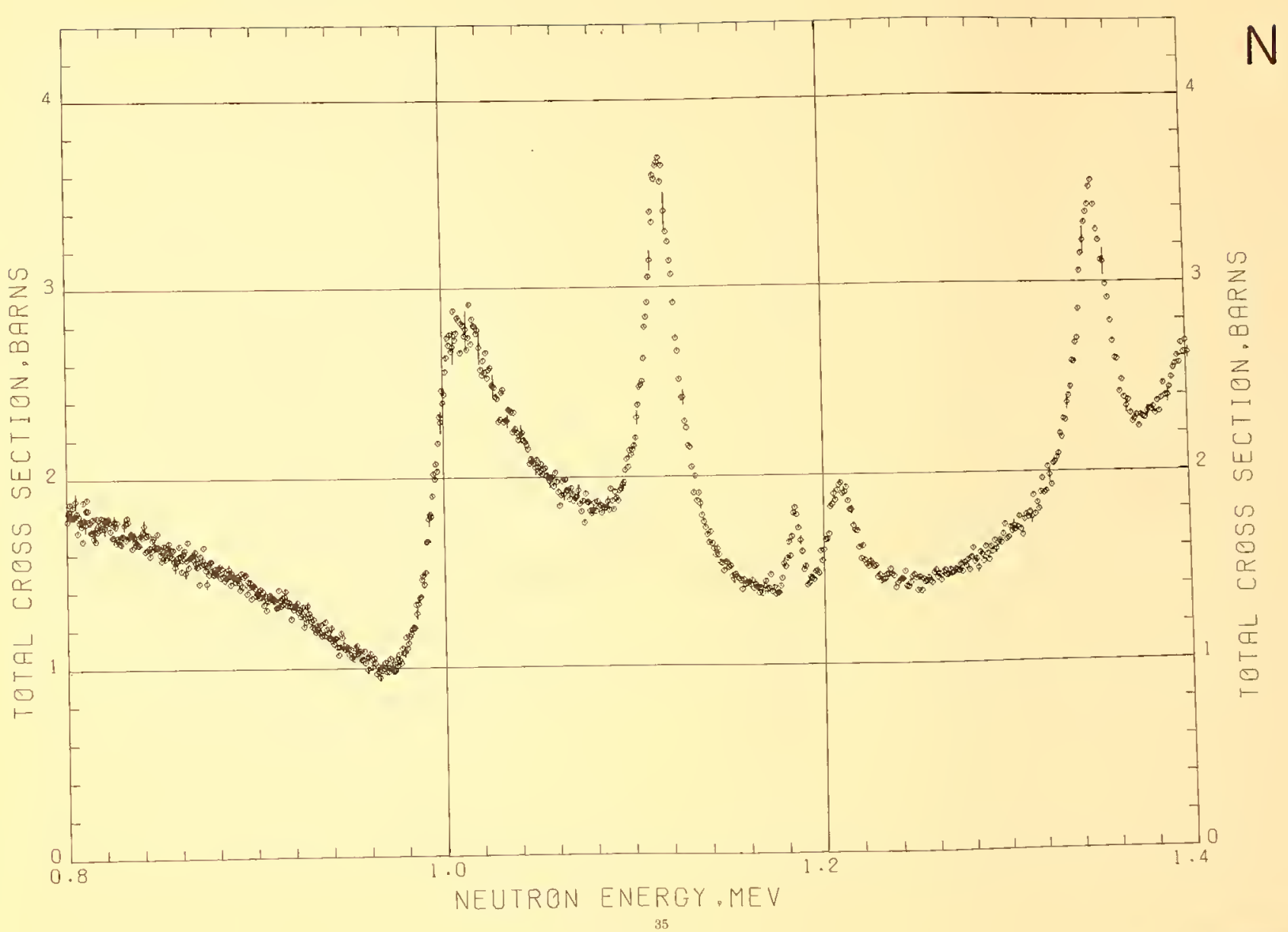




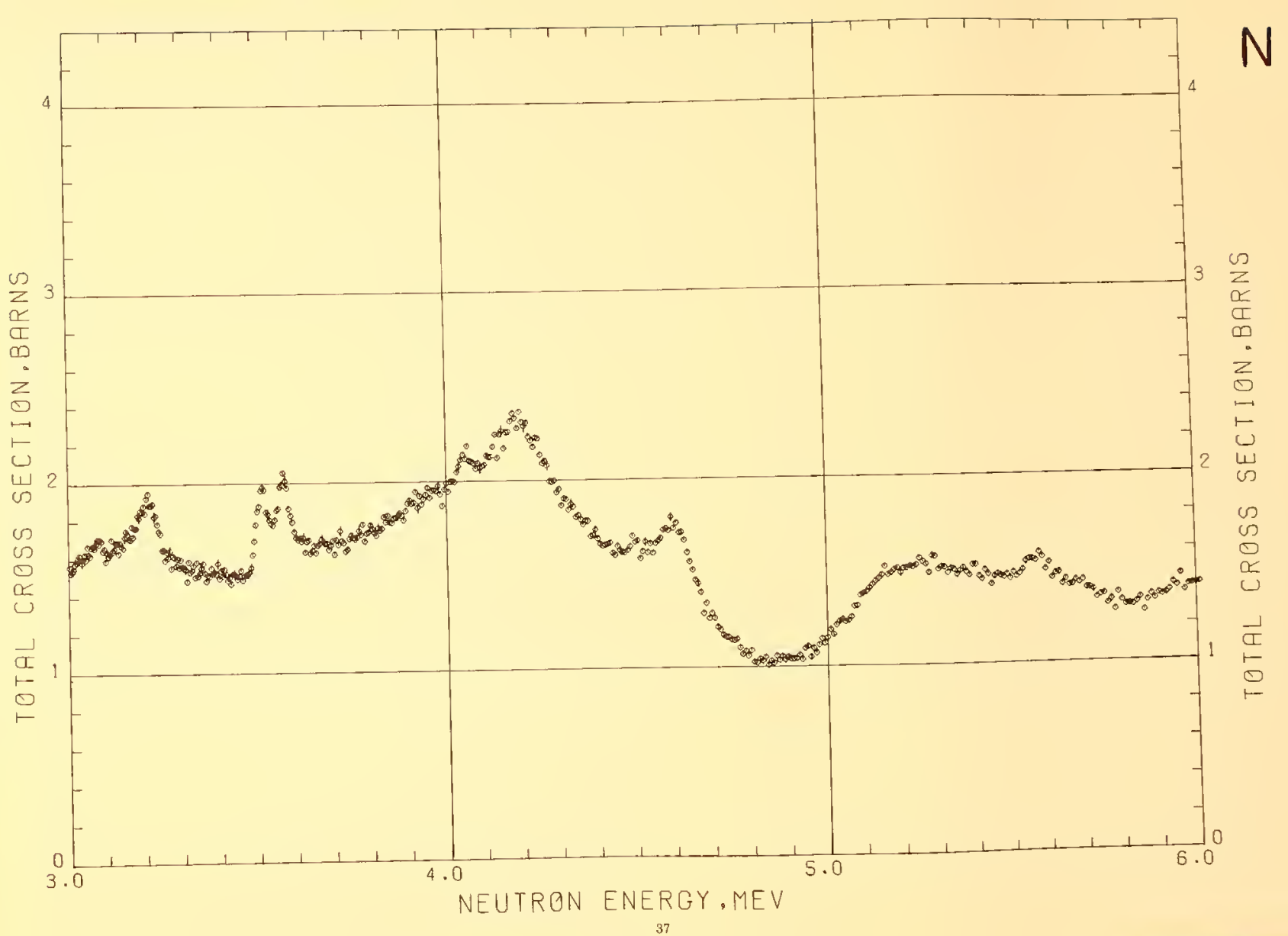




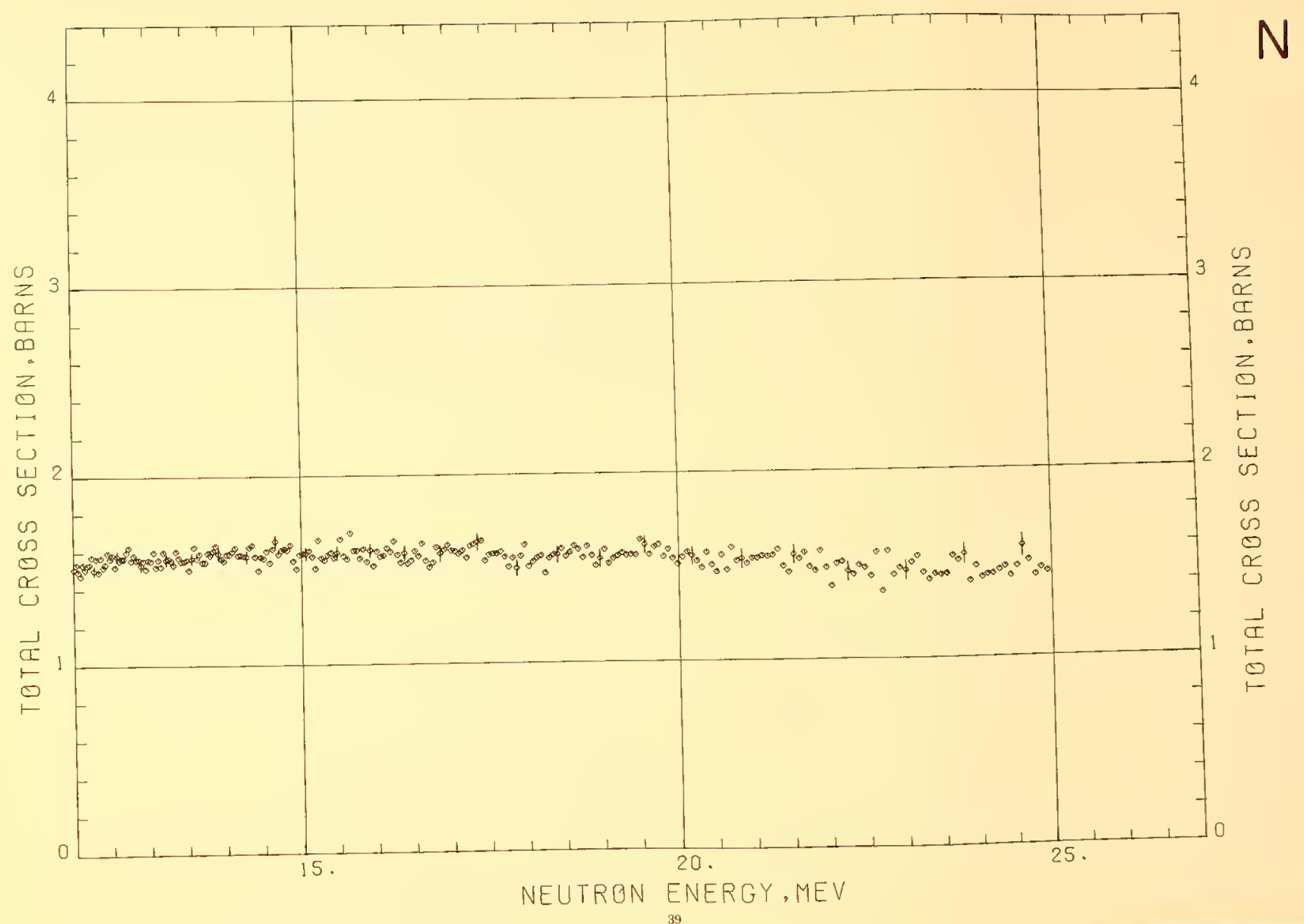



OXYGEN

Sample Material: $\quad$ quartz $\left(\mathrm{SiO}_{2}\right)$ single erystals

open: semiconductor grade silicon

Sample diameter: $\quad 5.08 \mathrm{~cm}$

Sample thickness: $\quad 7.54 \mathrm{~cm} ; n=0.396$ atoms/barn

$29.98 \mathrm{~cm} ; n=1.576$ atoms/barn

Literature Reference: R. A. Schrack, R. B. Schwartz, and H. T. Heaton II, Bull. Am. Phys. Soc. 17, 555 (1972).

Comments: Equality of silicon atoms/barn in the quartz and silicon samples can be deduced from the absence of structure due to silicon in the measured oxygen cross section. The statistical precision is degraded where there are large peaks in the silicon cross section (e. $5.570 \mathrm{keV}$ ), but there are no net fluctuations. 


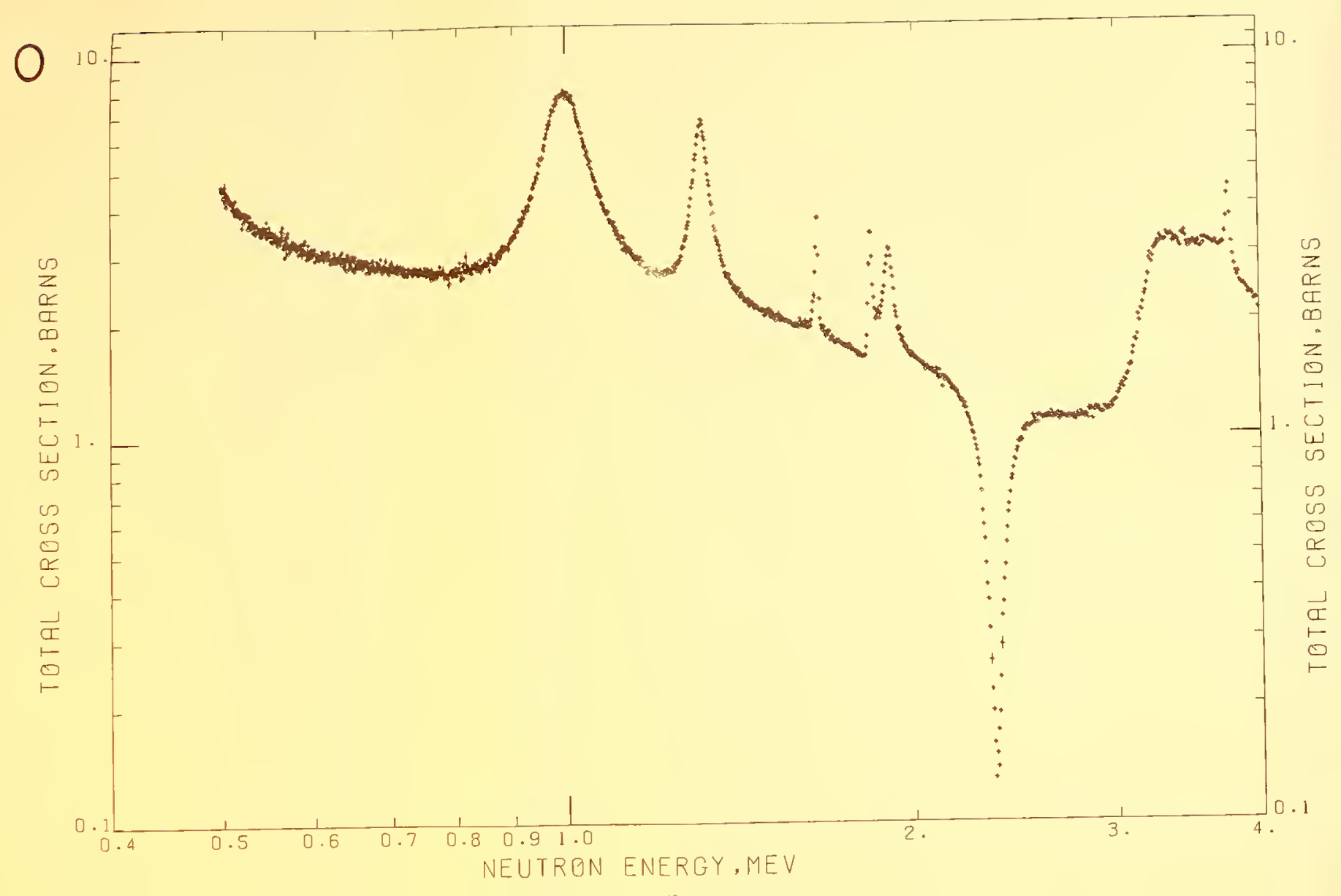




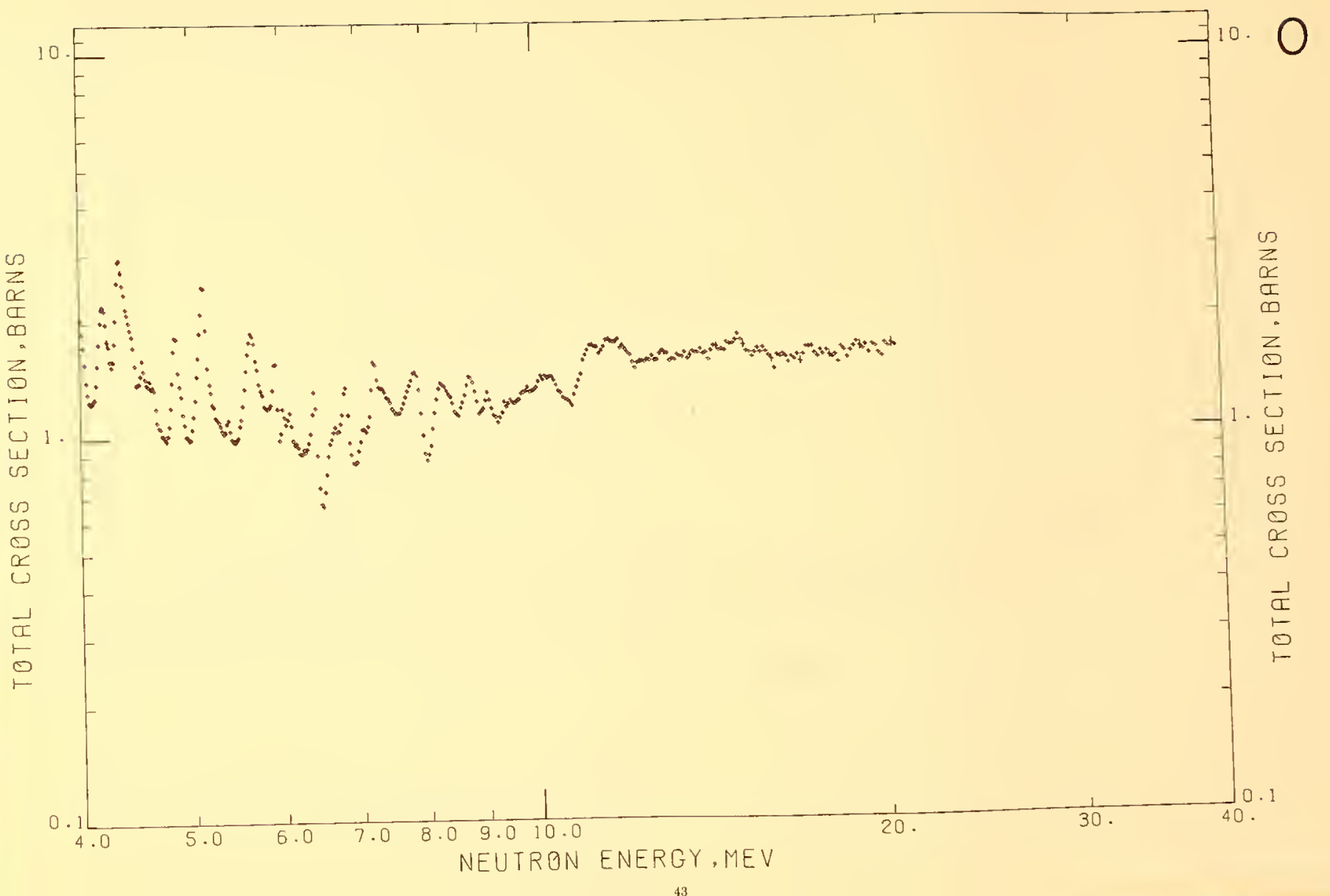




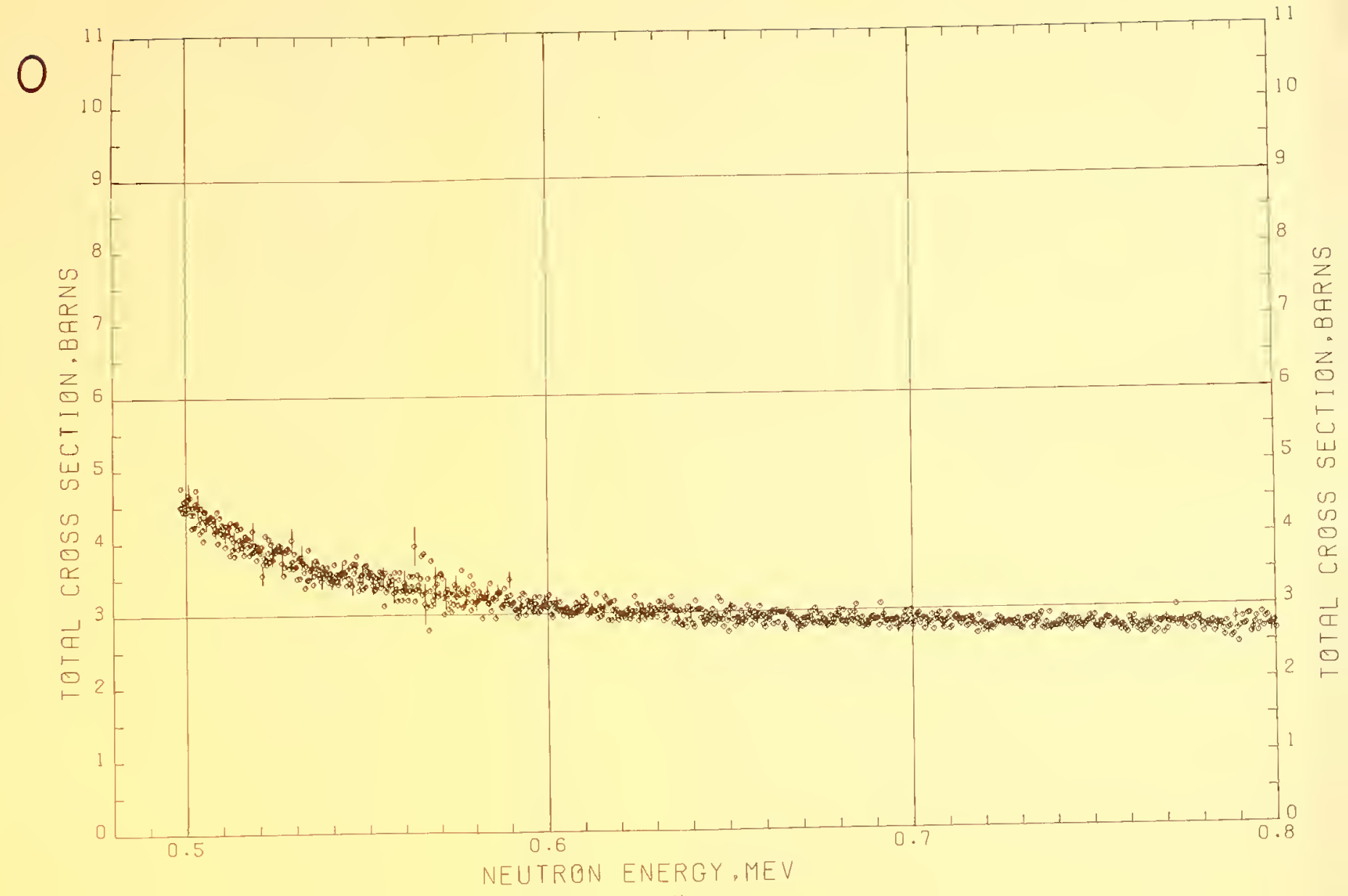




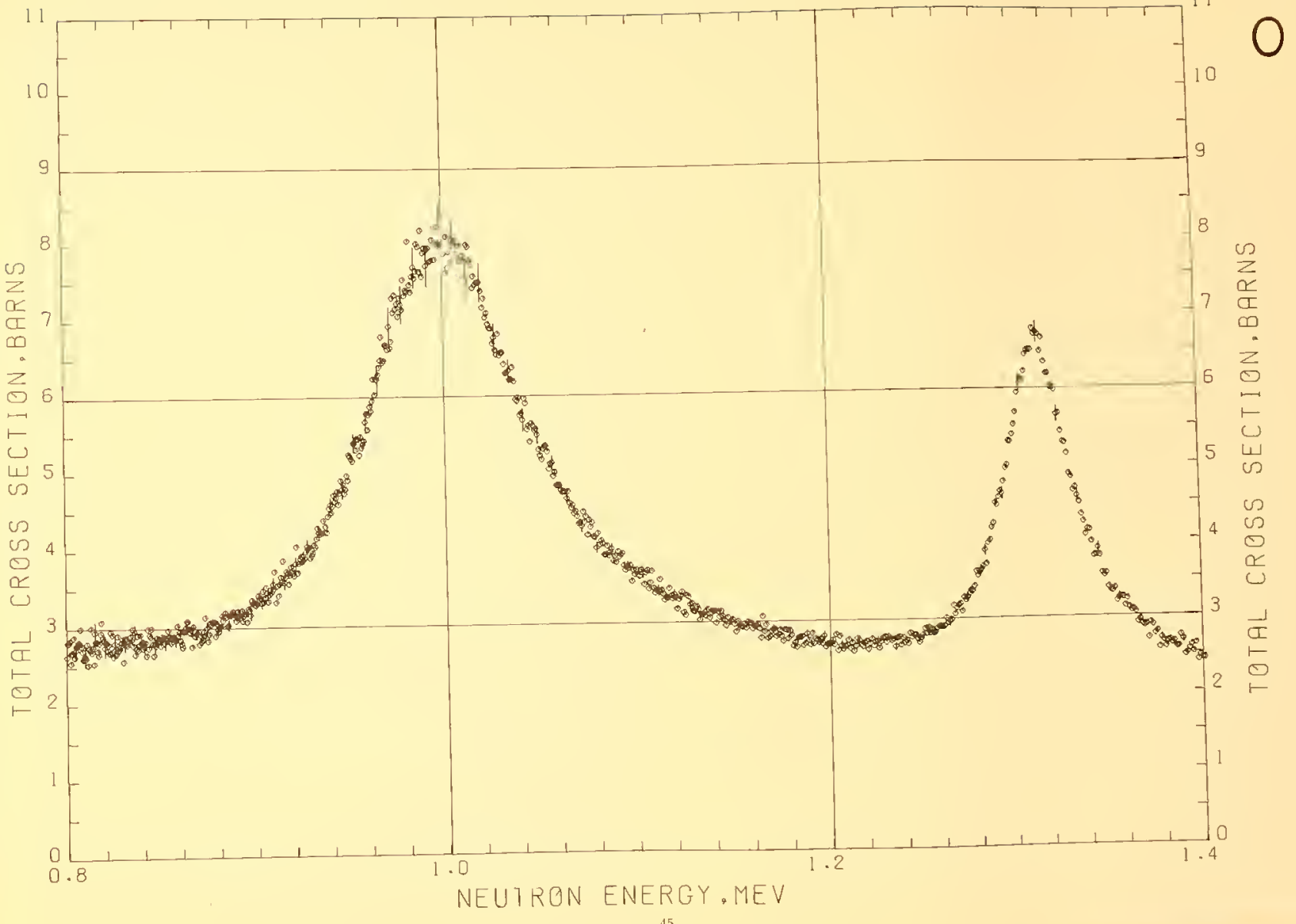




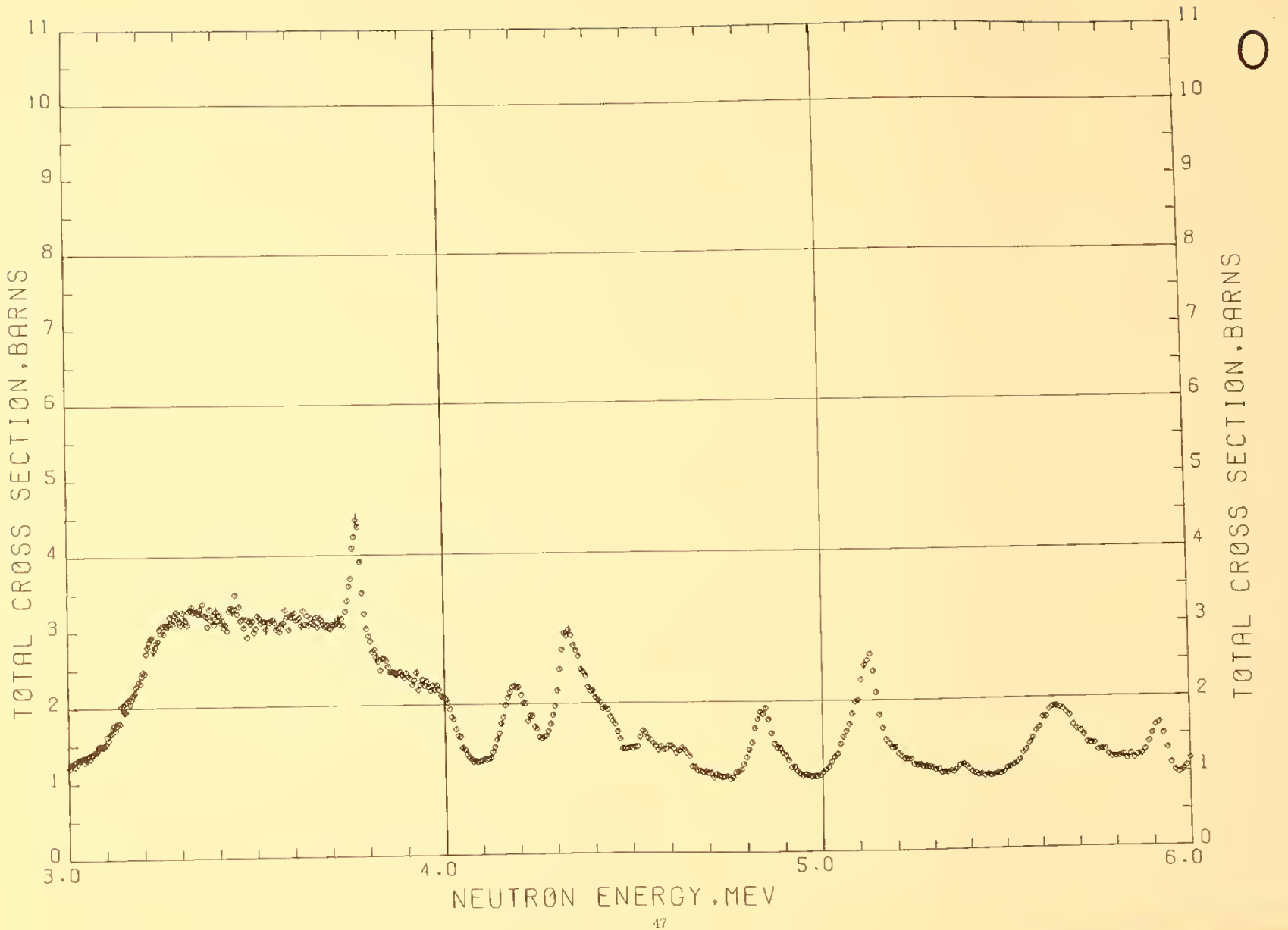




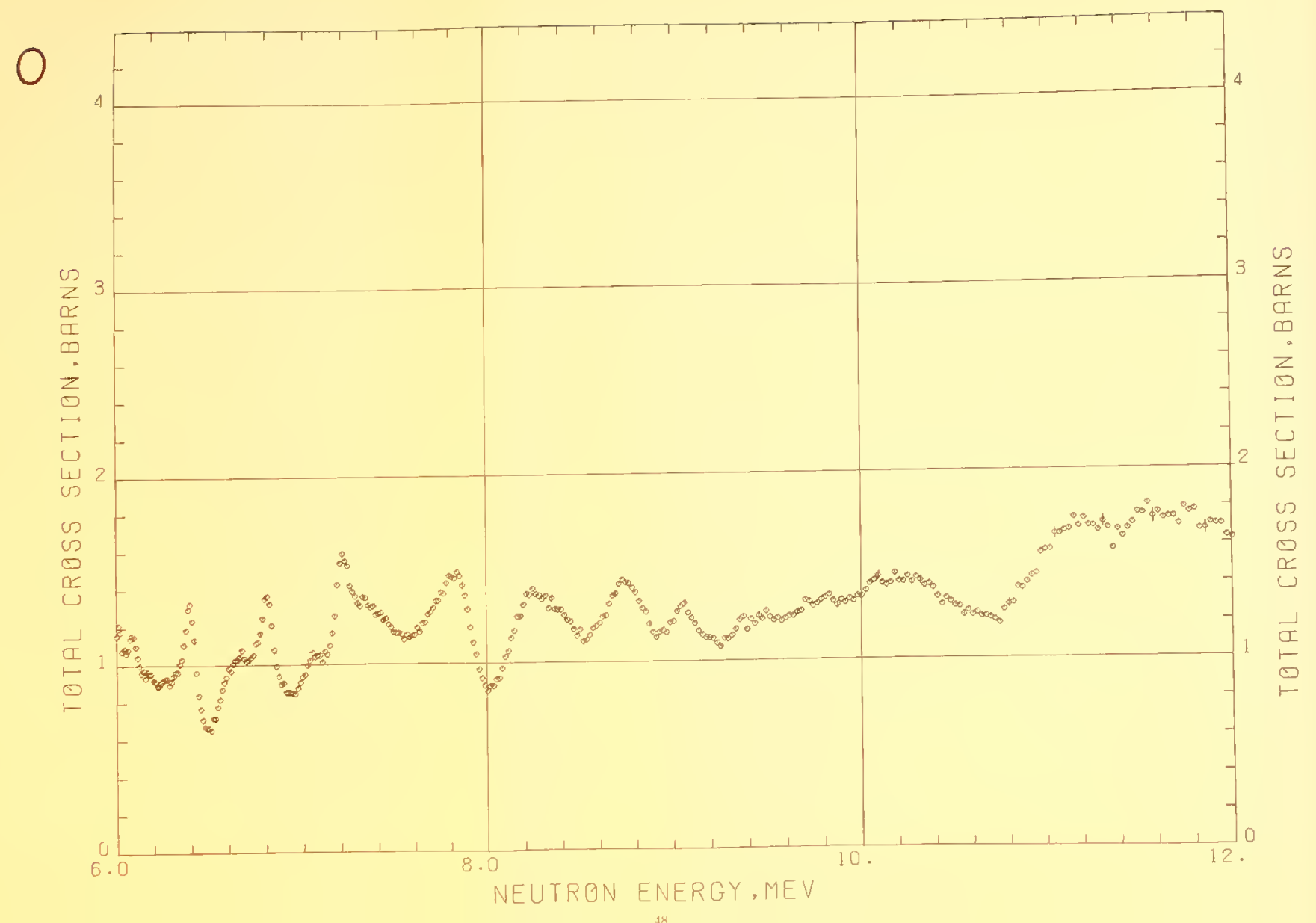




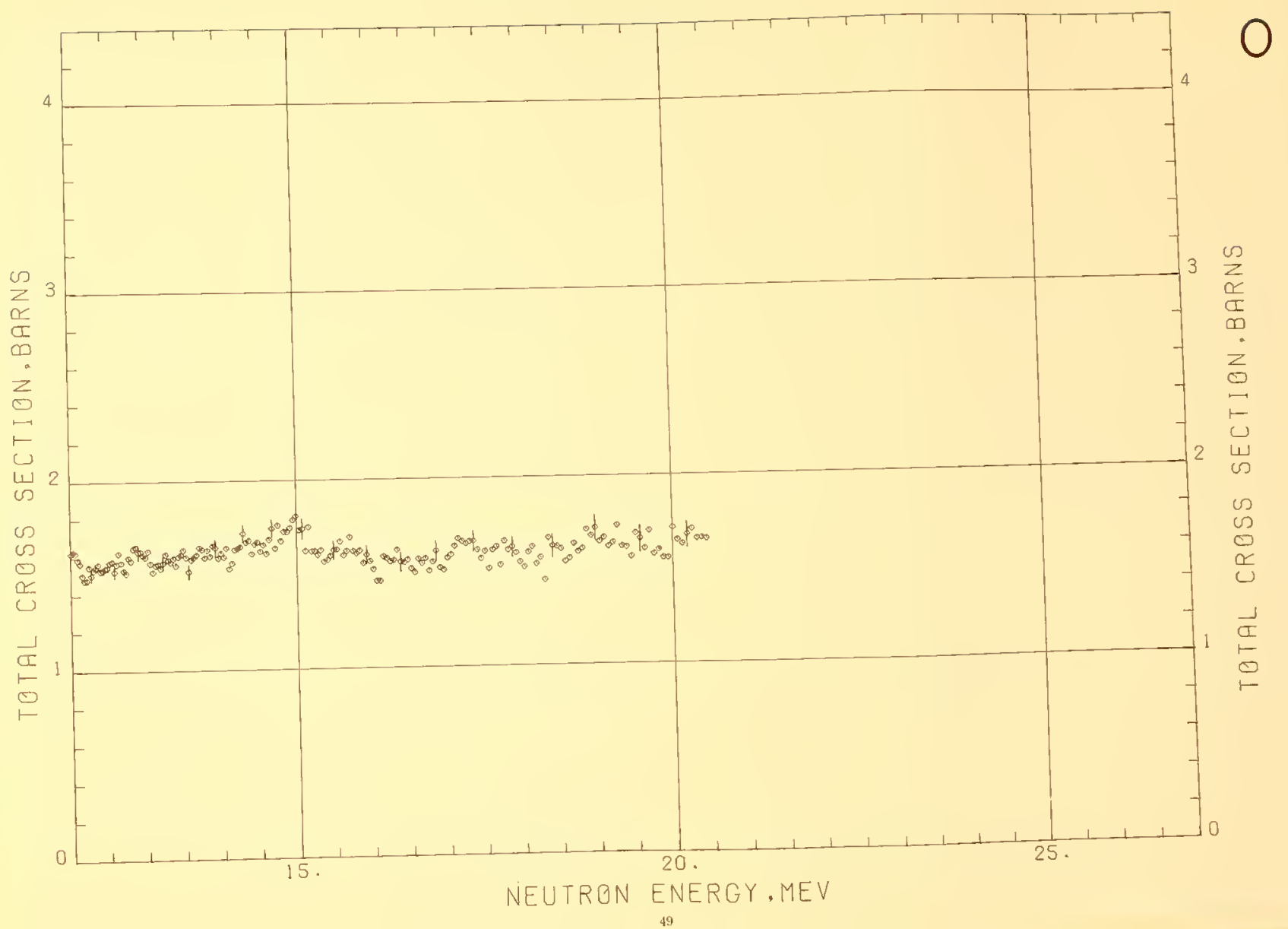





\section{ALUMINUM}

Sample Material: metallic aluminum plate

Sample Diameter: $\quad 12.7 \mathrm{~cm}$

Sample Thickness: $\quad 11.3 \mathrm{~cm}, n=0.6858$ atoms/barn

nalysis: The samples were fabricated from 1100 grade aluminum. The principal impurities were 0.62 percent iron Thercent copper. All other impurities were less than 0.1 pereent. 


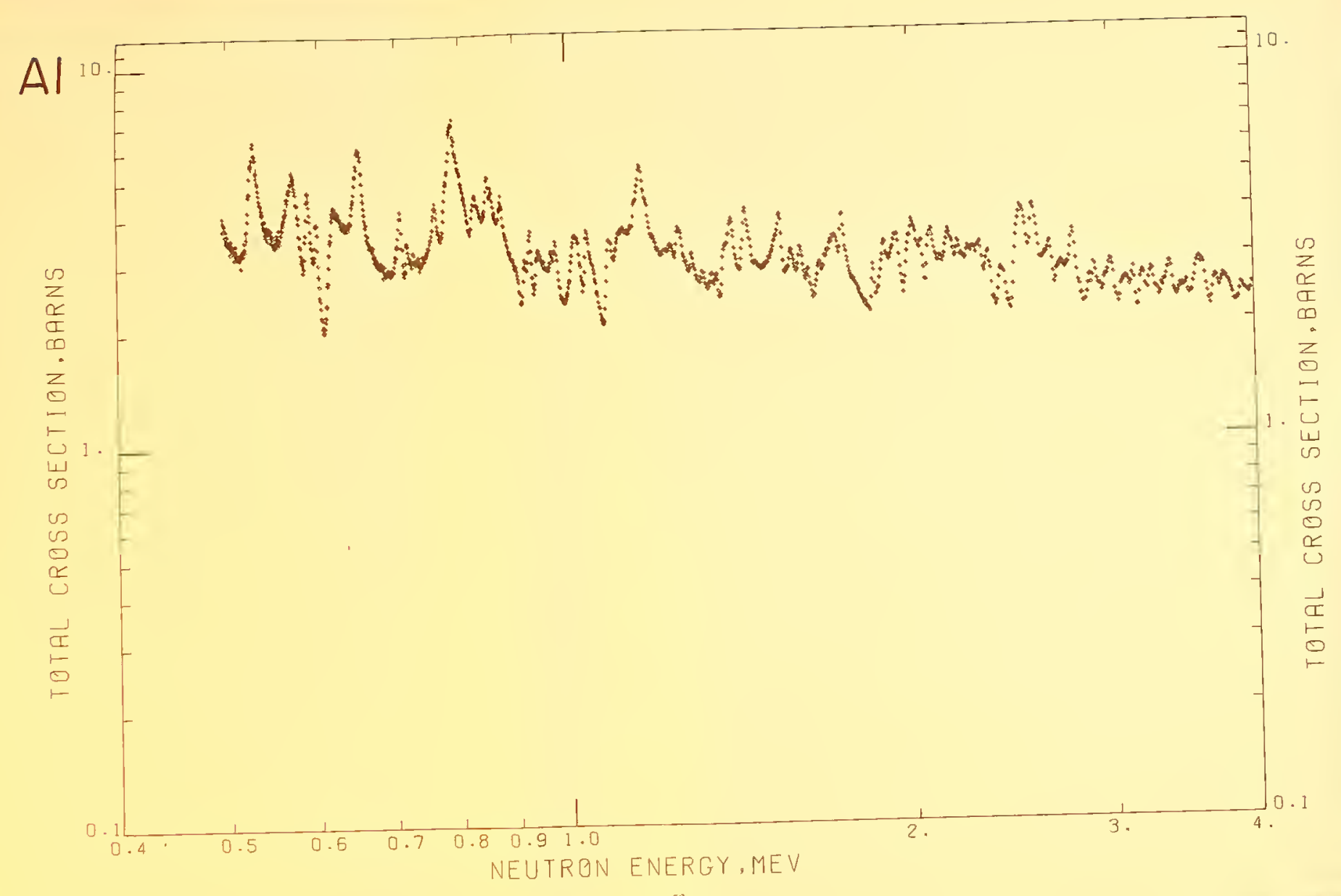




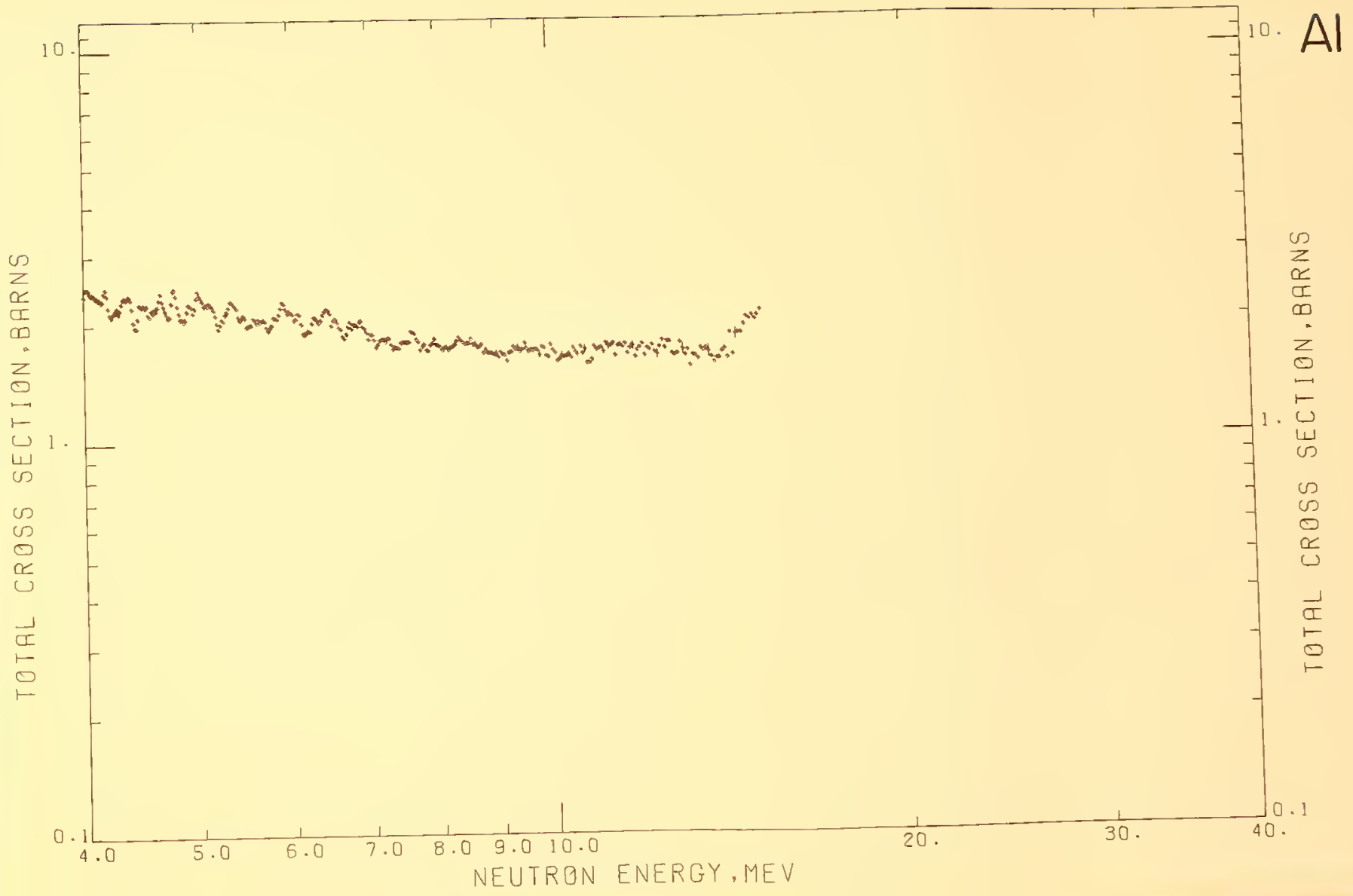




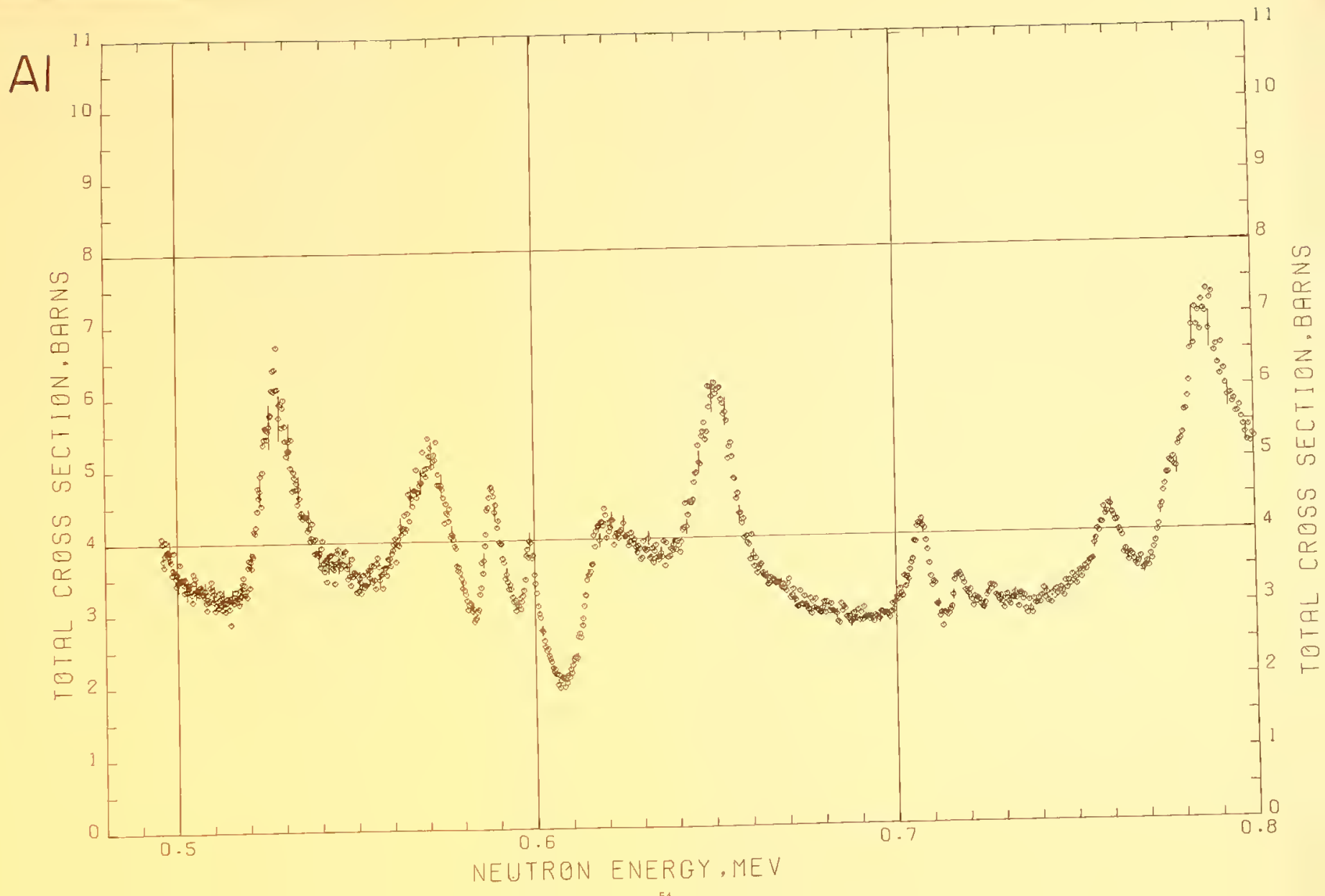




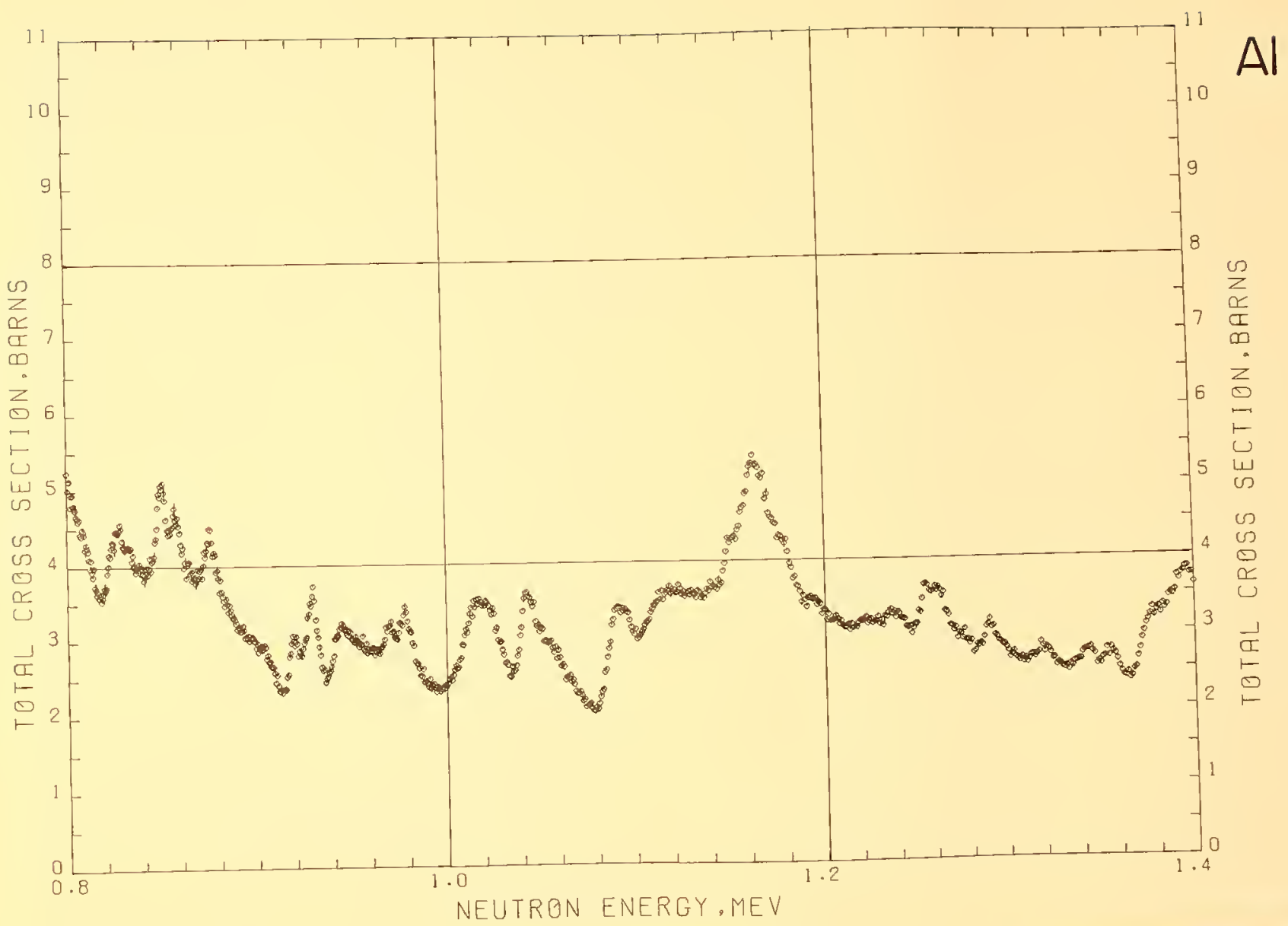




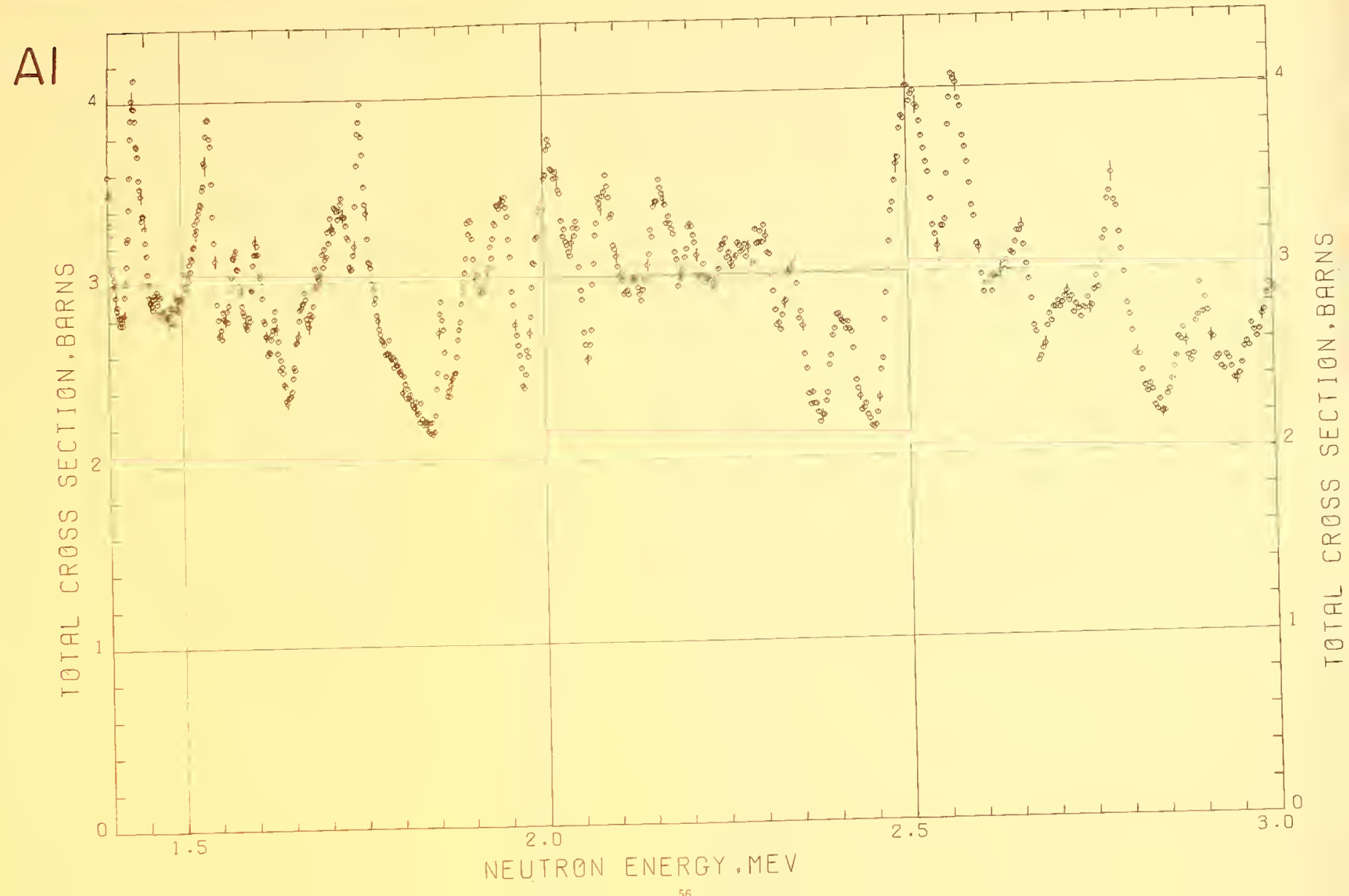




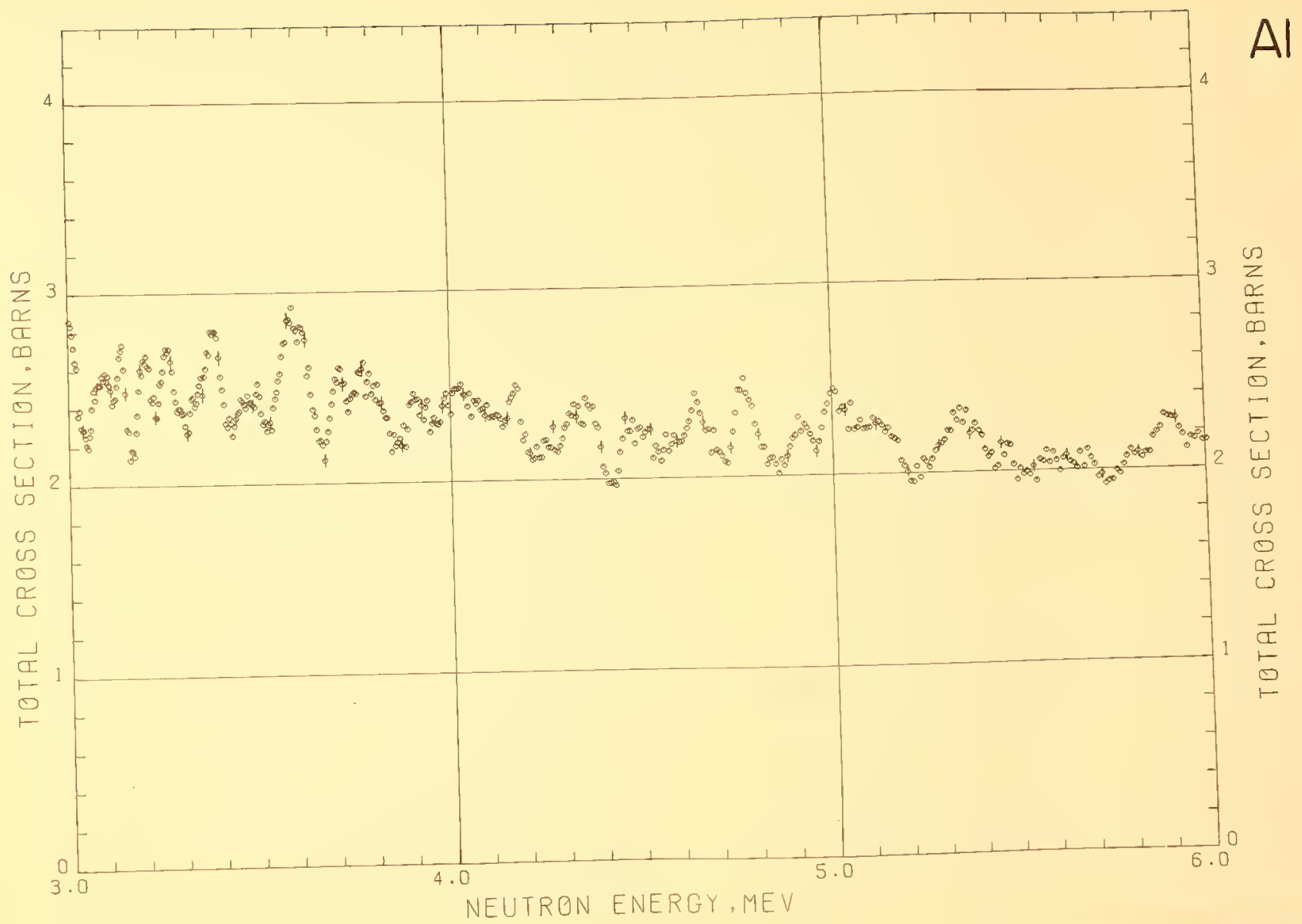




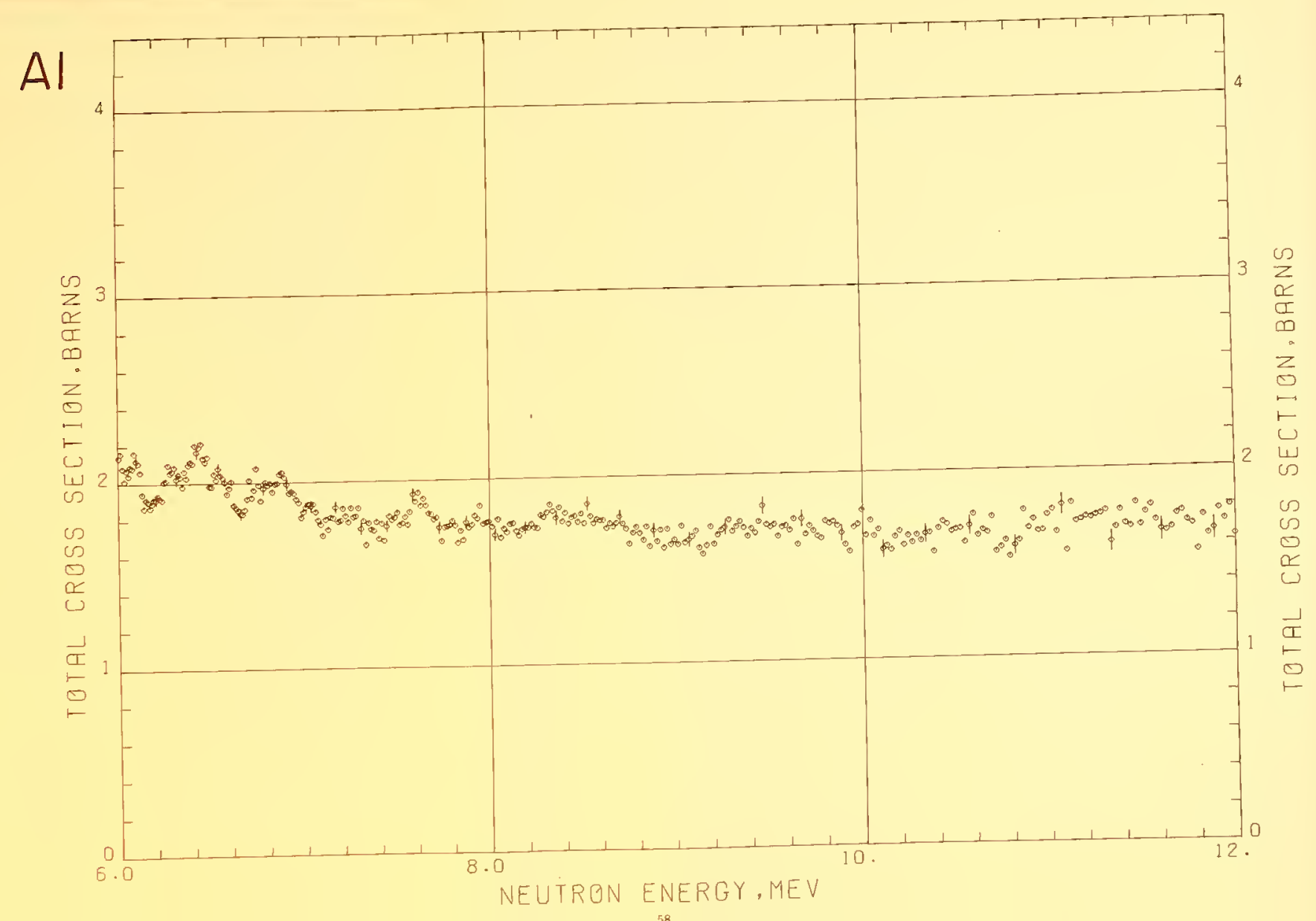




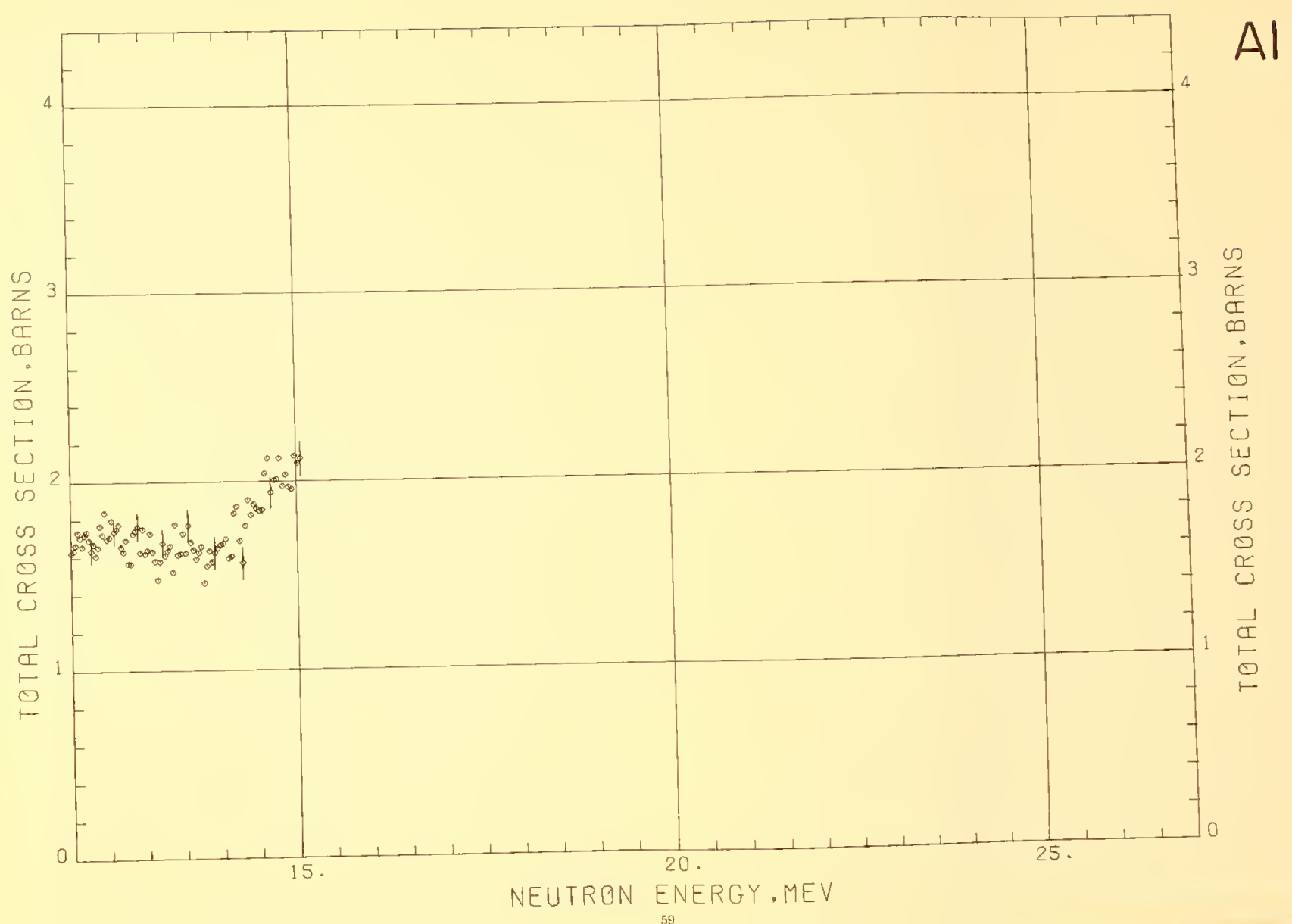





\section{SILICON}

Sample Haterial:

polyerystalline silicon bar

Sample Diameter: $\quad 5.08 \mathrm{~cm}$

Sample Thickress: $\quad 4.6 \mathrm{~cm}, n=0.2294$ atoms/barn

$17.9 \mathrm{~cm}, n=0.8957$ atoms $/$ barn

Literature Reference: R. A. Schrack, R. B. Sehwartz, and H. T. Heaton II, Bull. Am. Phys. Soc. 16, 495 (1971).

Comments: The samples were semiconductor grade silicon having impurity levels $<10^{-6}$. 


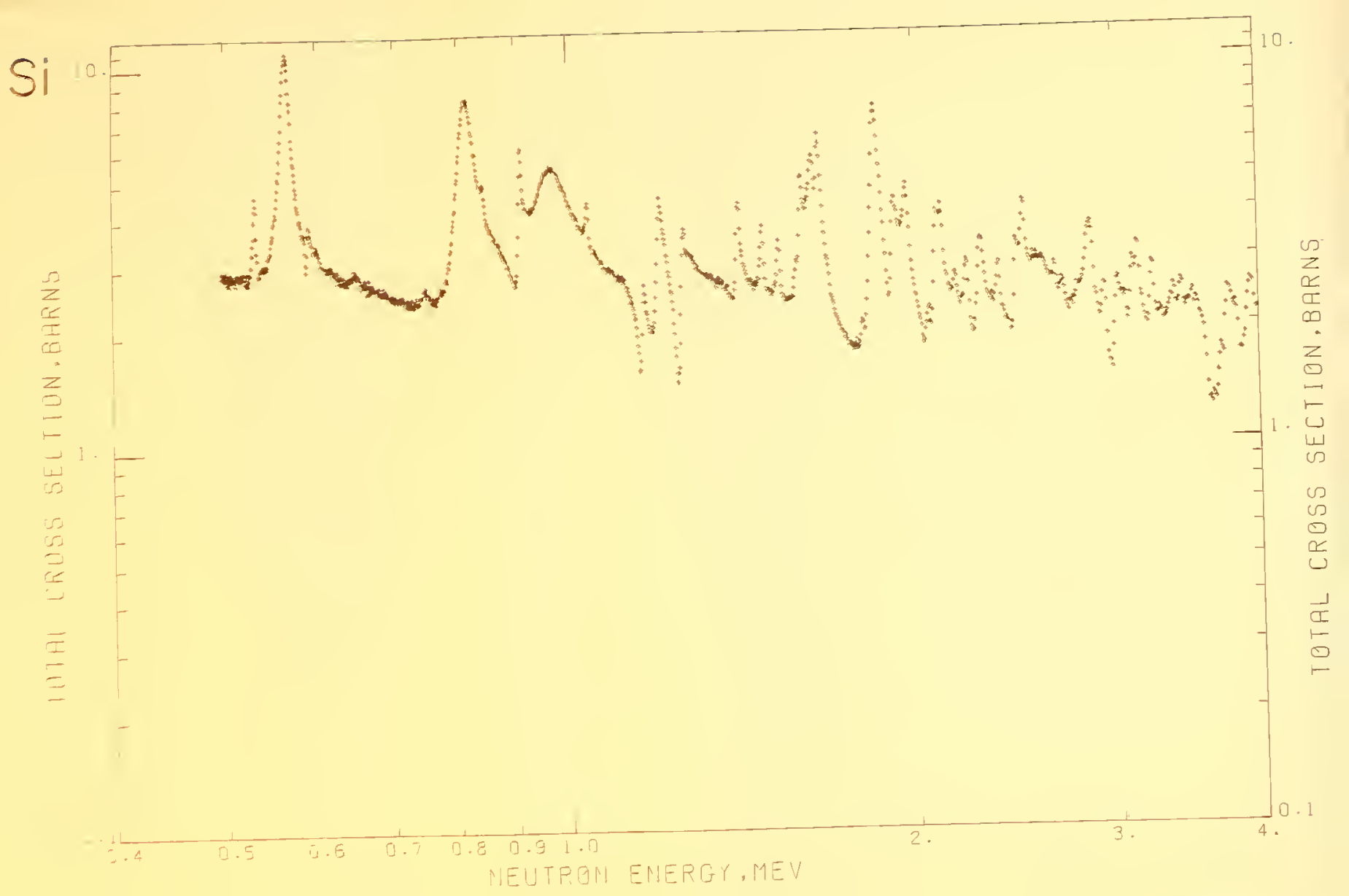




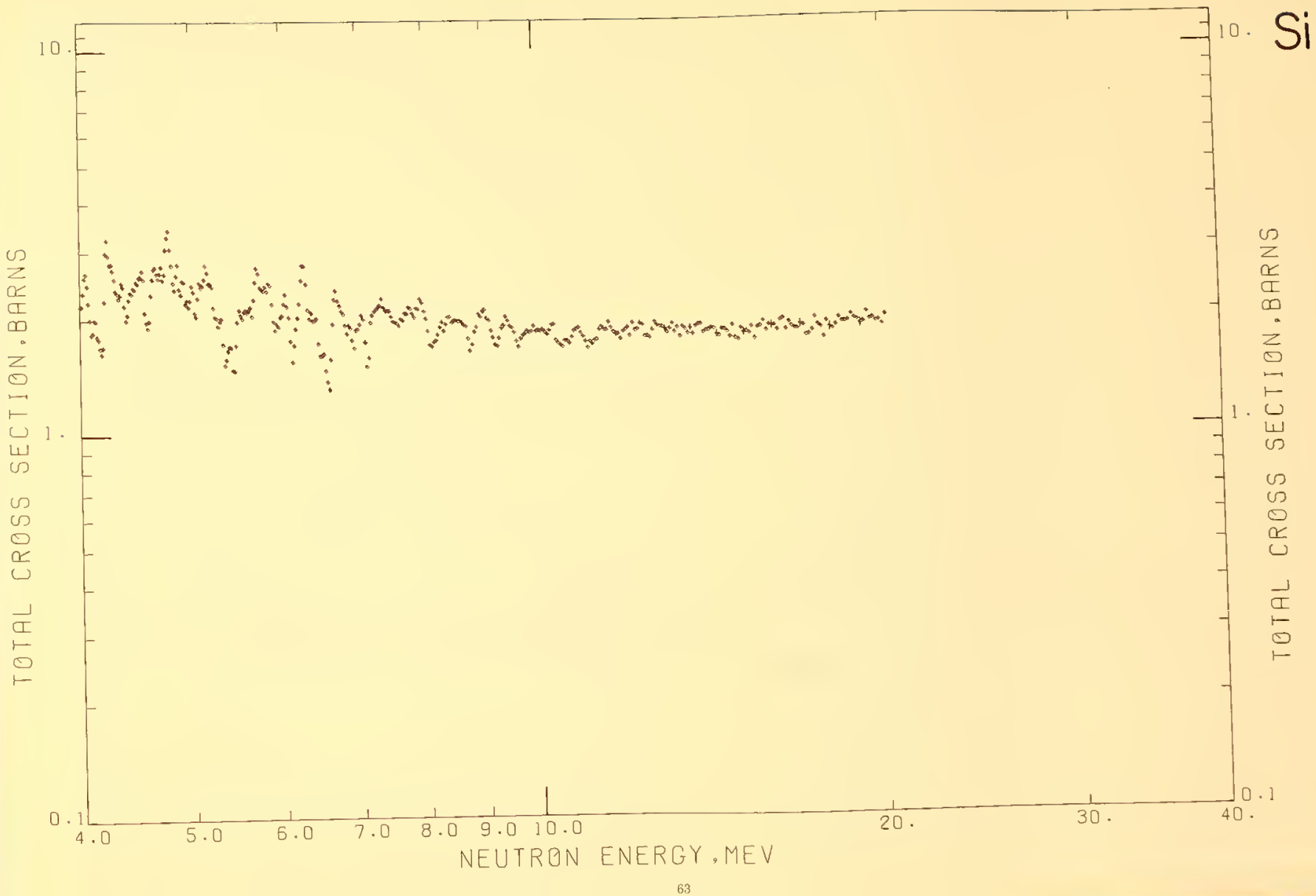




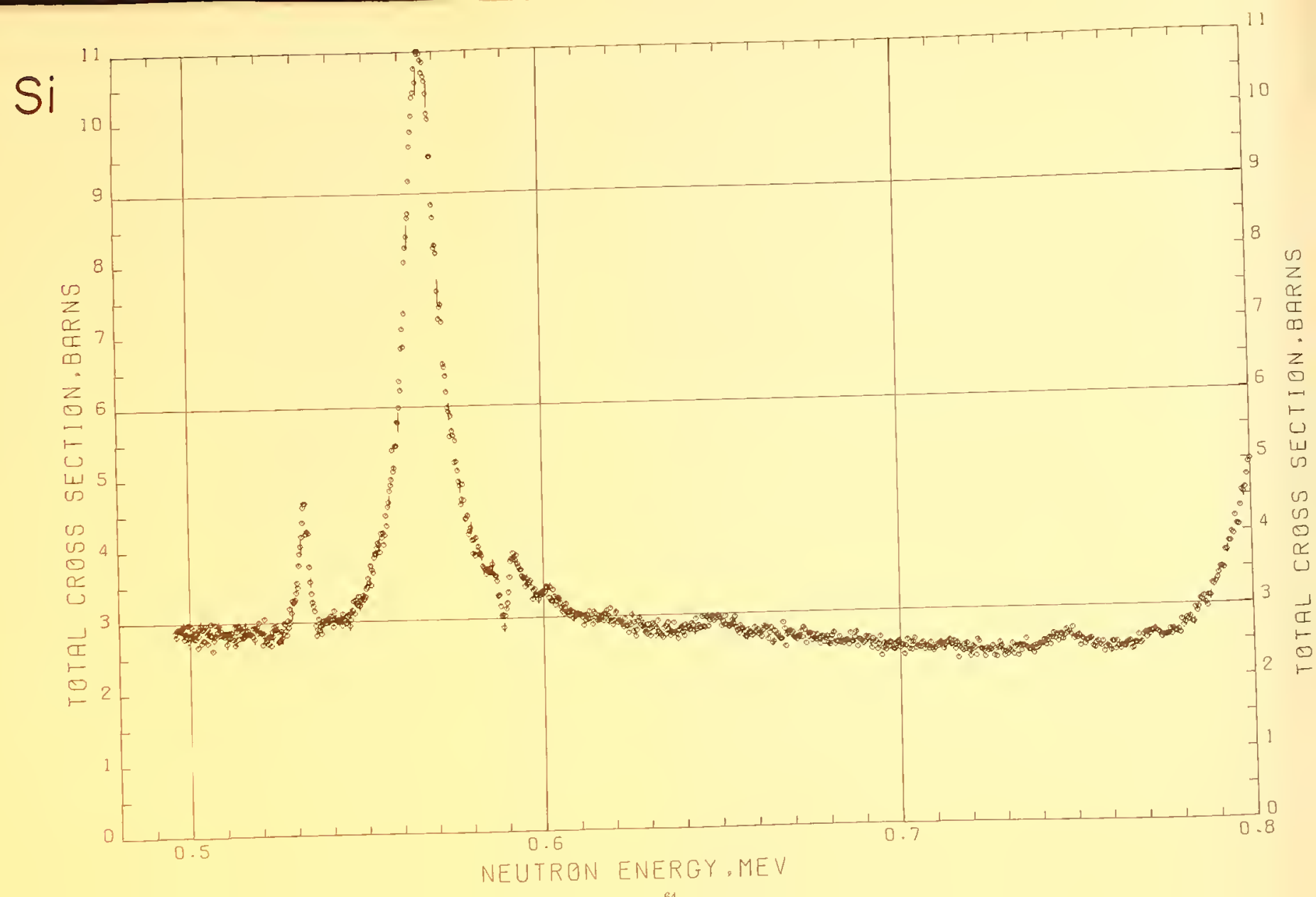




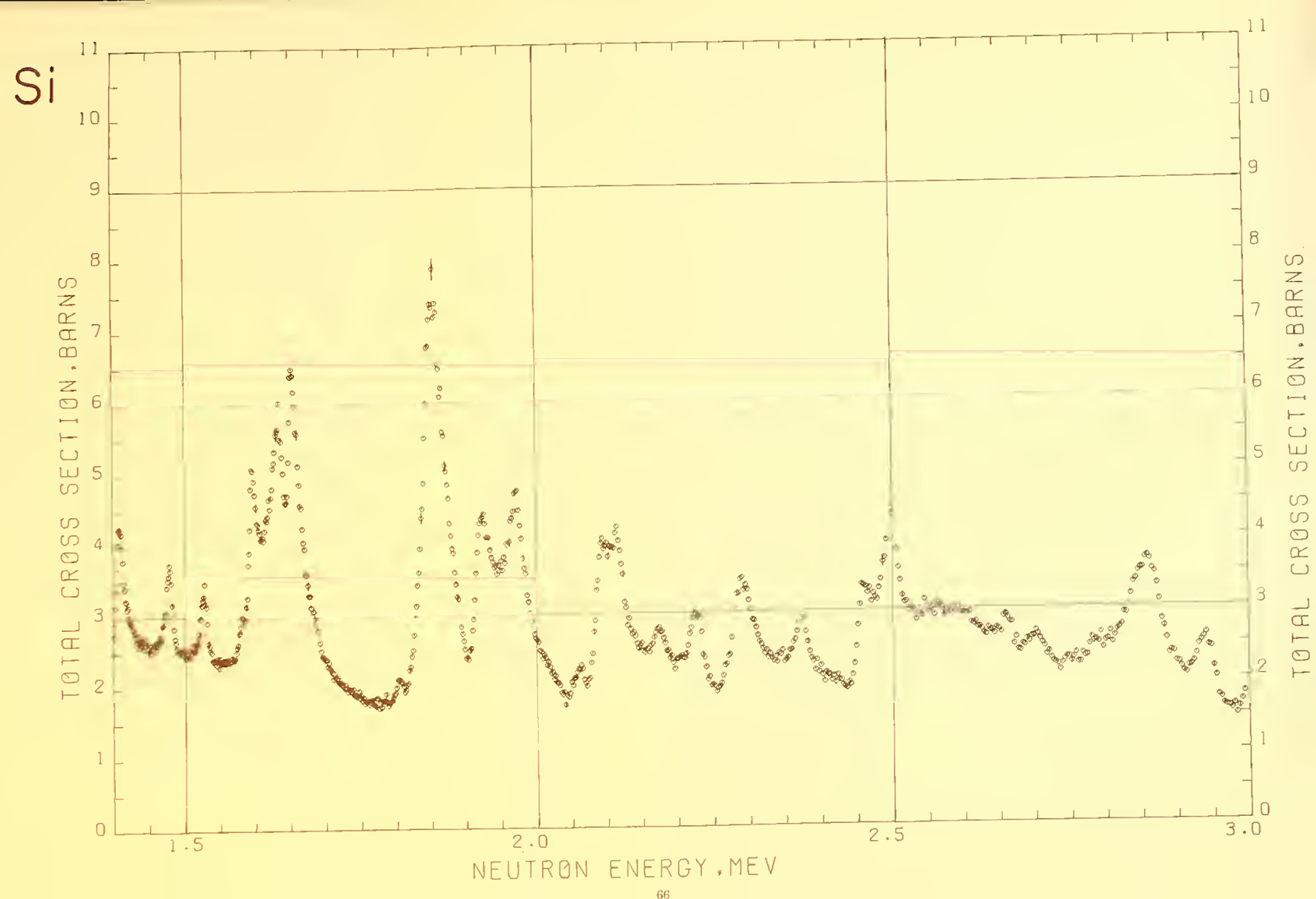




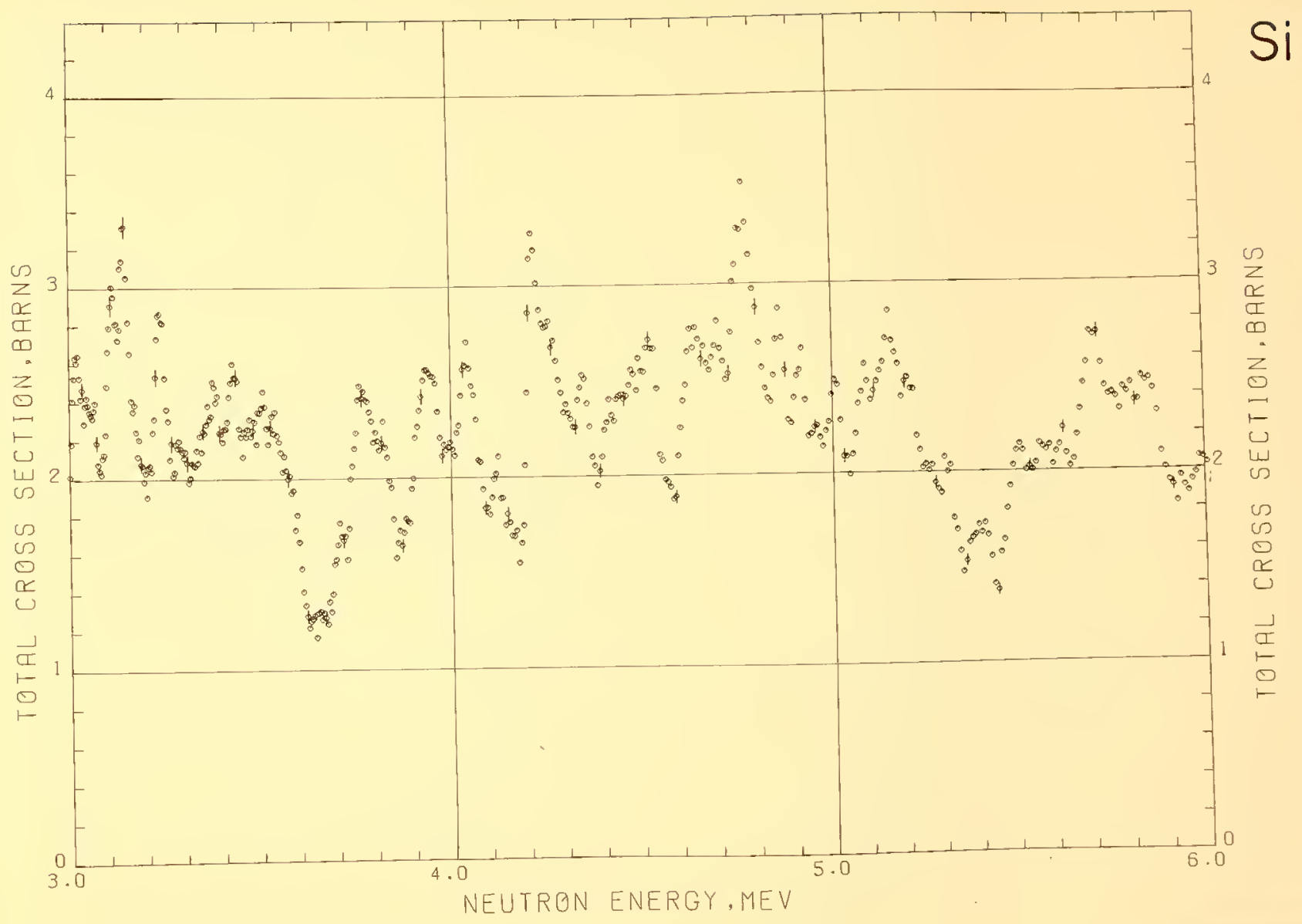




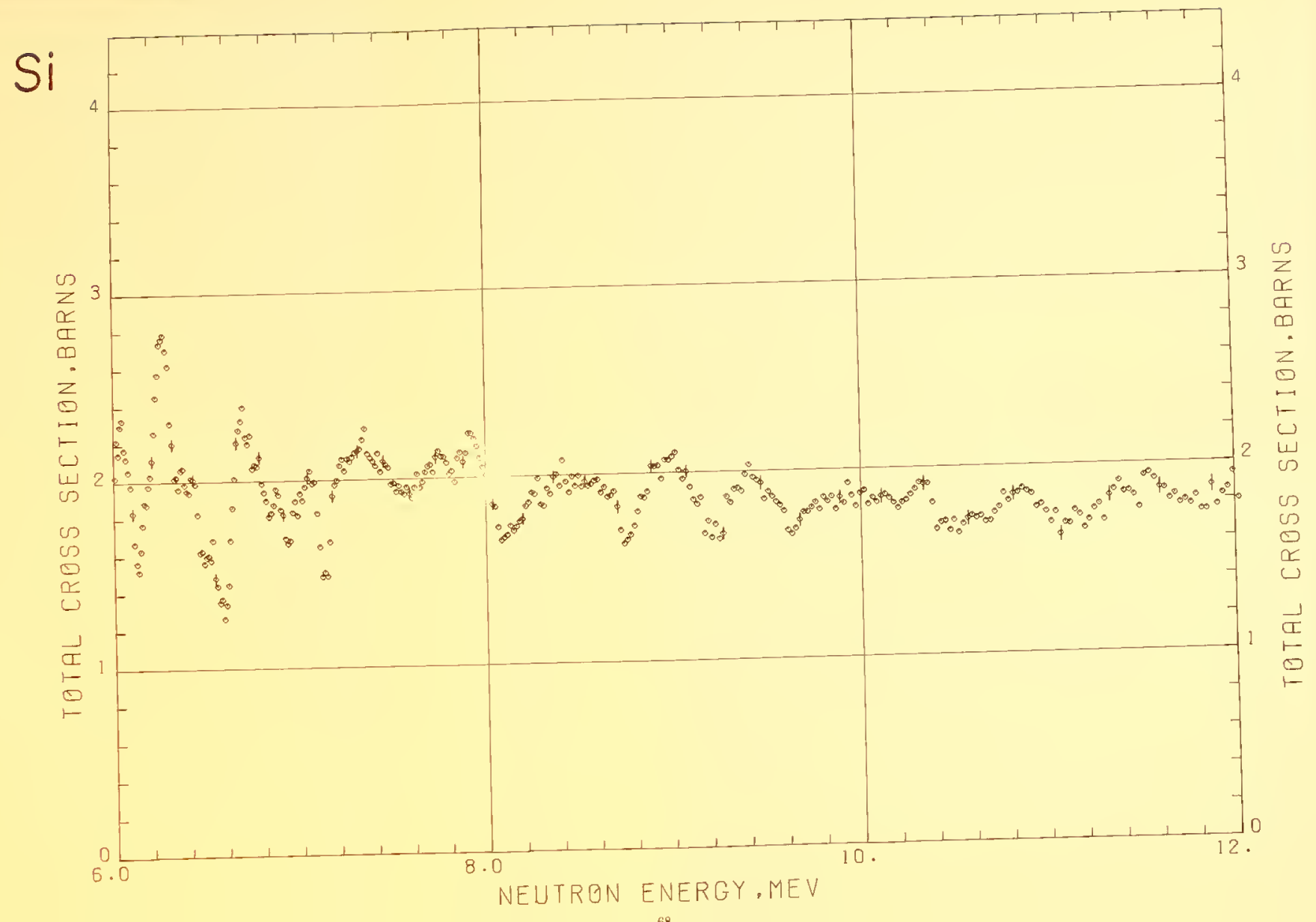




\section{CALCIUM}

Sample Haterial: metallic calcium

Sample Diameter: $\quad 12.7 \mathrm{~cm}$

Sample Thickness: $\quad 14.5 \mathrm{~cm}, 1=0.3331$ atoms $/ \mathrm{bar}$ $44.7 \mathrm{~cm}, \pi=1.027$ atoms/barn

Analysis. The samples were fabricated from 99 percent purity metal and placed in metal containers to prevent exces. sive samples largest sive oxidation. A gualitative spectrographic analysis of the samples disclosed the impoter than 0.1 percent but less than 1 percent.

Literature Reference: R. A. Schrack, R. B. Schwartz, and H. T. Heaton II, Bull. Am. Phys, Soc. 17, 555 (1972). 


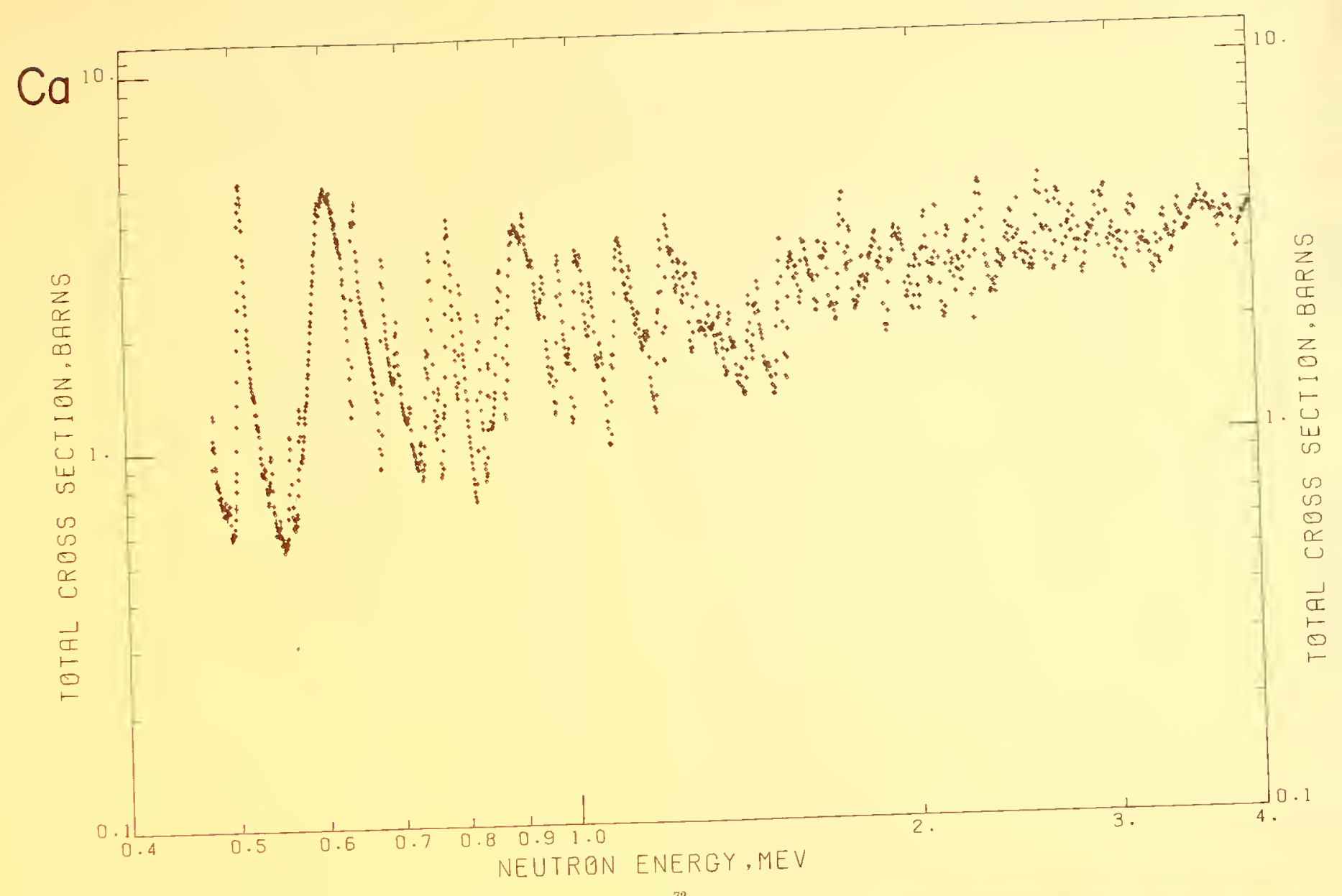




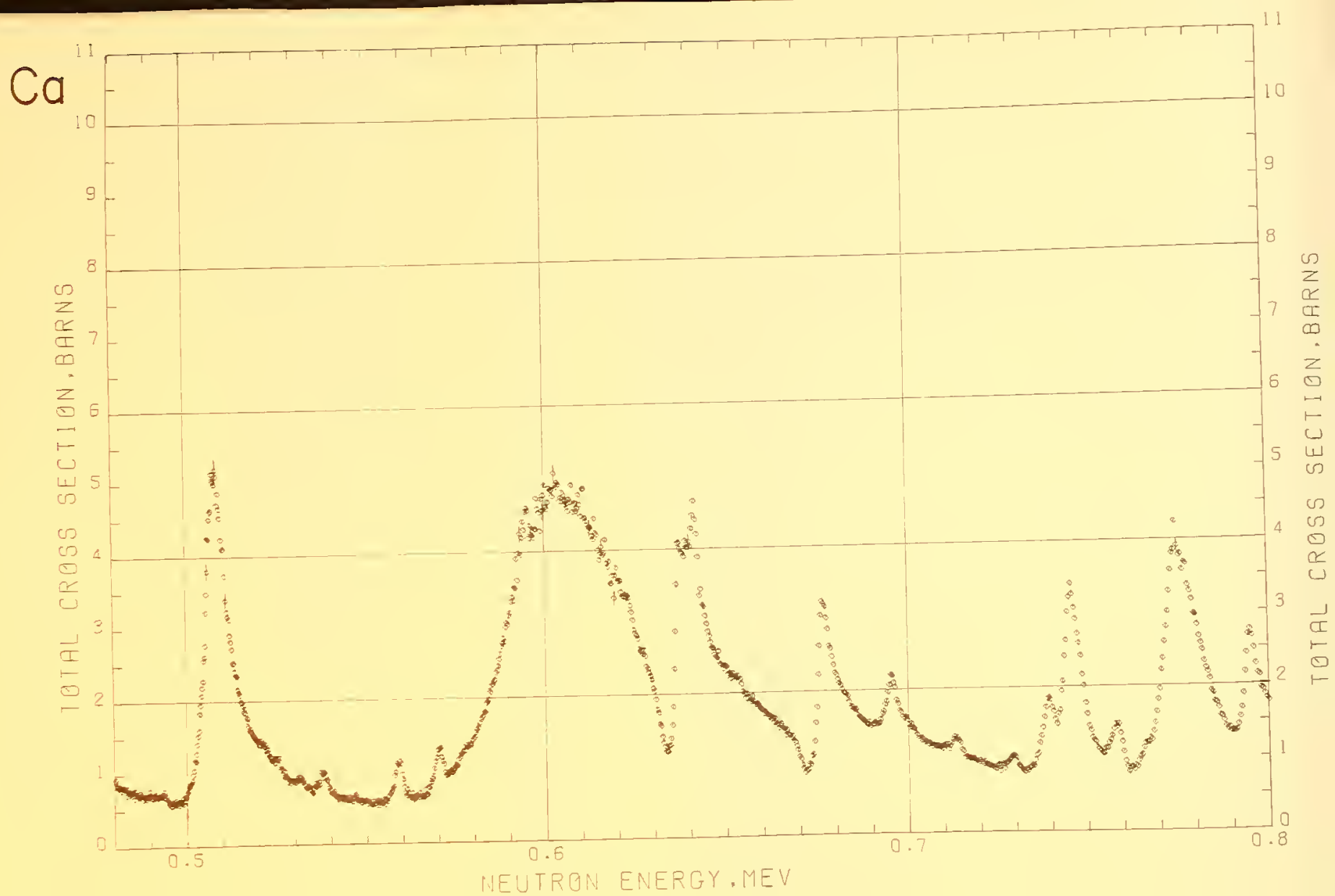




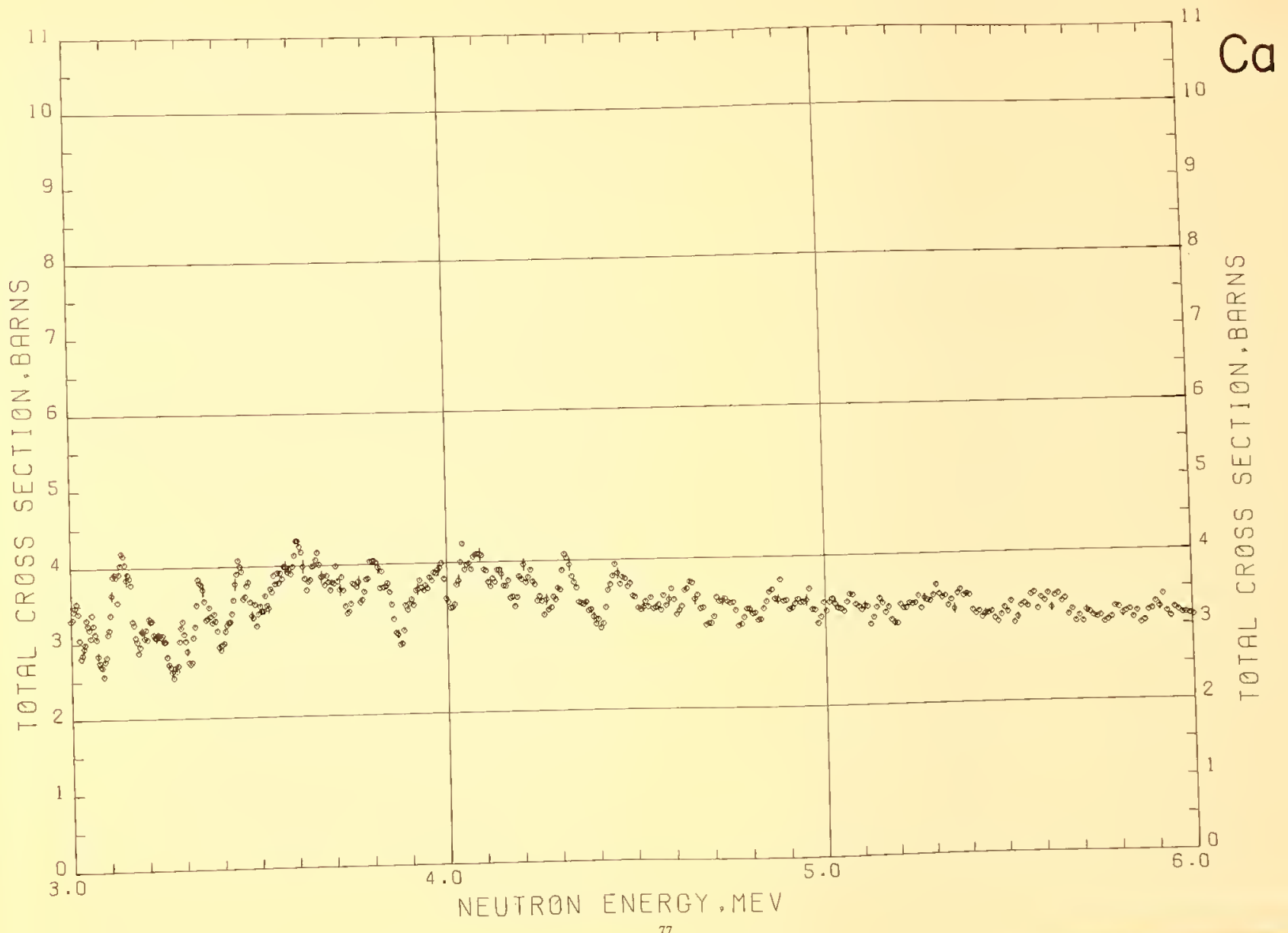




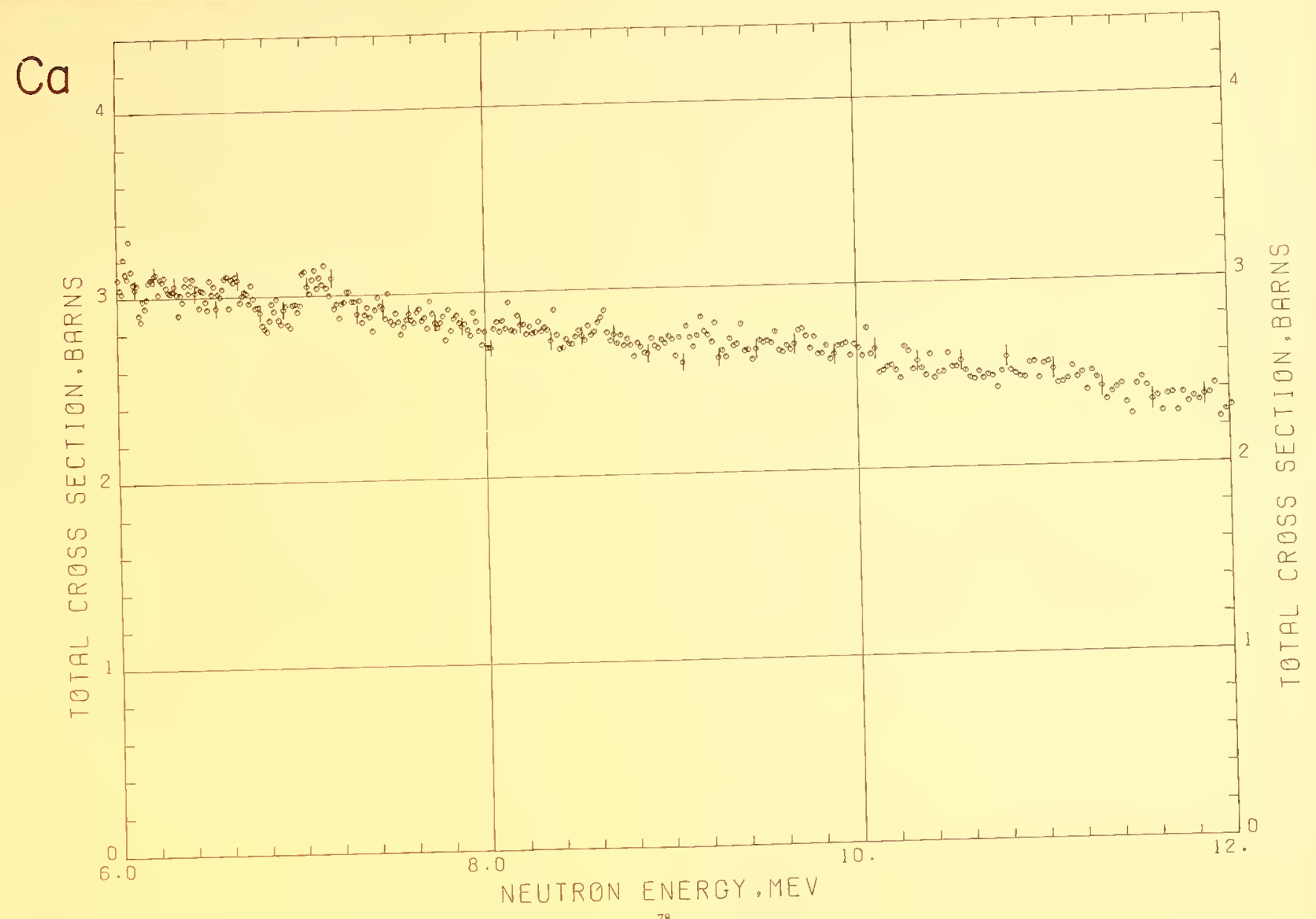




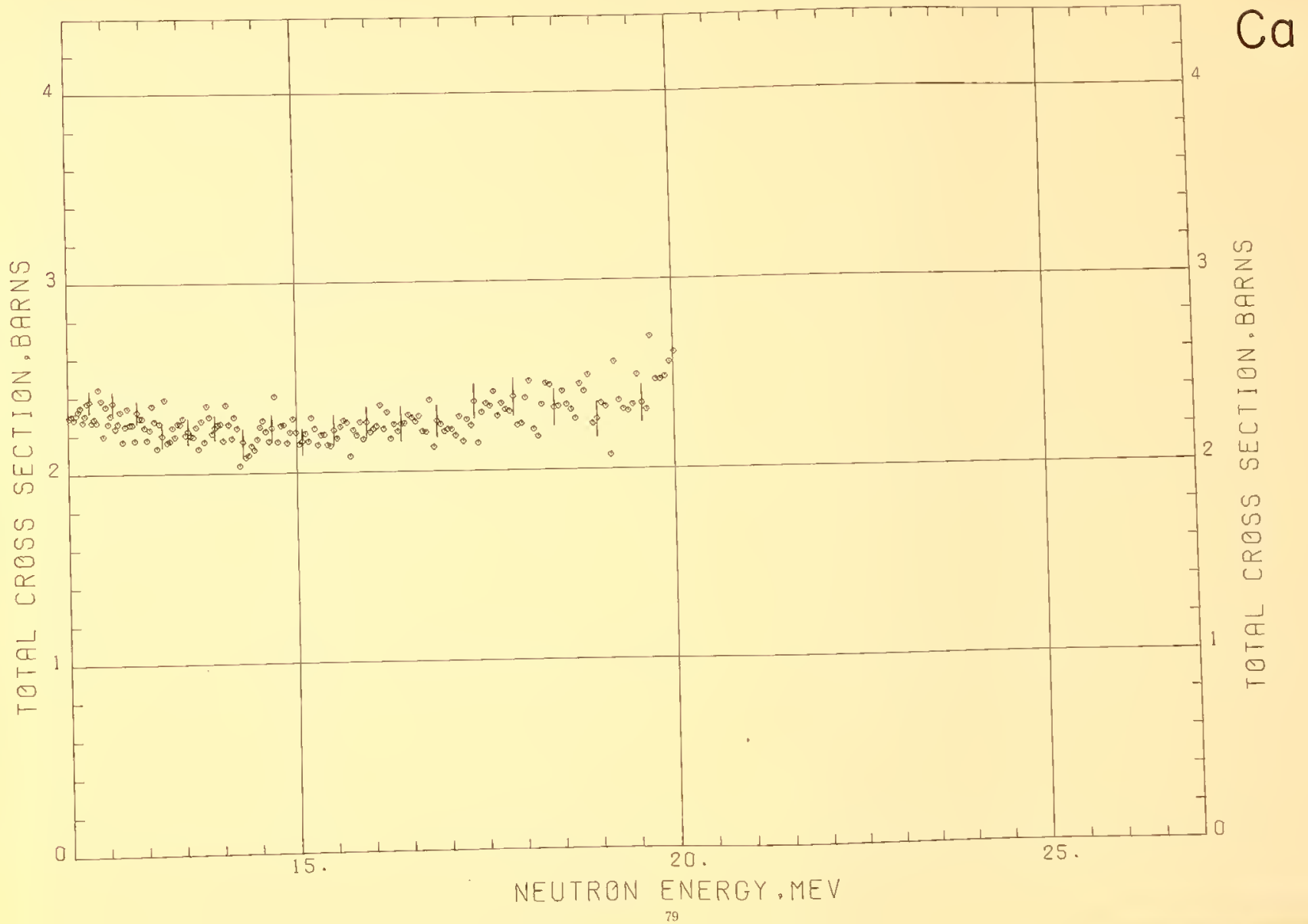


TITANIUM

Sample Material: metallic titanium bar

Sample Diameter: $\quad 12.7 \mathrm{~cm}$

Sample Thickness: $\quad 10.7 \mathrm{~cm}, n=0.6368$ atoms $/ \mathrm{bar} n$

Literature Reference: R. B. Schwartz, R. A. Schrack, and H. T. Heaton II, Bull. Am. Phys. Soc. 14, 494 (1969).

Analysis: A qualitative spectrographic analysis of the sample showed no impurities at levels greater than 0.1 percent. 


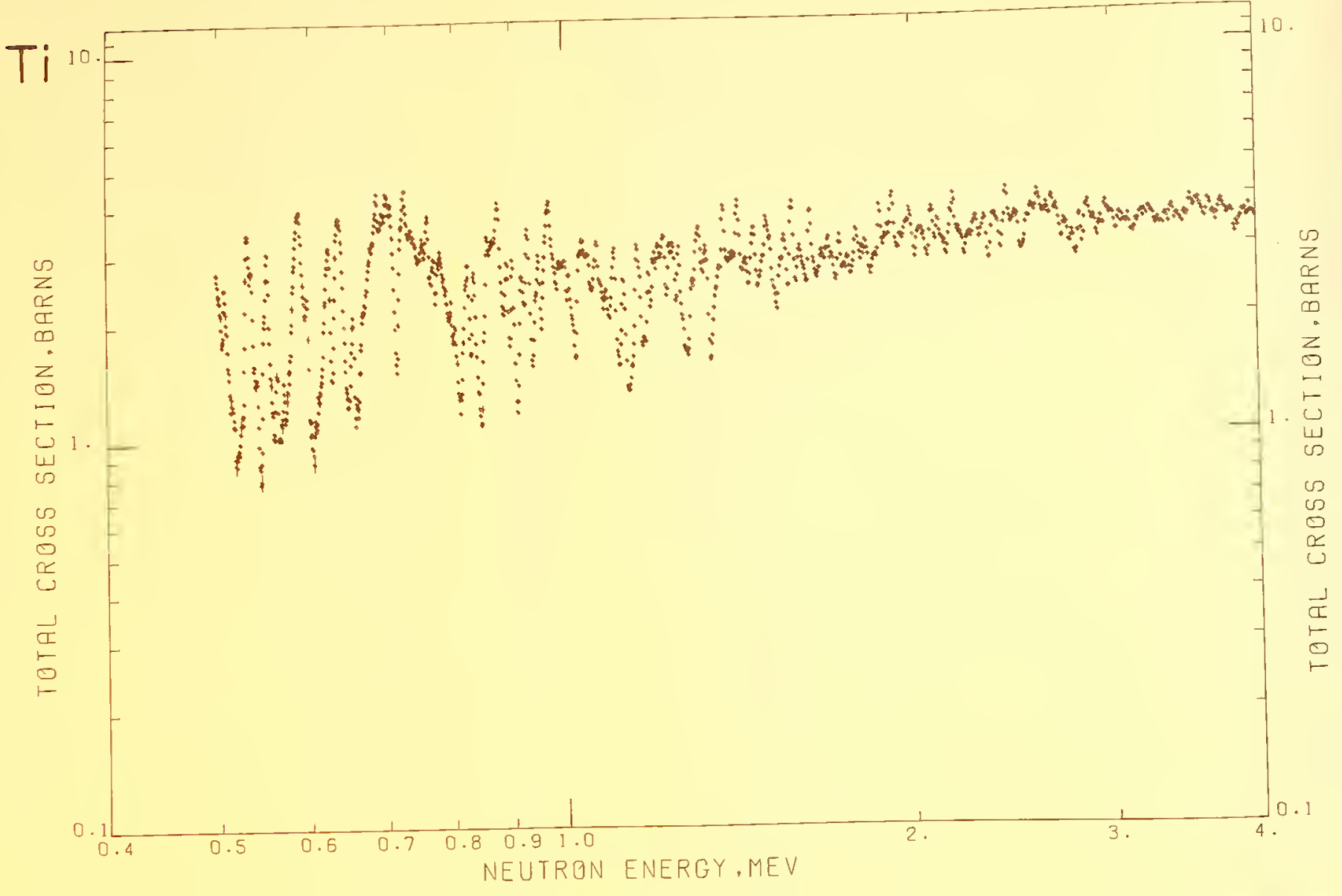




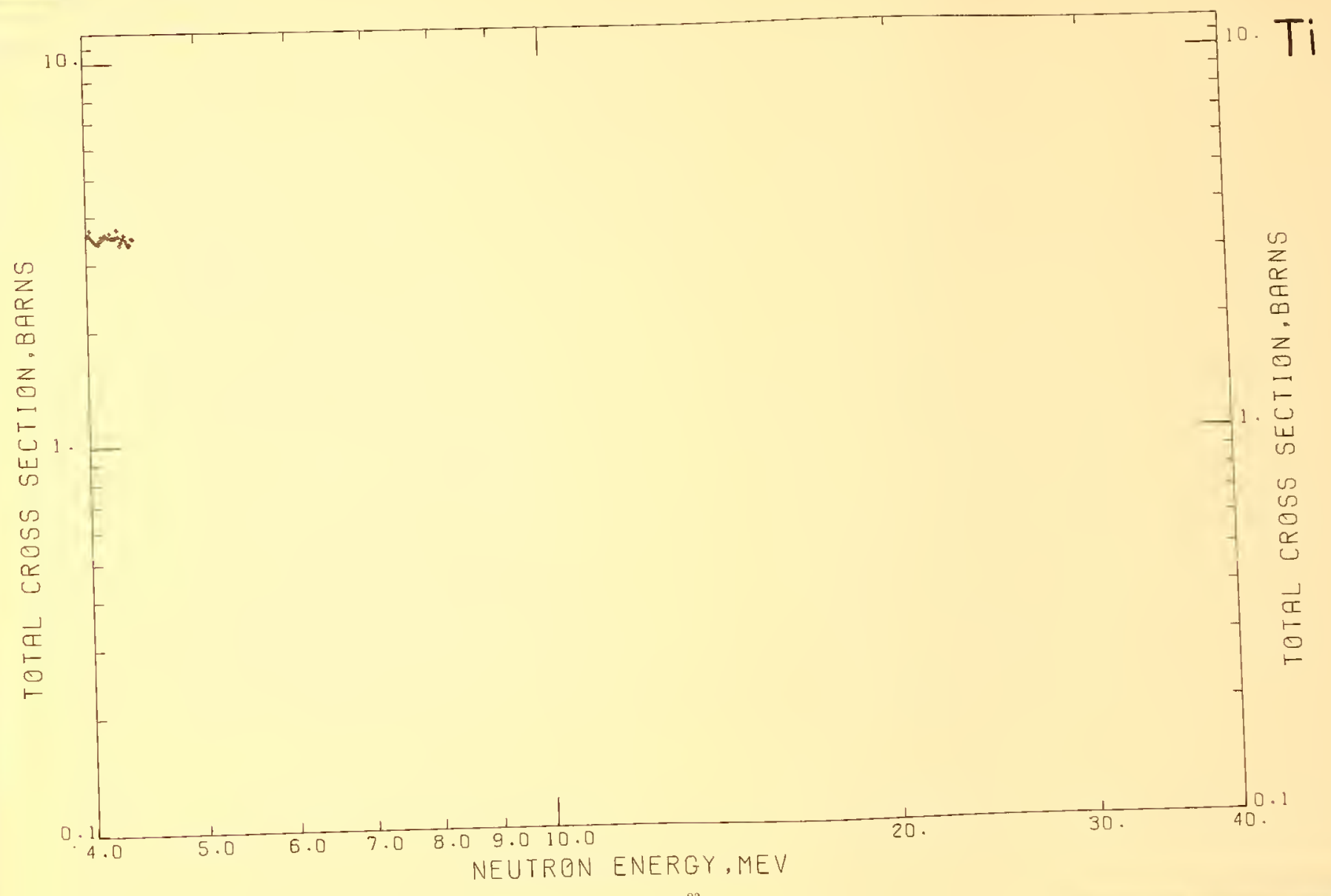




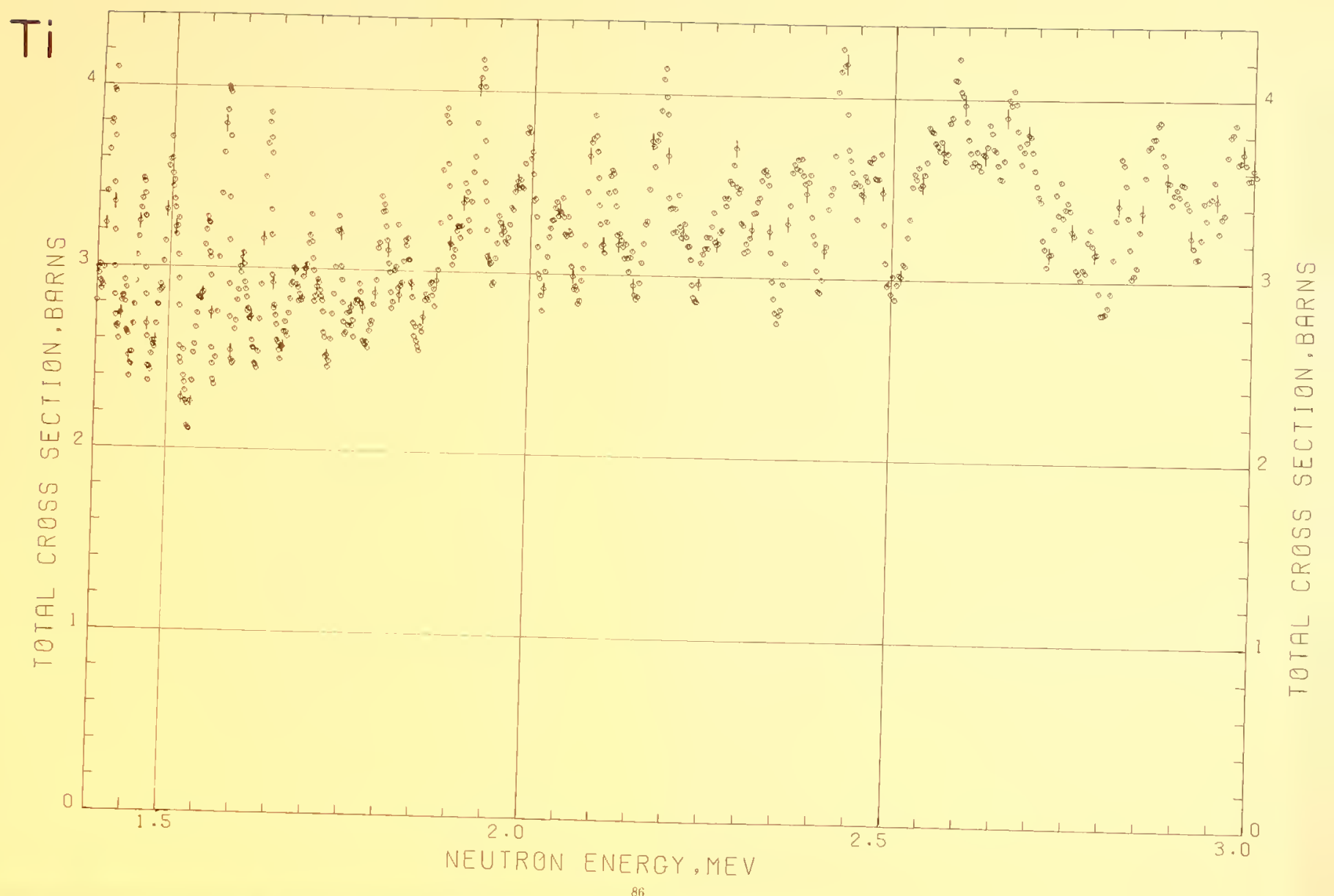




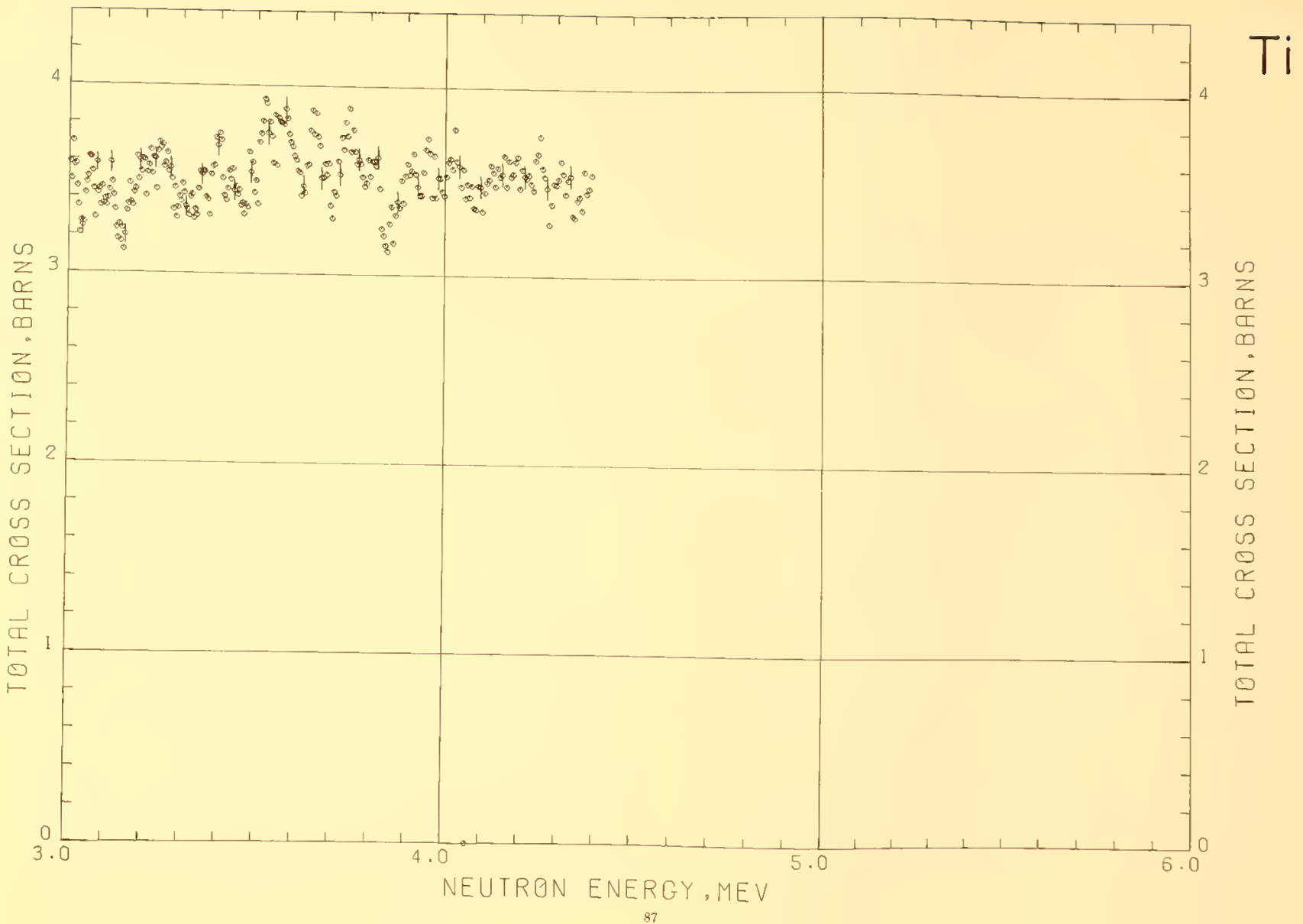



Sample Material: metallic iron

Sample Diameter: $\quad 12.7 \mathrm{em}$

Sample Thickness: $\quad 2.94 \mathrm{~cm}, n=0.2490$ atoms/barn

$11.8 \mathrm{~cm}, n=0.9997$ atoms/barn

Analysis: The samples were fabricated of SAE 1017 steel containing 0.9 percent manganese. The presence of the manganese may, at worst, introduce spurious fluctuations of percent manganese. The presence of the region where there are sharp resonances $(\leqslant 2 \mathrm{MeV})$ and should have negligible effect at higher energies. 


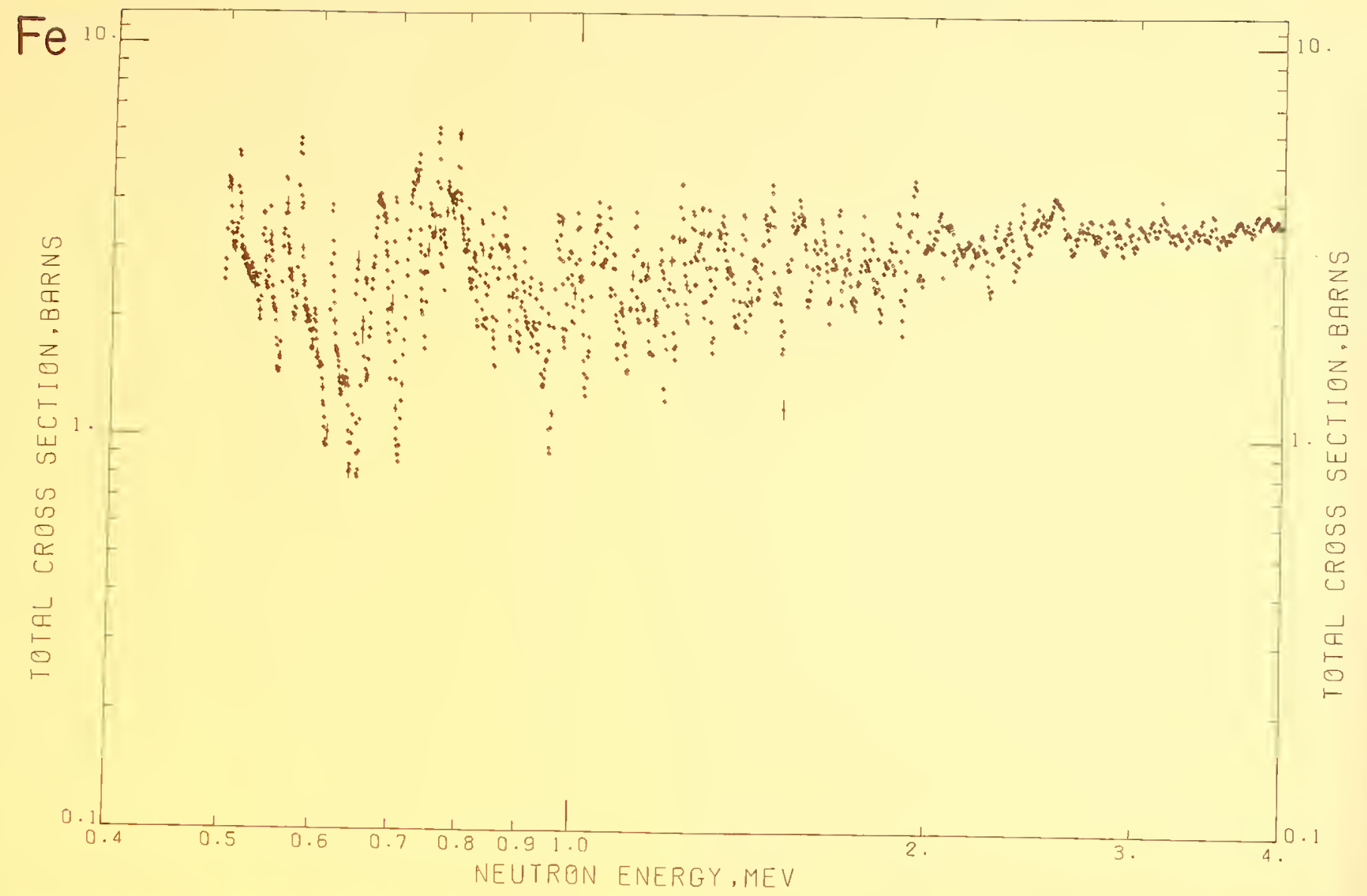




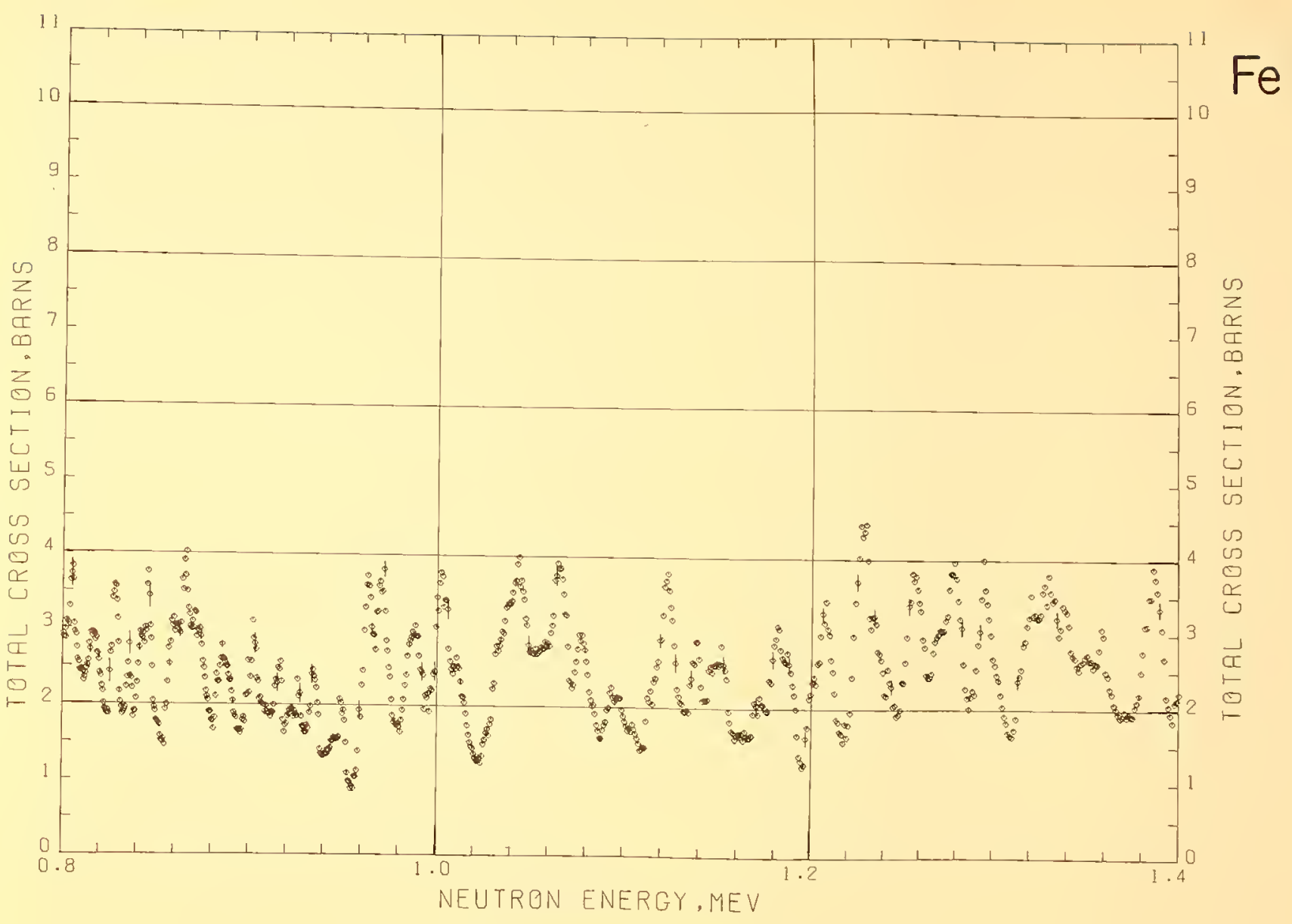




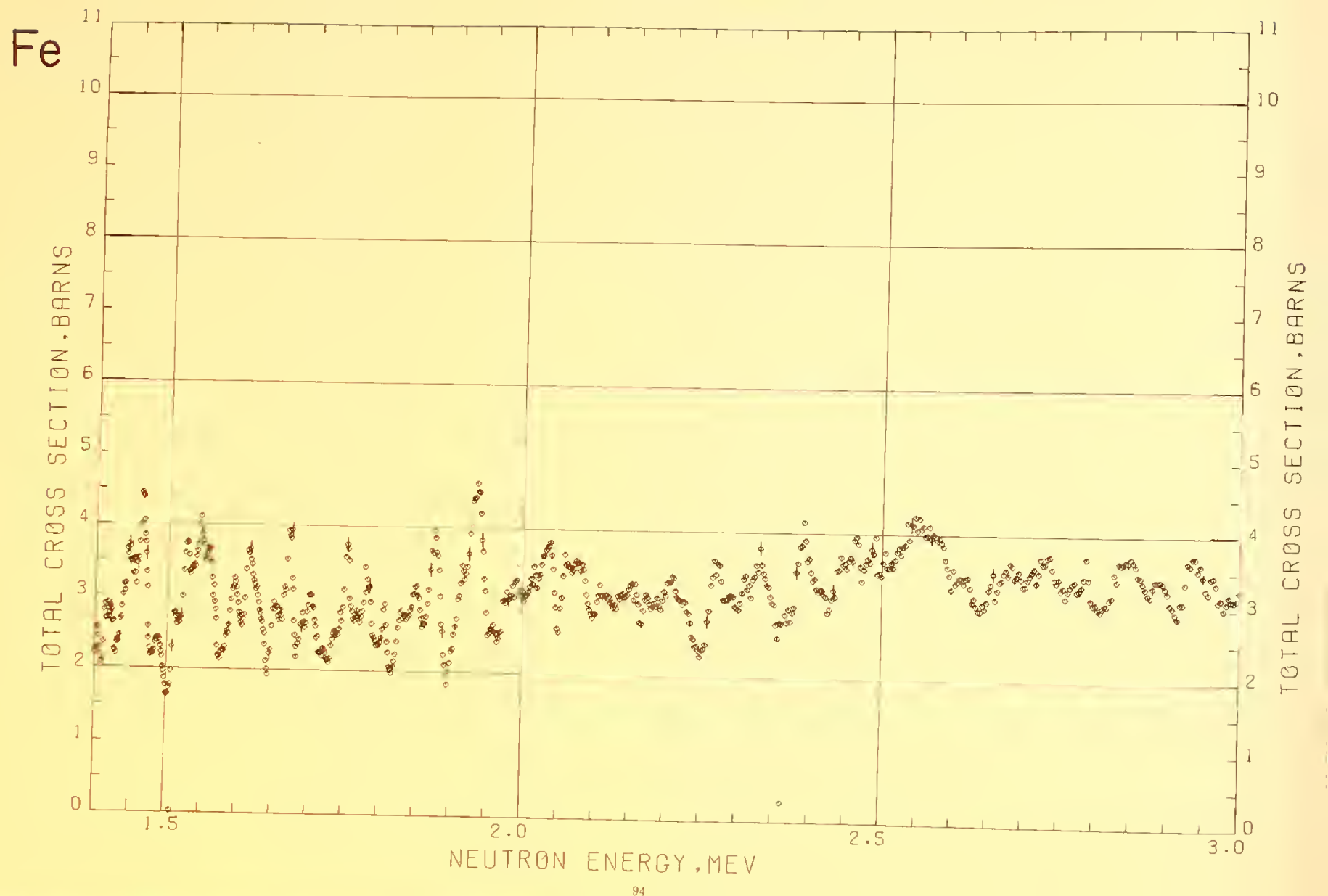




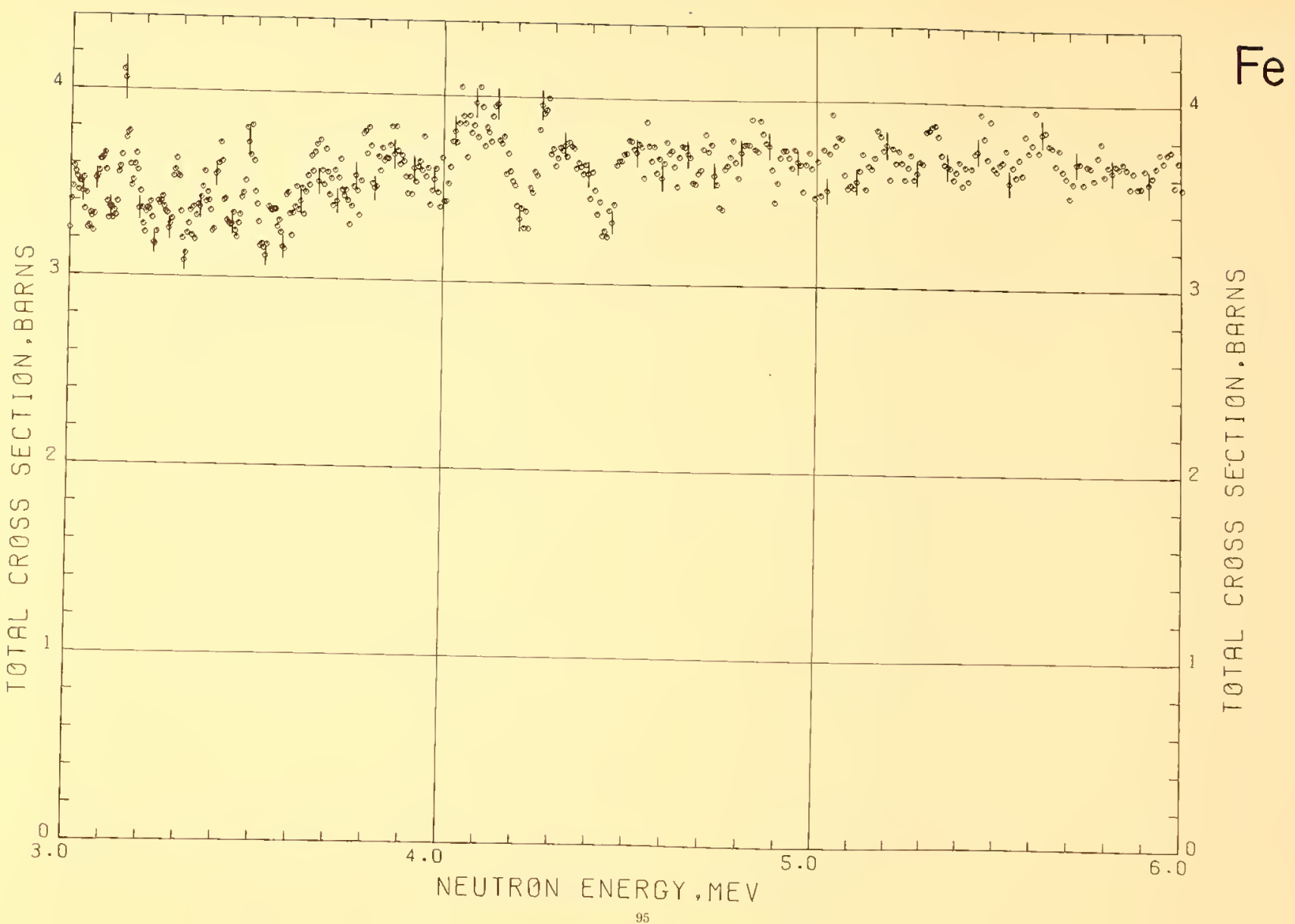




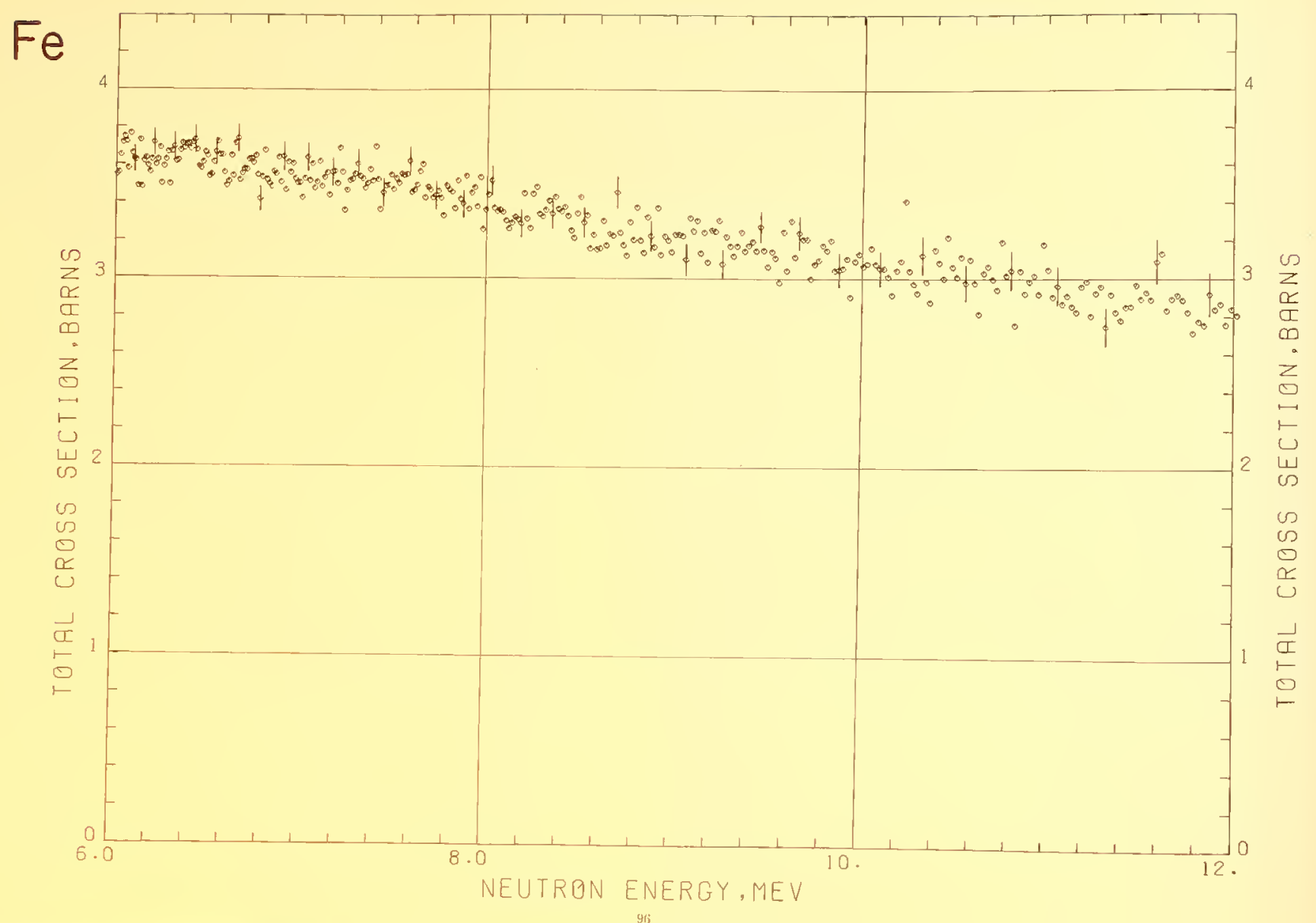




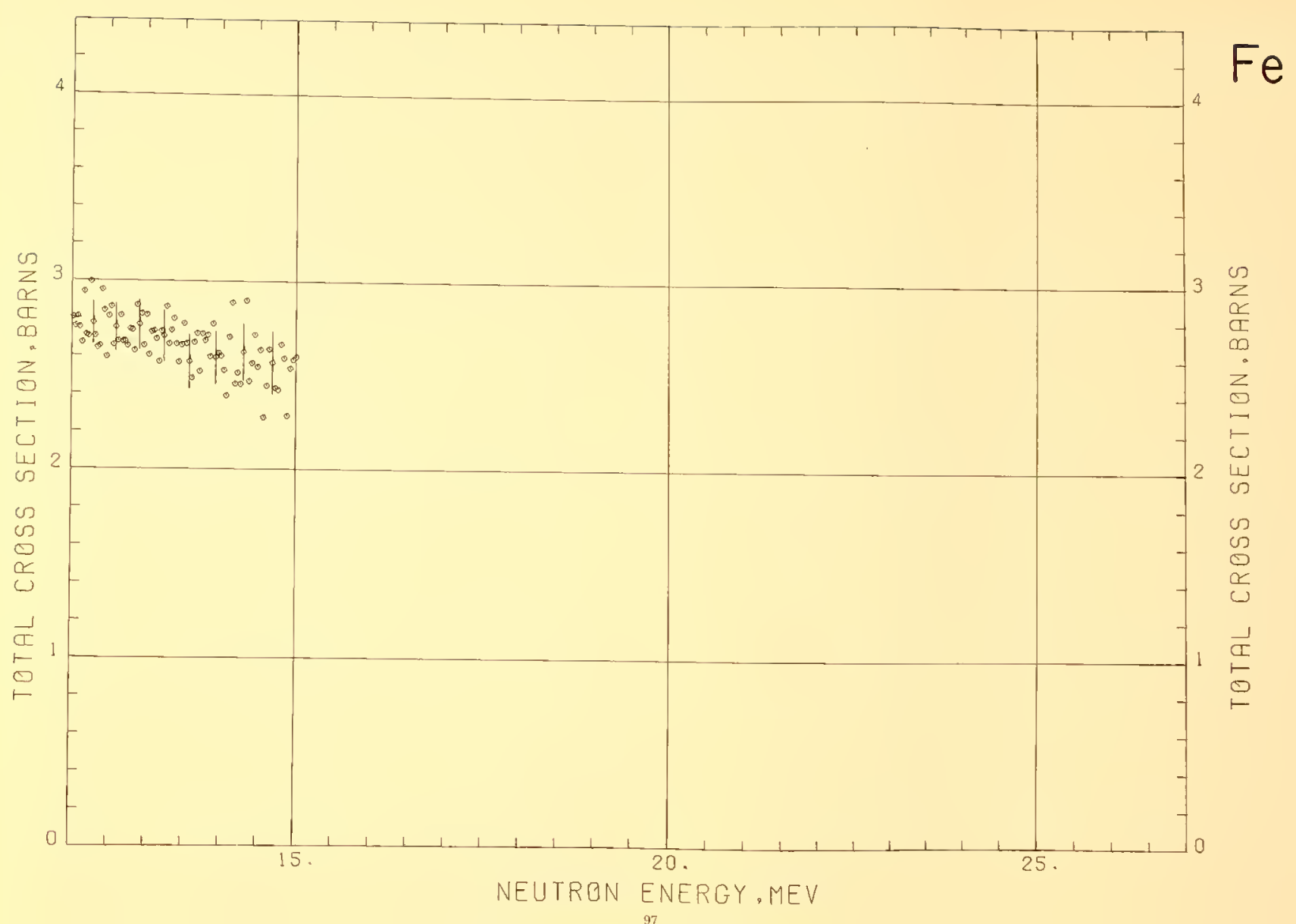




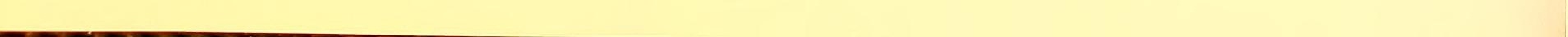




\section{NICKEL}

Sample Material: $\quad$ nickel 200 cold drawn rod

Sample Diameter: $\quad 5.08 \mathrm{~cm}$

Sample Thickness: $\quad 4.46 \mathrm{~cm}, n=0.4047$

$11.37 \mathrm{~cm}, n=1.03$

Analysis: Qualitative spectrographic analysis of the sample showed no impuritieg greater than 0.1 percent. 


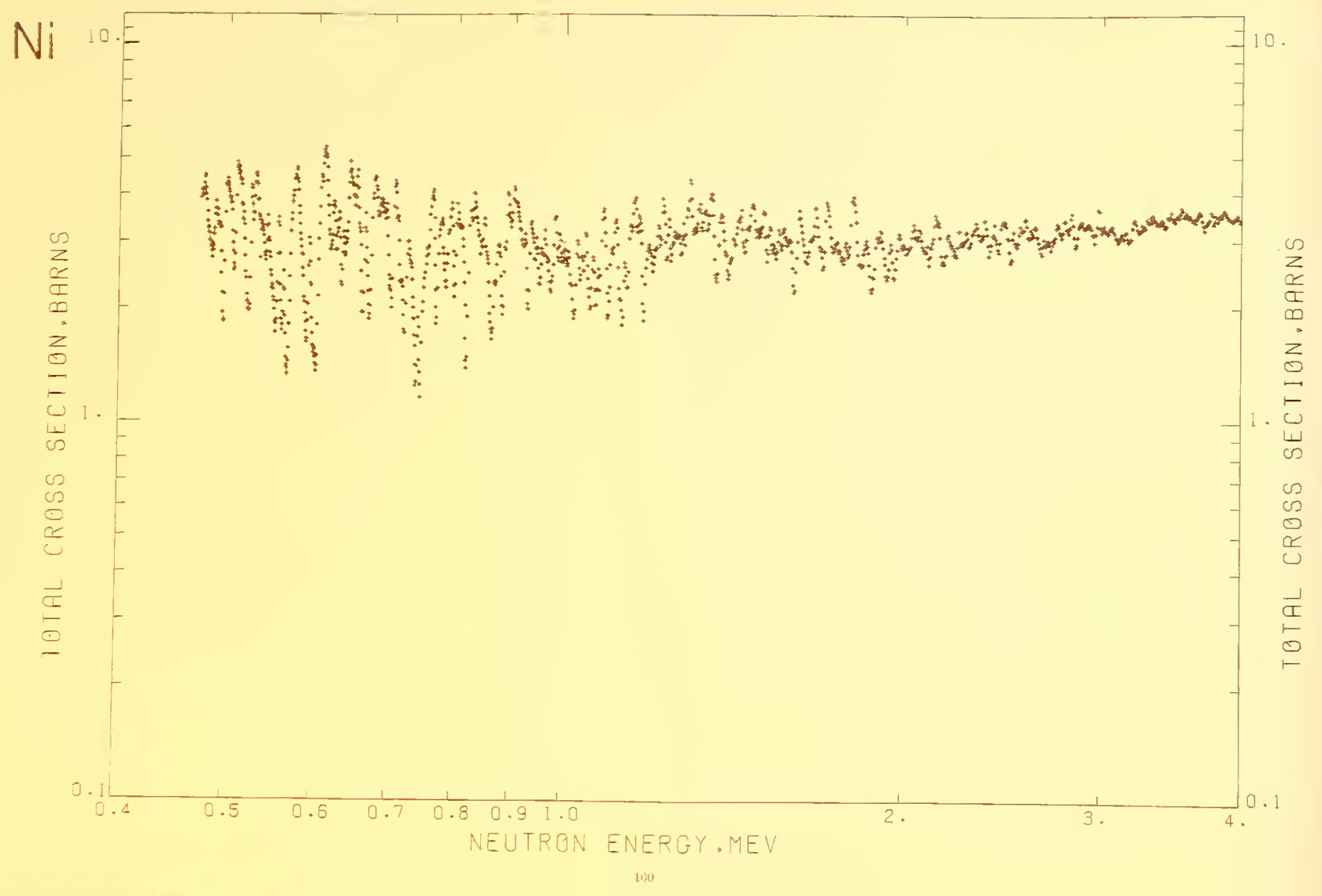




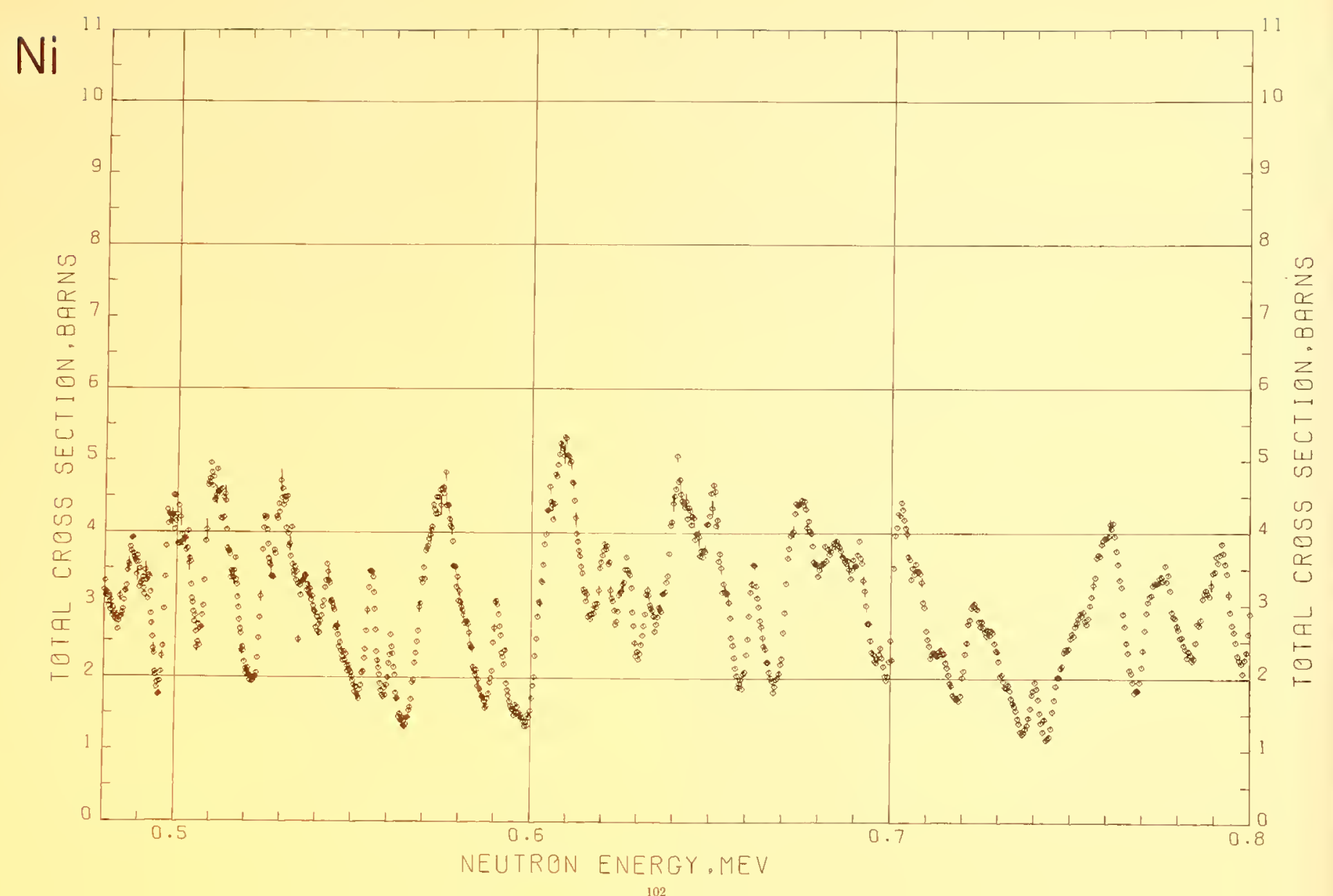




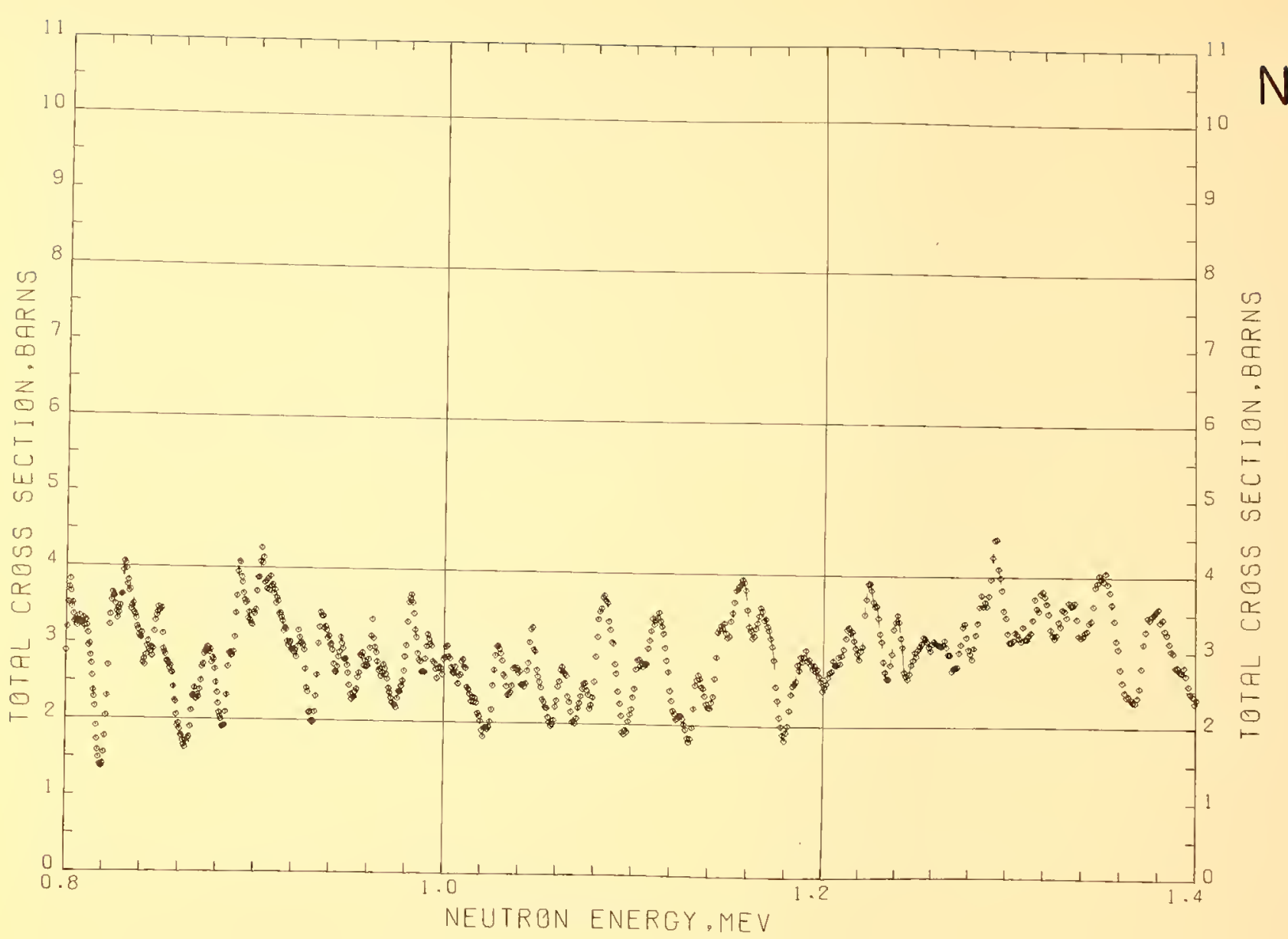


$\mathrm{Ni}$

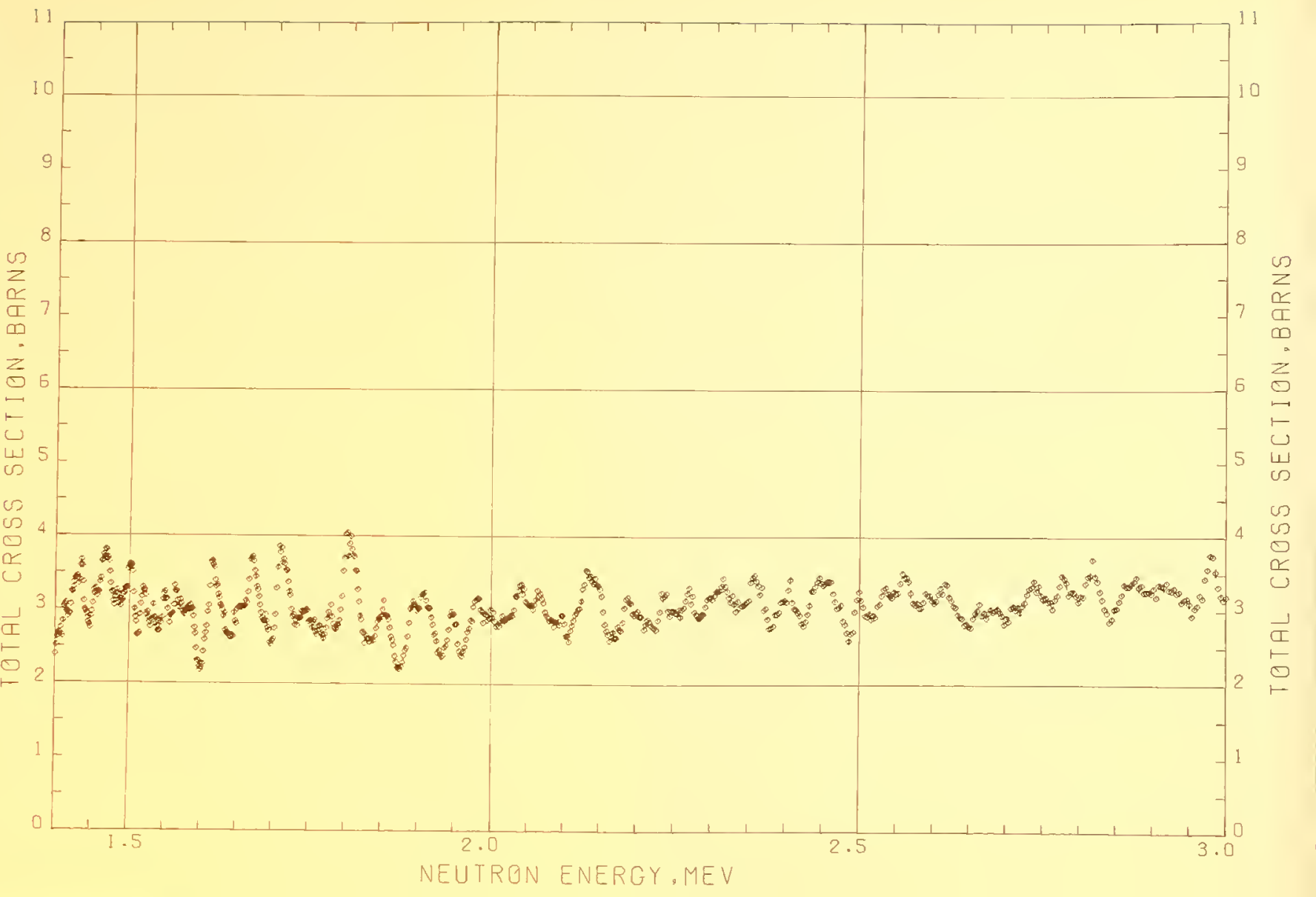




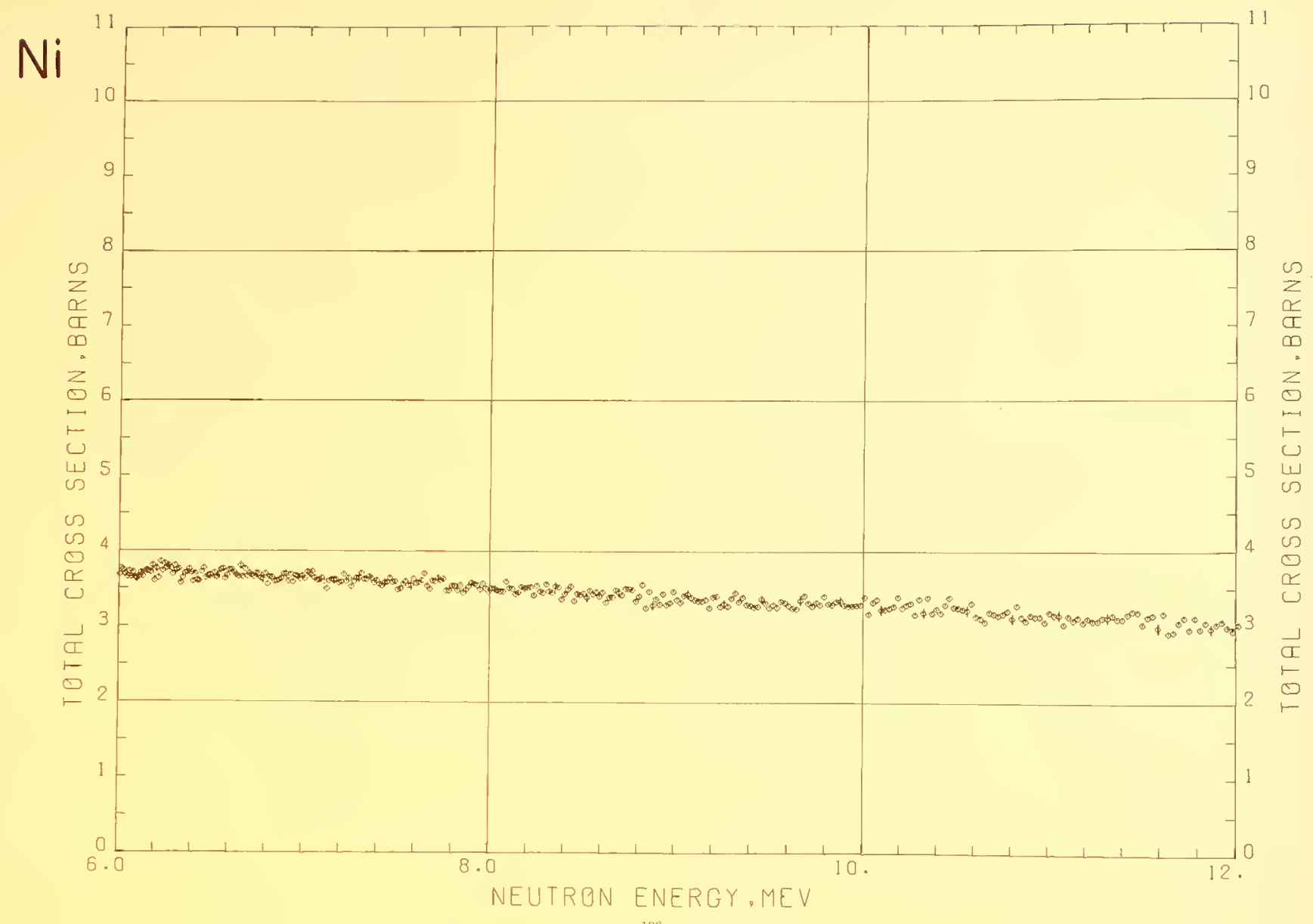



Sample Material: metallic lead sheet

Sample Diameter: $\quad 12.7 \mathrm{~cm}$

Sample Thickness: $\quad 7.6 \mathrm{~cm}, n=0.2614$ atoms $/ \mathrm{barn}$

Analysis: A qualitative spectrographic analysis was made on the sample; the principal impurity was copper, present to less than 0.1 percent. All other impurities were less than 0.01 percent. 


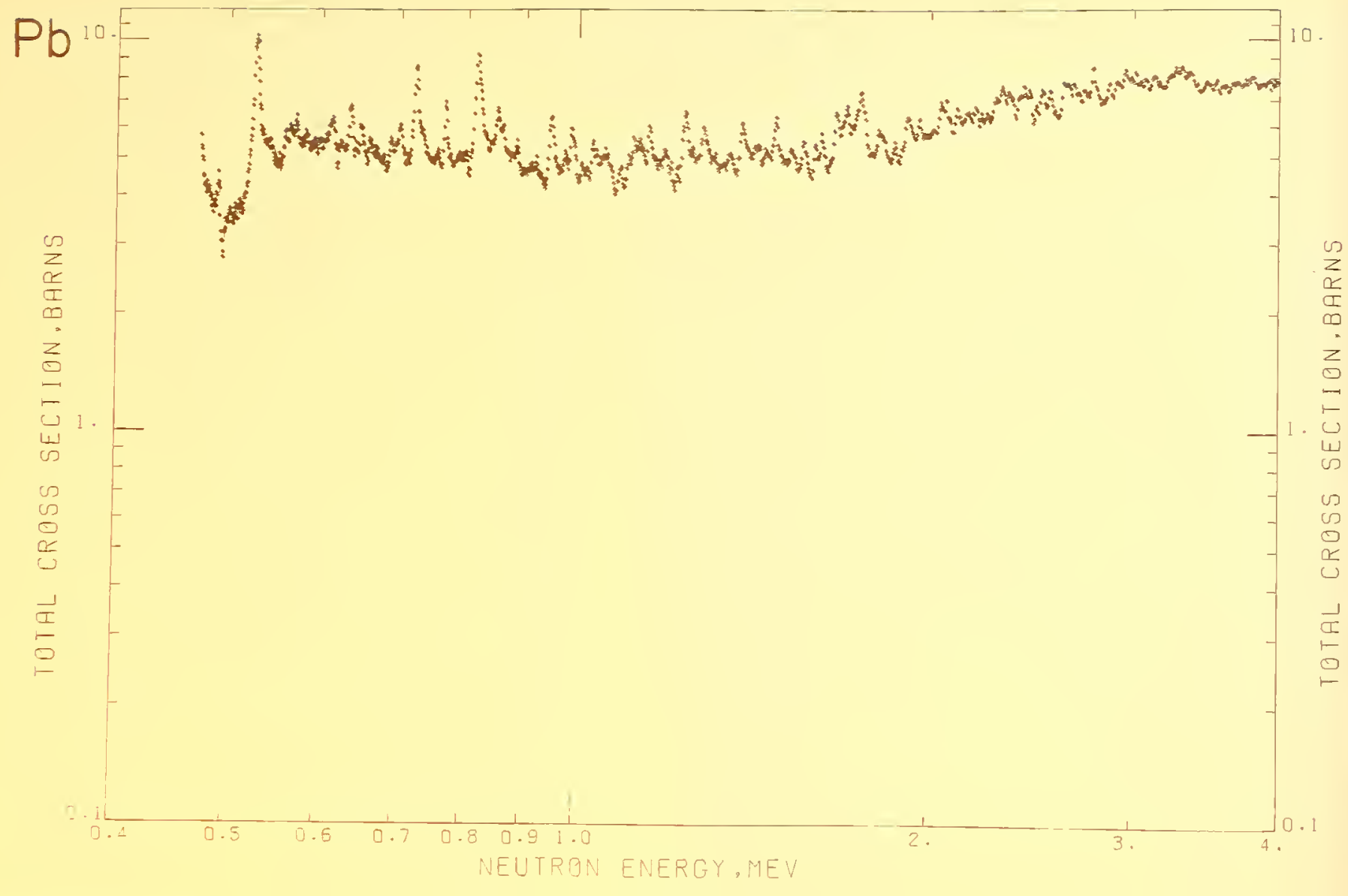




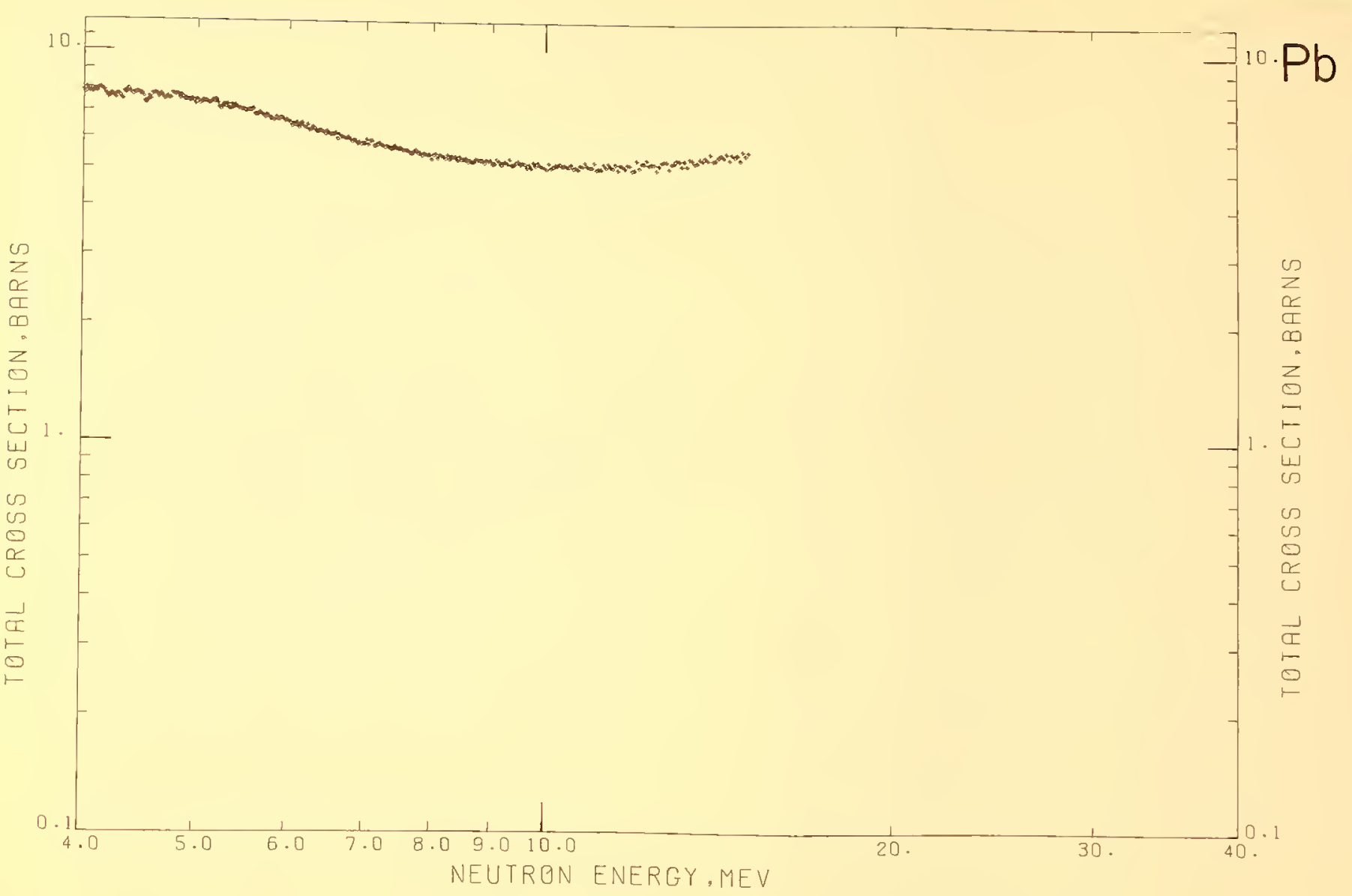


$\mathrm{Pb}$

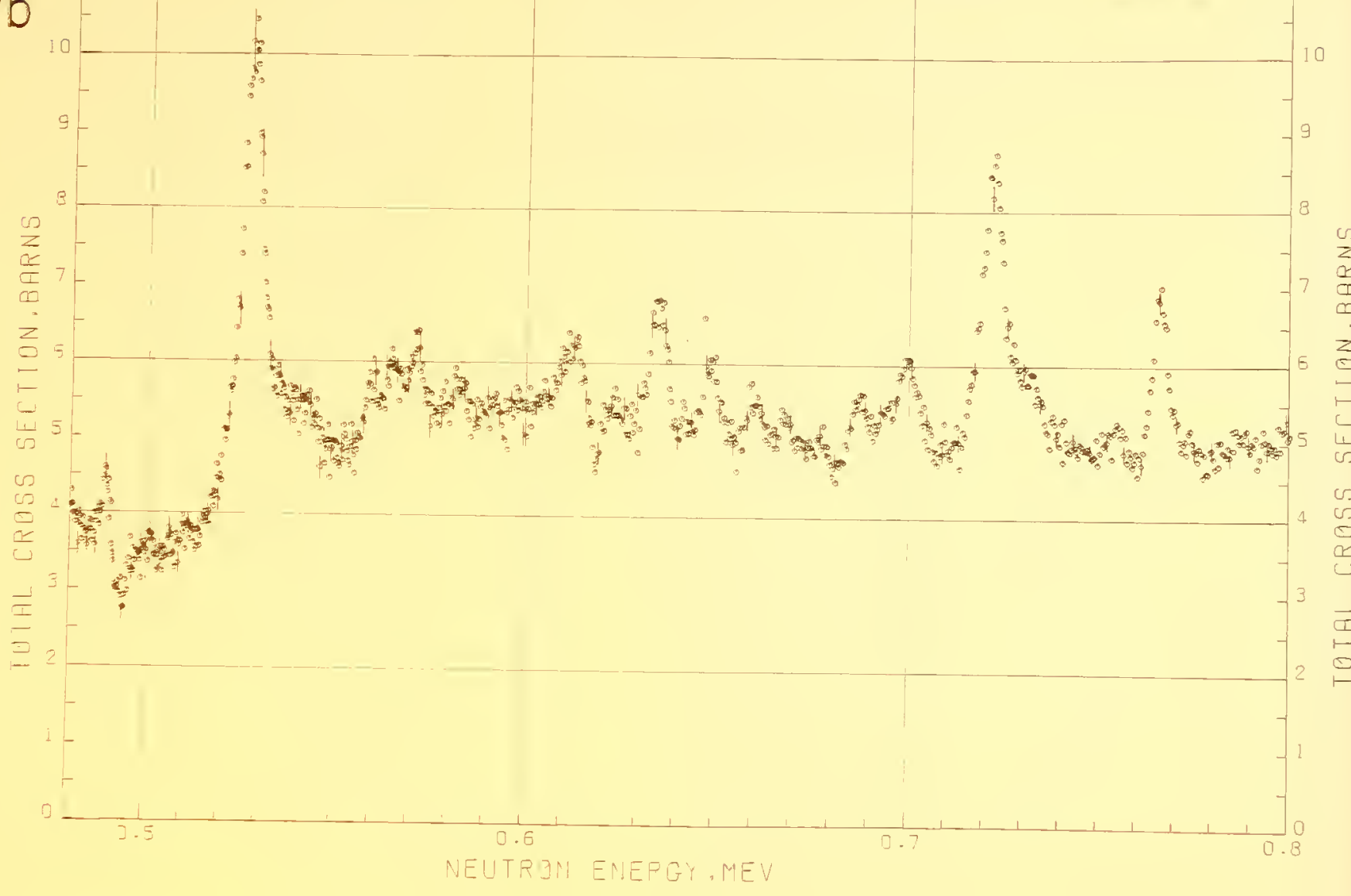




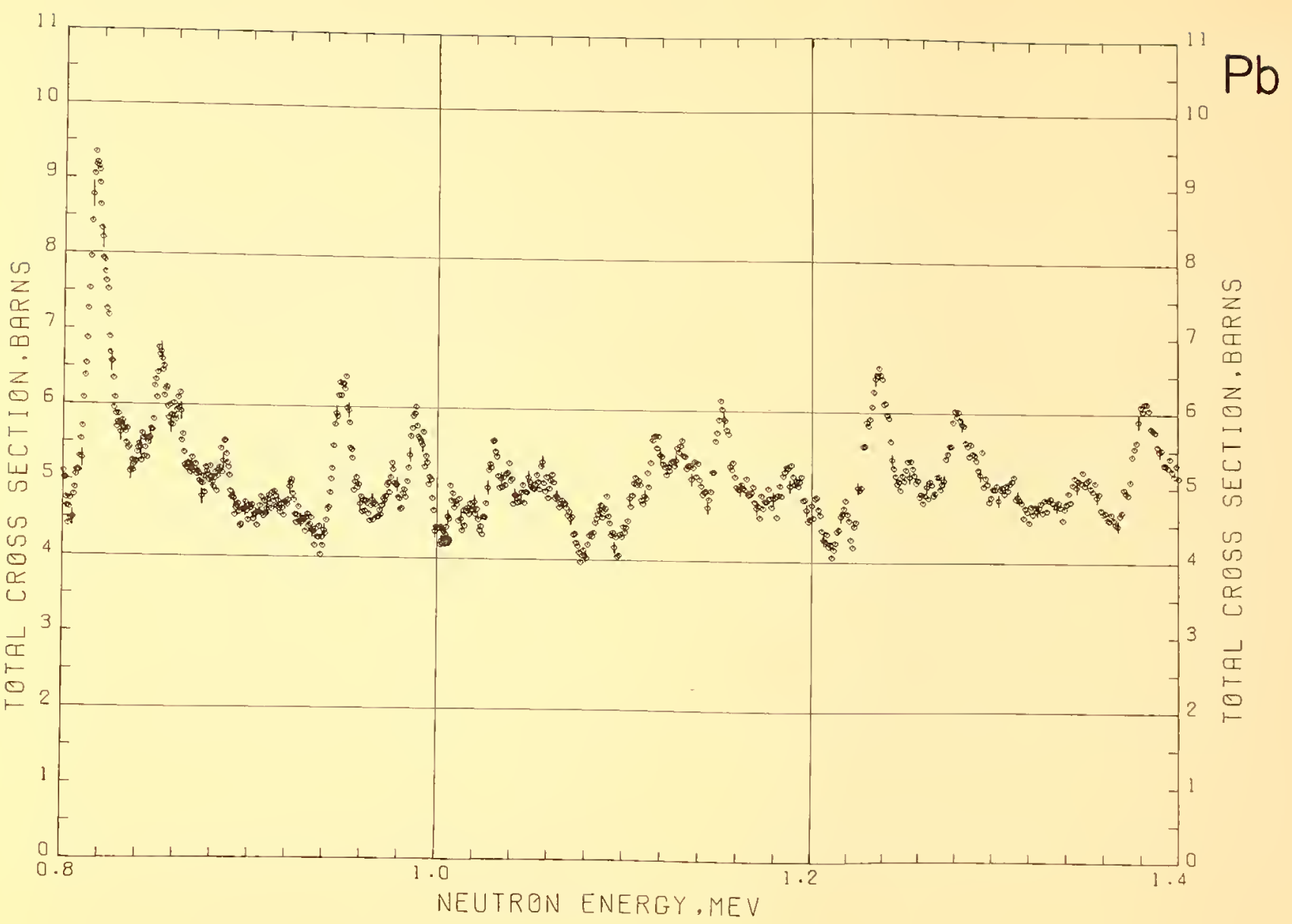




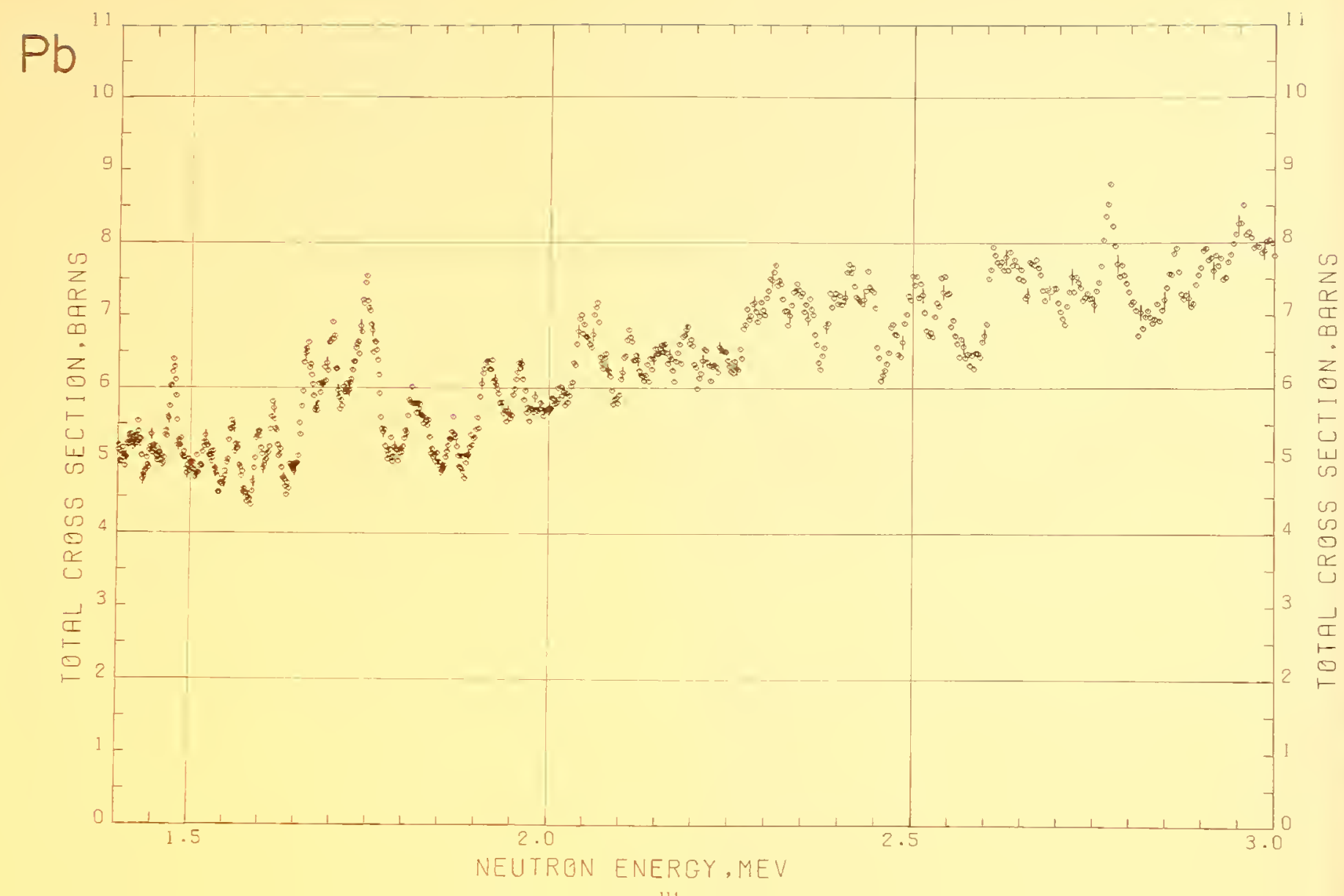




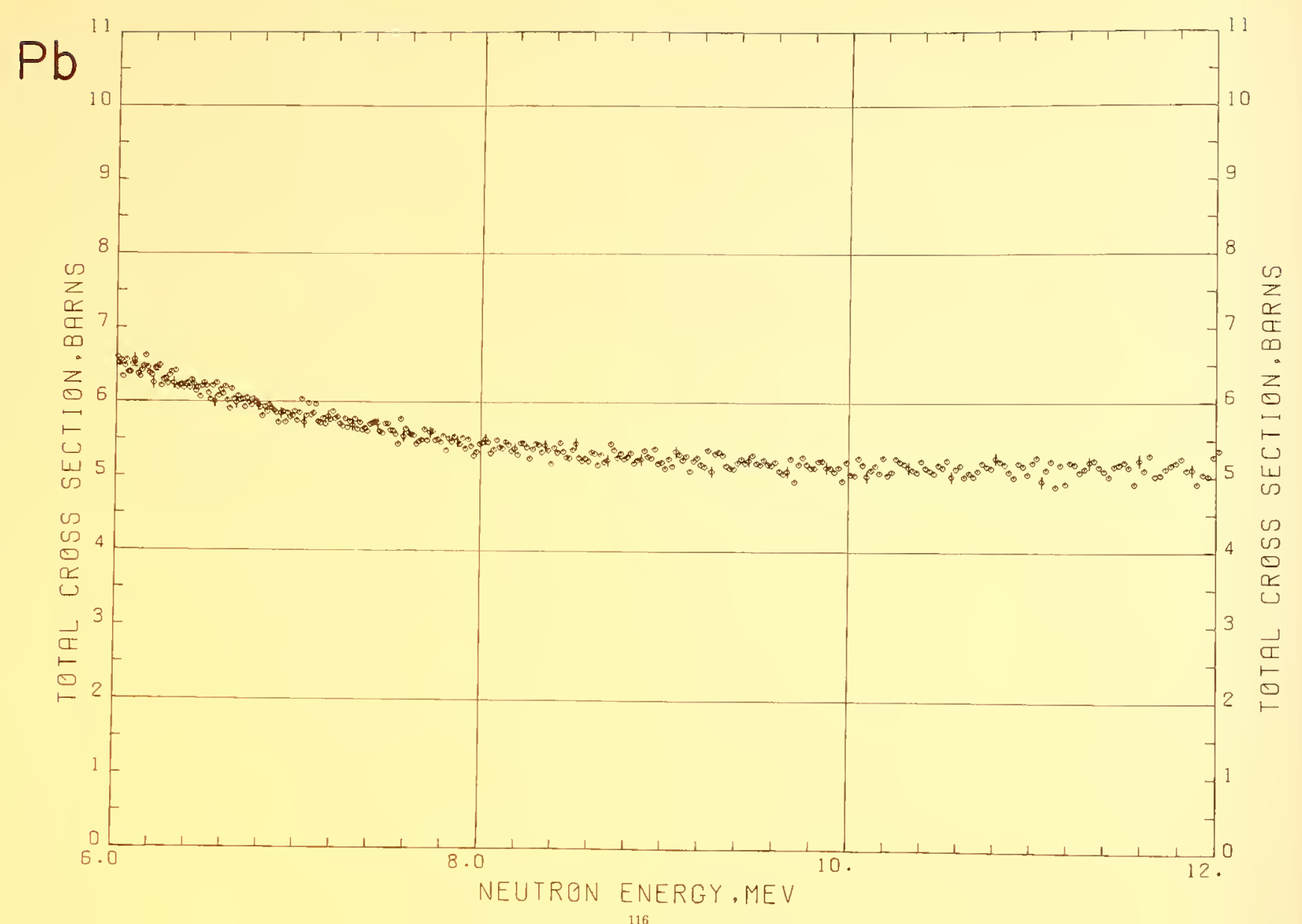





\section{${ }^{235}$ URANIUM}

Sample Material: enriched metallic uranium

Sample Diameter: $\quad 1.91 \mathrm{~cm}$

Sample Thickness: $\quad 4.45 \mathrm{~cm}, n=0.2136$ atoms/barn

Analysis:

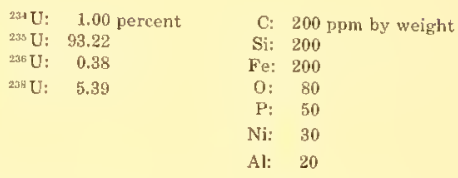

Literature Reference: R. B. Schwartz, H. T. Heaton II, J. Menke, and R. A. Sehrack, Bull. Am. Phys. Soc. 18 (1973) 539

Comments: The measured cross section has been corrected for the ${ }^{235} \mathrm{U}$ and carbon content, using our previously measured values of these cross sections. Since the maximum correction was 0.4 percent, any errors in the corrections would introduce a totally negligible error in the final cross section. Systematic errors in the final corrected cross sections due to the remaining impurities are $<0.1$ percent.

Acknowledgment: We should like to thank the Los Alamos Scientific Laboratory for providing us with the sample, and for doing the chemical and isotopic analysis. 


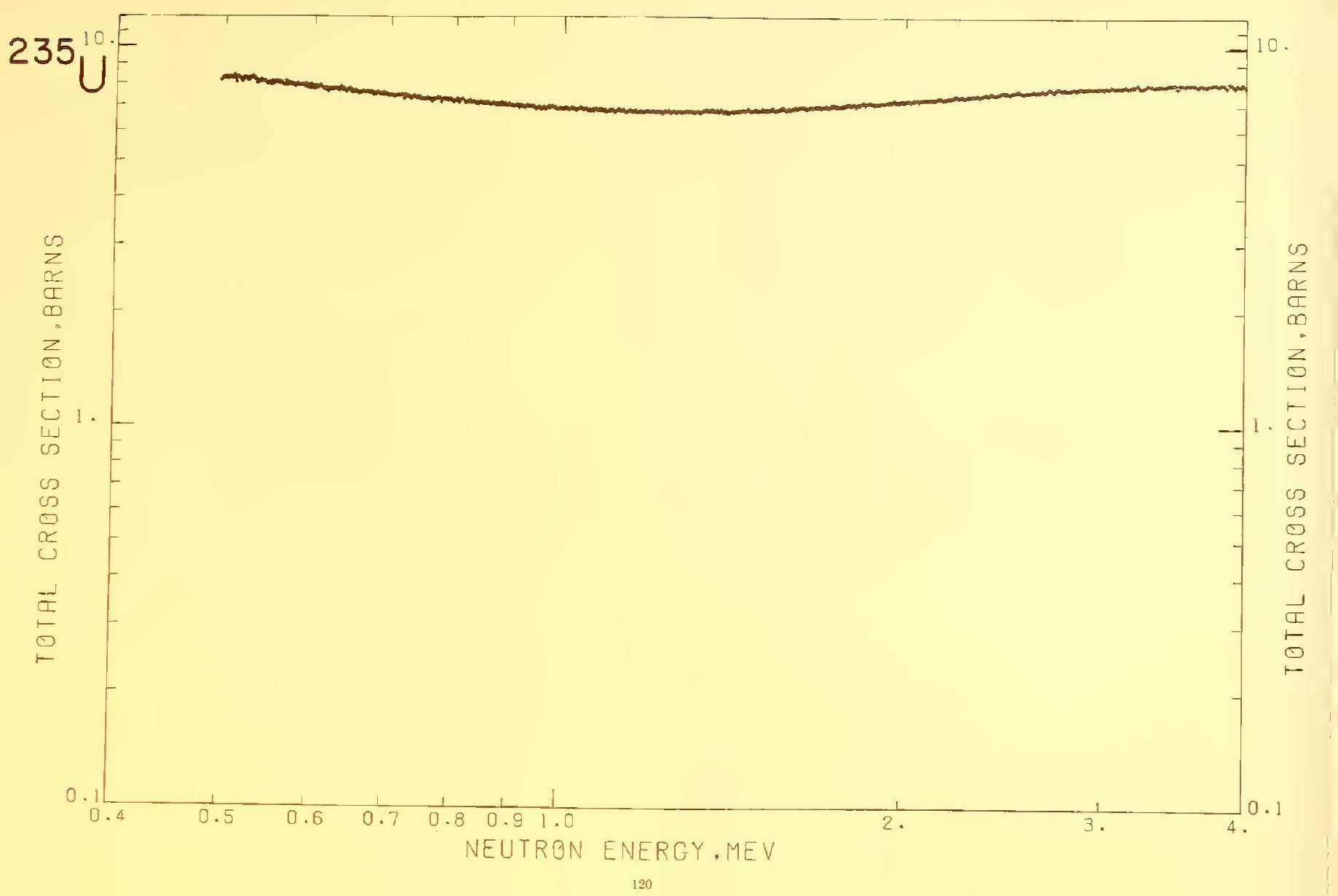




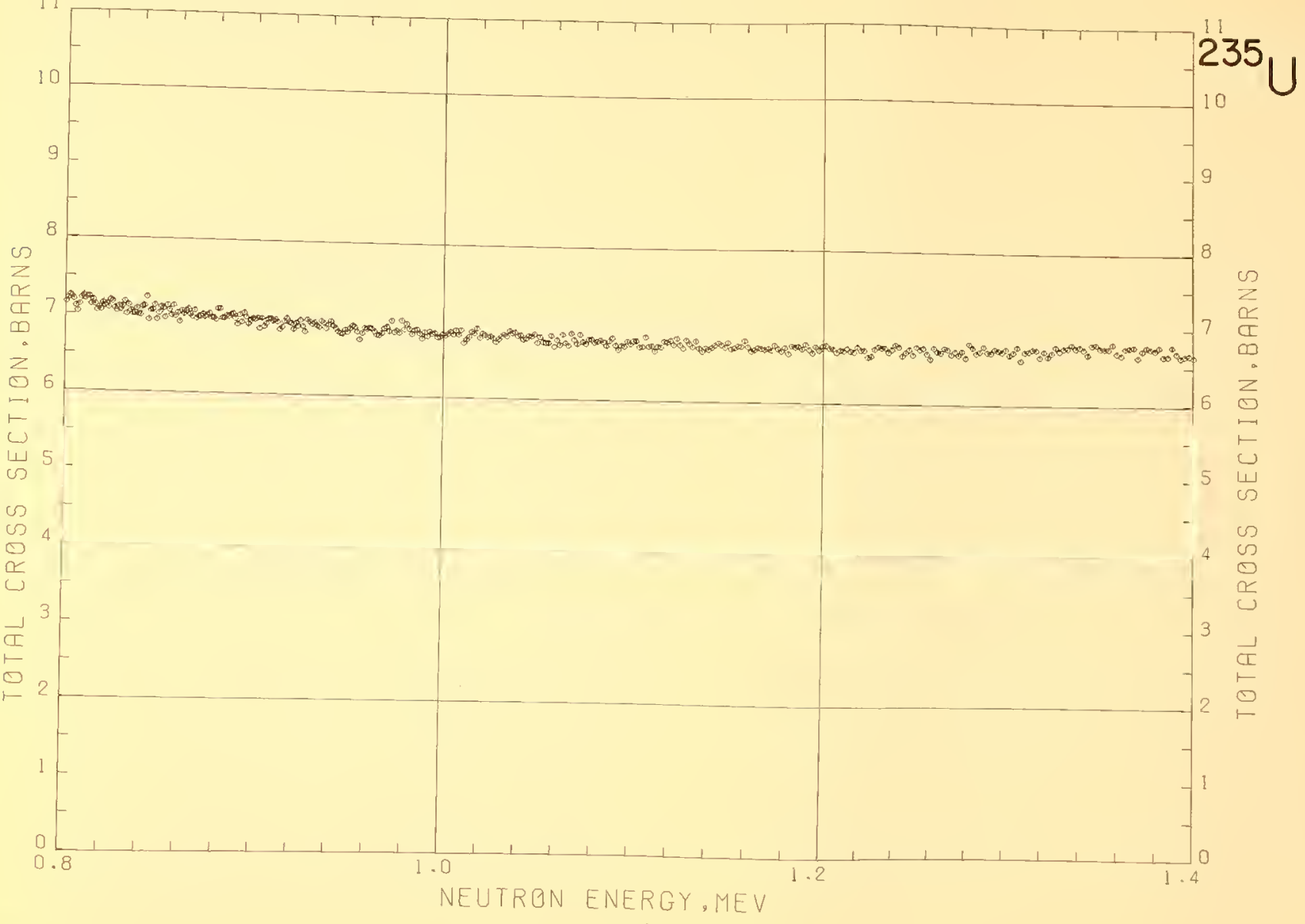




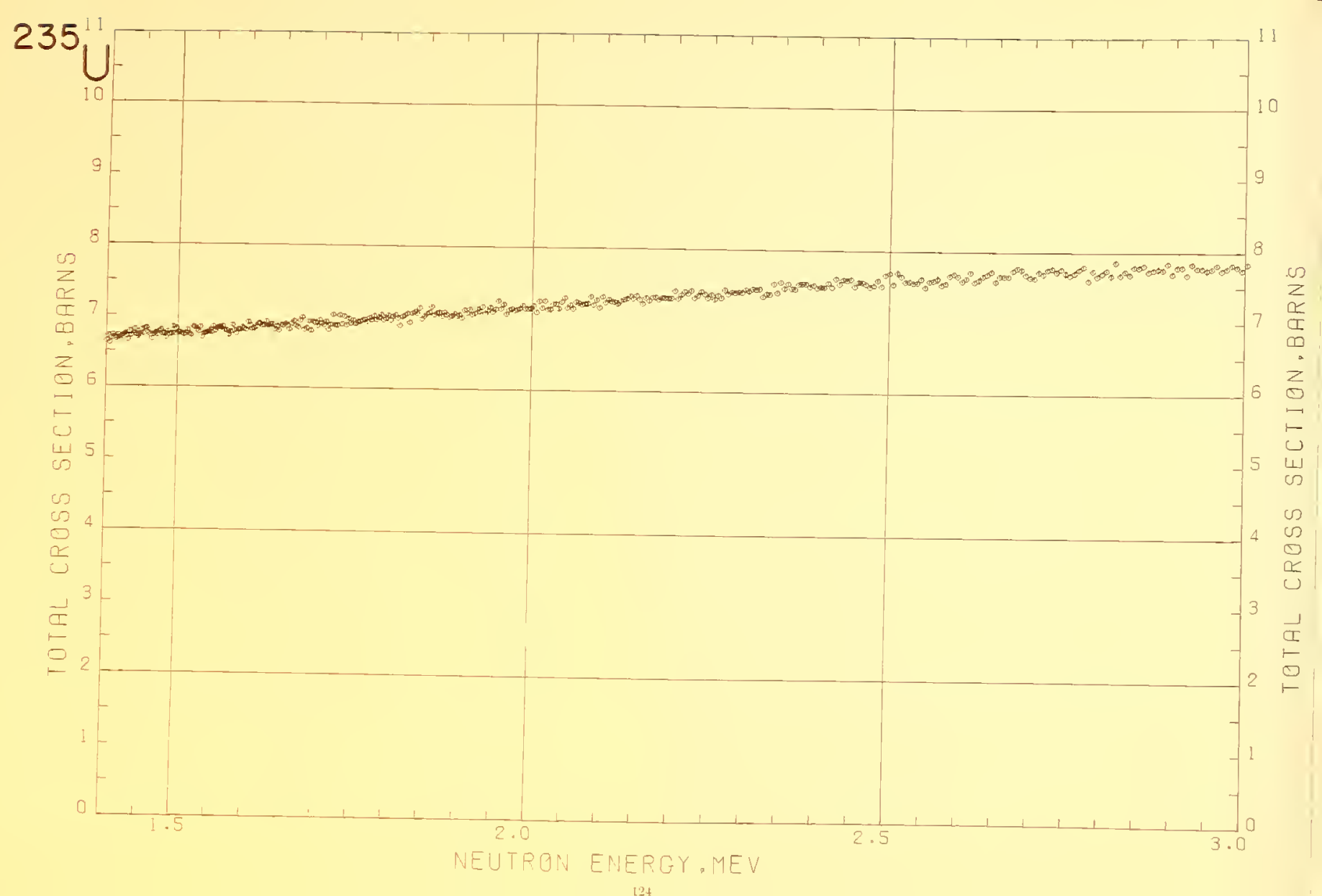




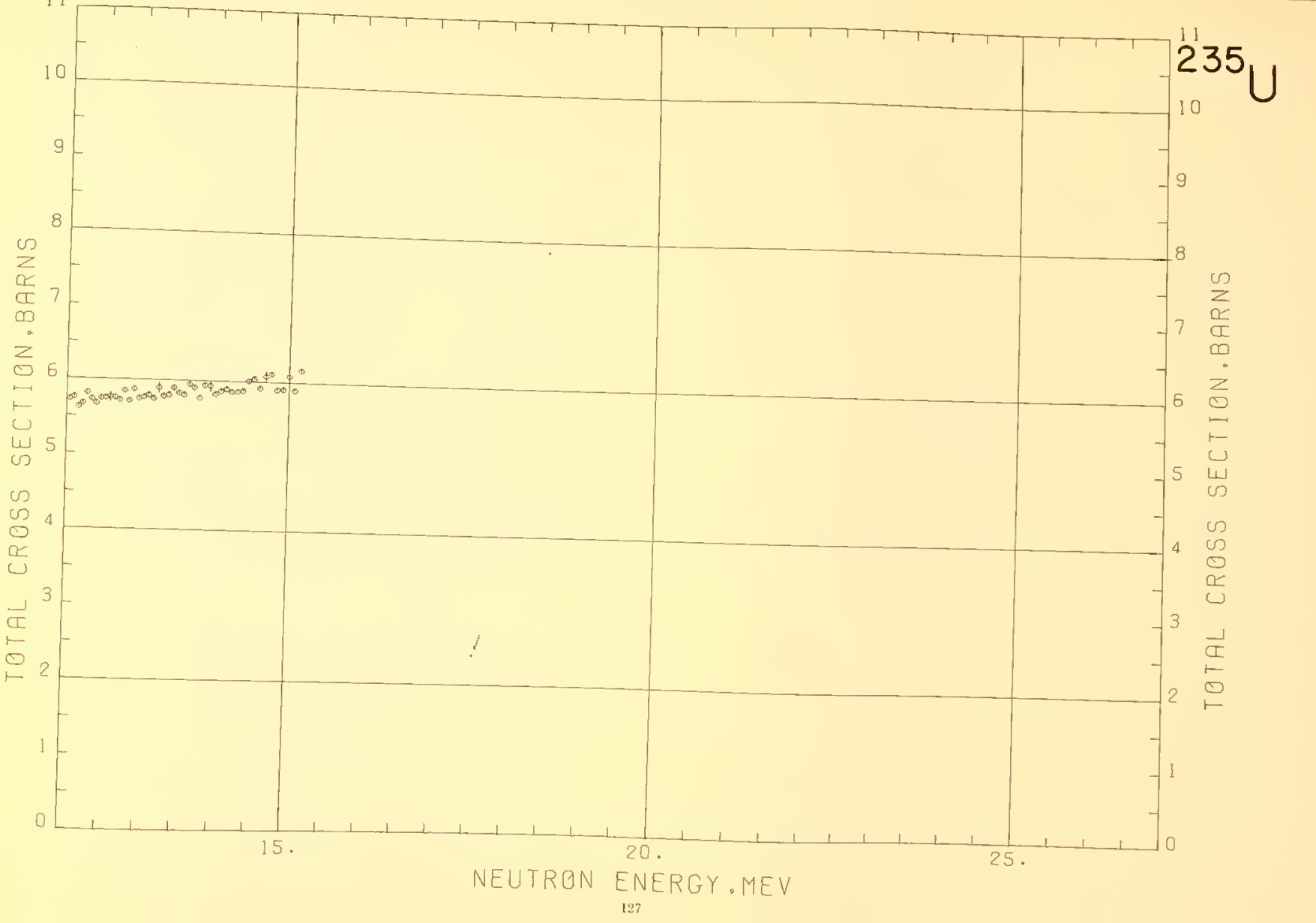


$-9$ 


\section{${ }^{238}$ URANIUM}

Sample Material:

depleted uranium metal

Sample Sizes:

$5.08 \mathrm{~cm}$ diam; $1.91 \mathrm{~cm}$ thick; $n=0.0914$

$5.08 \mathrm{~cm}$ diam; $4.45 \mathrm{~cm}$ thick; $n=0.212$

$1.91 \mathrm{~cm}$ diam; $4.45 \mathrm{~cm}$ thick; $n=0.2132$

Analysis:

${ }^{203} \mathrm{U}: 0.19$ percent

${ }^{27 \%} \mathrm{U}: 99.80$

C: 350 ppm by weight
Si: 400

Fe: 100

o: 85

Ni: $\quad 30$

$\mathrm{Al}: \quad 15$

Literature Reference: R. B. Schwartz, H. T. Heaton II, J. Menke, and R. A. Schrack, Bull. Ann. Phys. Soc. 18 (1973)

Comments: The measured cross sections have been corrected for the carbon and silicon content, using our previously in the corrections for these cross sections. Since the magnitude of the corrections is $<1 / 2$ percent, any errors gligible in the final cross section. Systematic erroror

Acknowledgment: We should like to thank the Los Alamos Scientifie Laboratory tor providing with the and for performing the chemical and isotopic analysis 


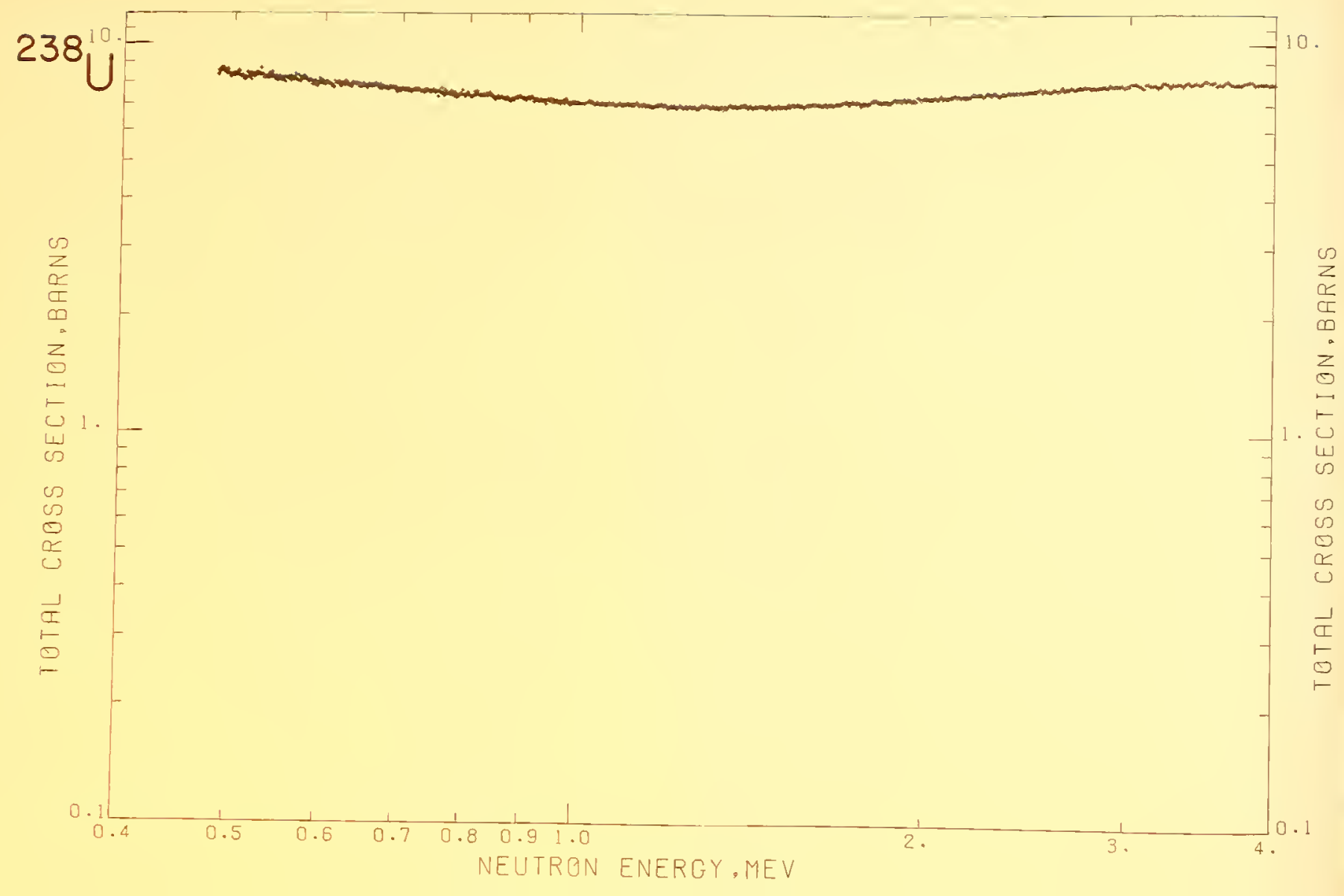




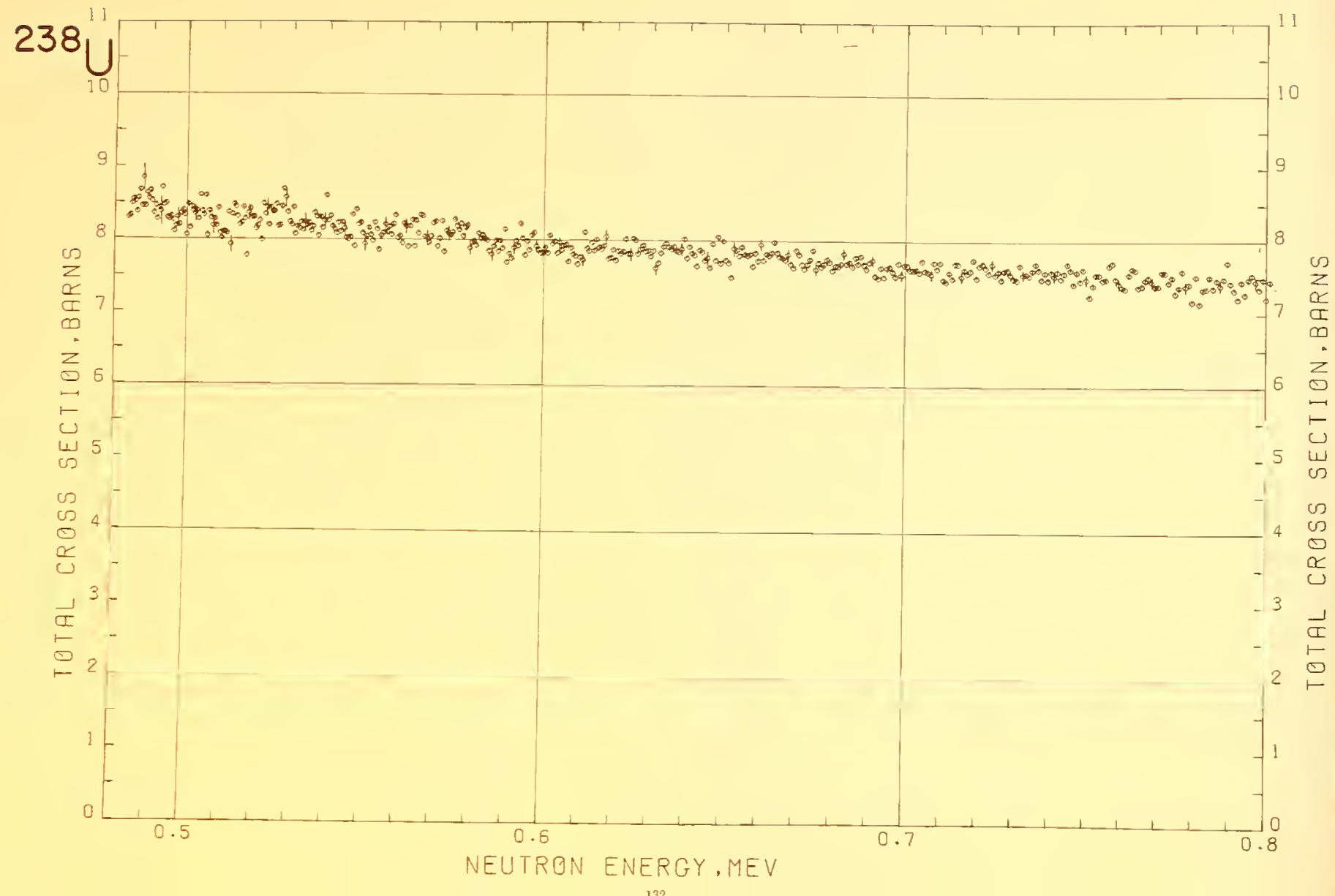




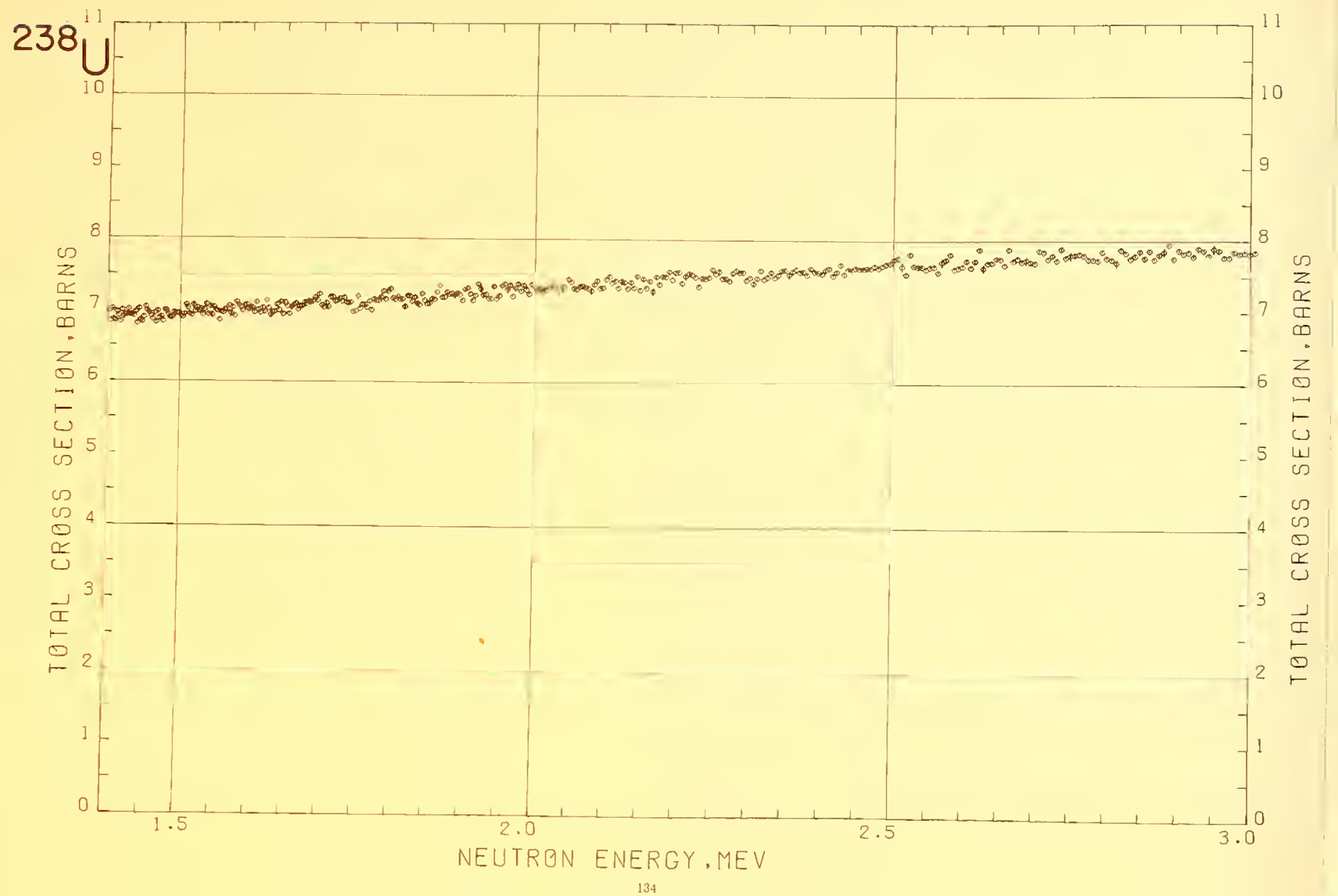




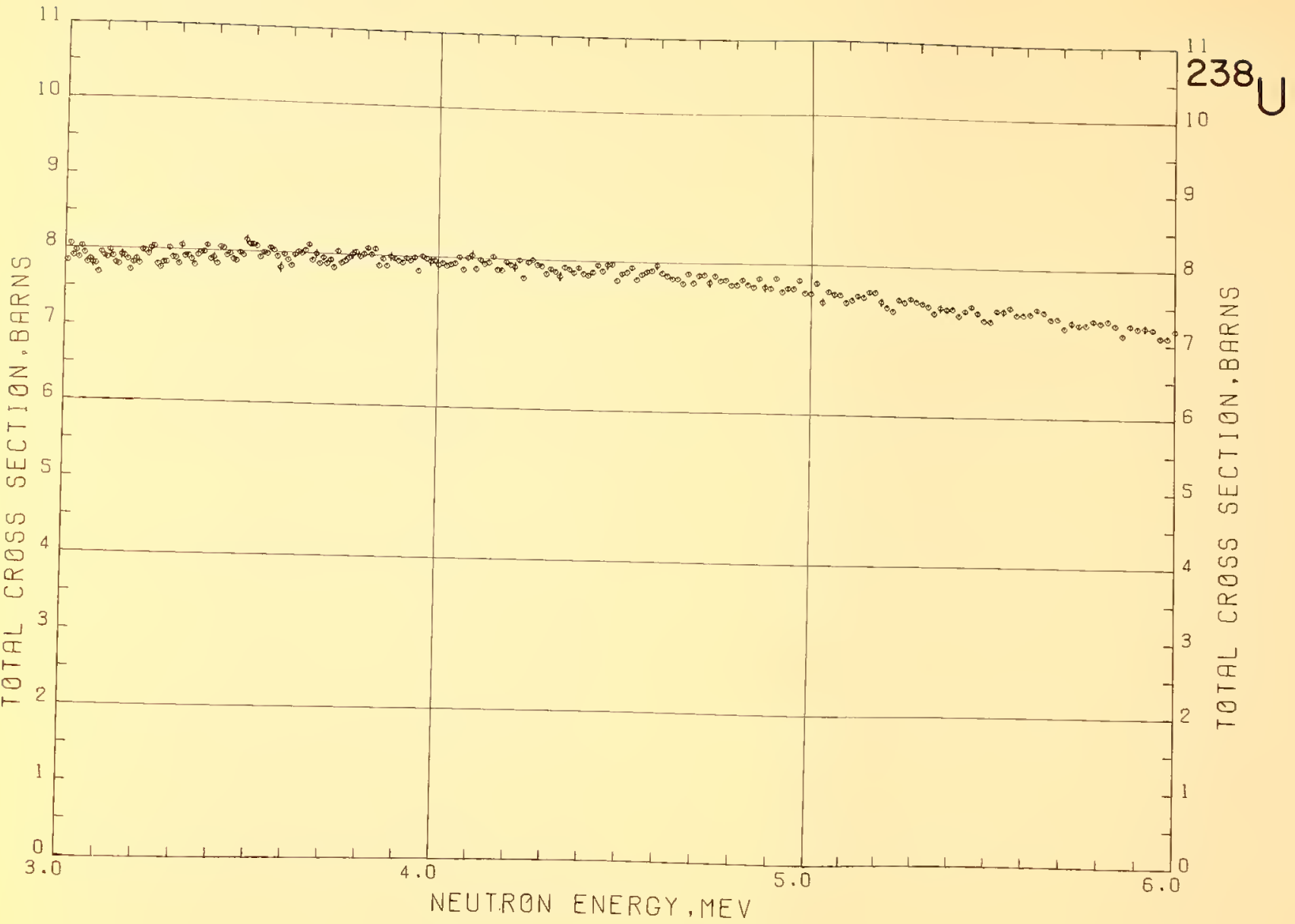




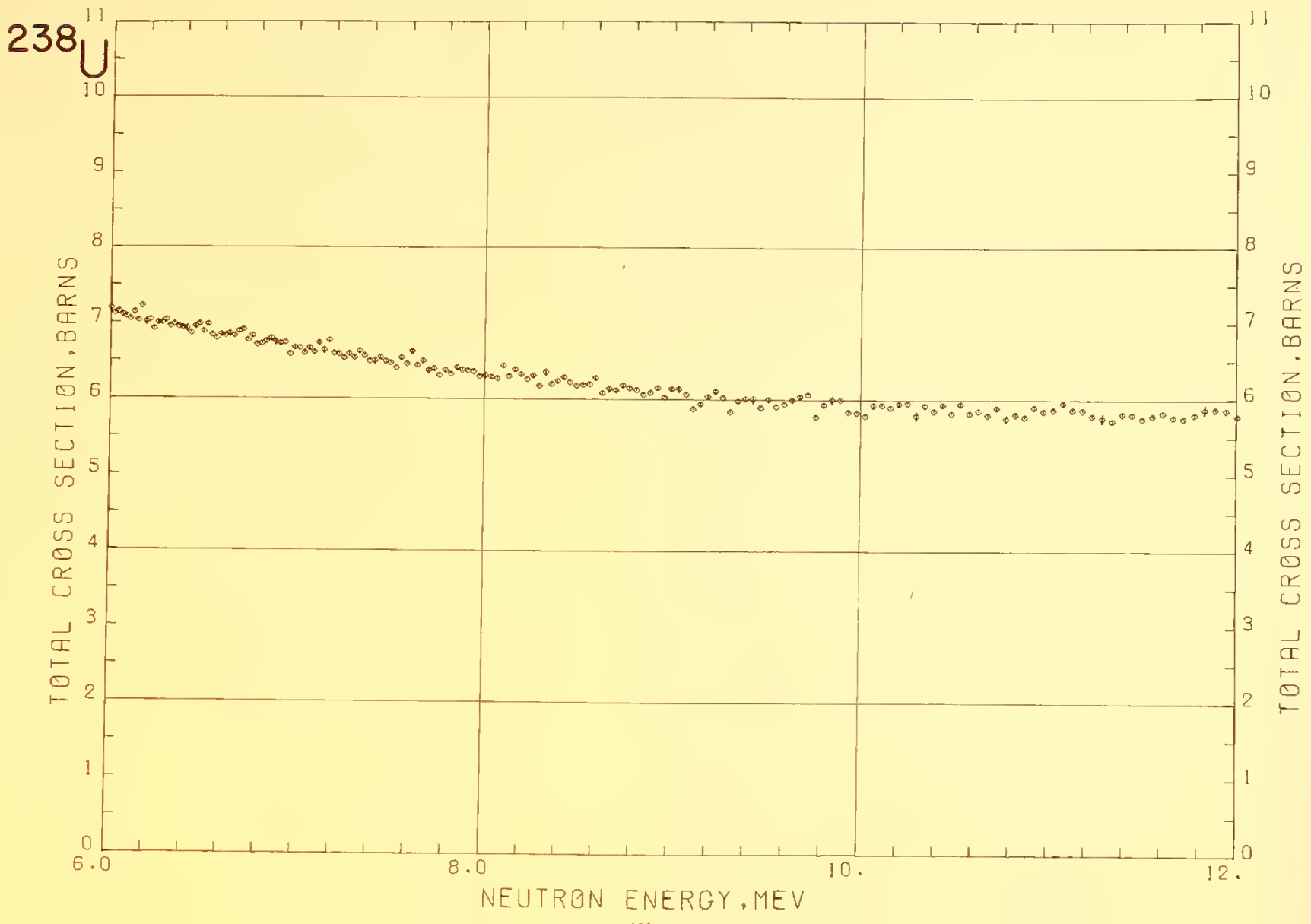





\section{${ }^{239}$ PLUTONIUM}

Sample Material: plutonium metal

Sample Diameter: $\quad 1.91 \mathrm{~cm}$

Sample Thickness: $\quad 4.45 \mathrm{~cm}, \quad n=0.2207$ atoms/gram

Analysis:

\begin{tabular}{|c|c|c|c|}
\hline${ }^{23} \mathrm{Pu}$ : & 0.01 percent & o: & $260 \mathrm{ppm}$ by weight \\
\hline${ }^{239} \mathrm{Pu}:$ & 93.94 & Al: & 15 \\
\hline Pu: & 5.66 & C: & 15 \\
\hline "Pu: & 0.37 & $\mathrm{H}:$ & 10 \\
\hline
\end{tabular}

Literature Reference: R. B. Schwartz, H. T. Heaton II, J. Menke, and R. A. Schrack, Bull. Am. Phys. Soc. 18 (1973) 539.

Comments: The measured cross section has been corrected for the oxyren in thesampe using

ured value of the cross section. Since the nagnitude the oxygen in the sample, using our previously meas. correction would introduce an. Since the magnitude of the correction is < 1/2 percent, any error in the for the ${ }^{210} \mathrm{Pu}$ content of the sample since tion in this energy range. It is vple since we do not have accurate measurements of the "*0 Pu cross sec. that in this energy range. It is very likely, however, that the ${ }^{240} \mathrm{Pu}$ cross section will be very similar to

We should like to thank the Los Alamos Seientific Laboratory for providing us with the sample,
and for doing the chemical and isotopic analysis. 


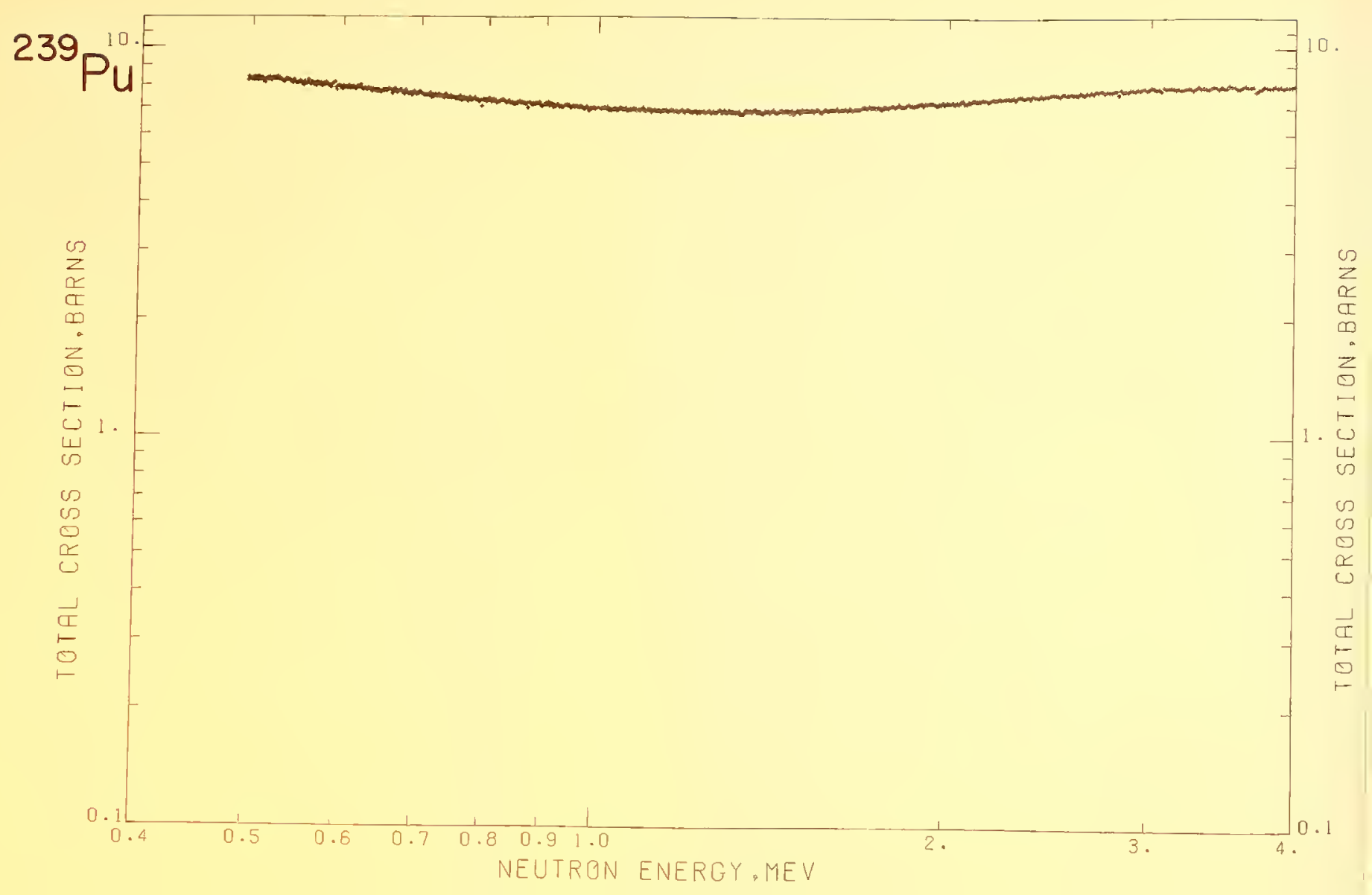




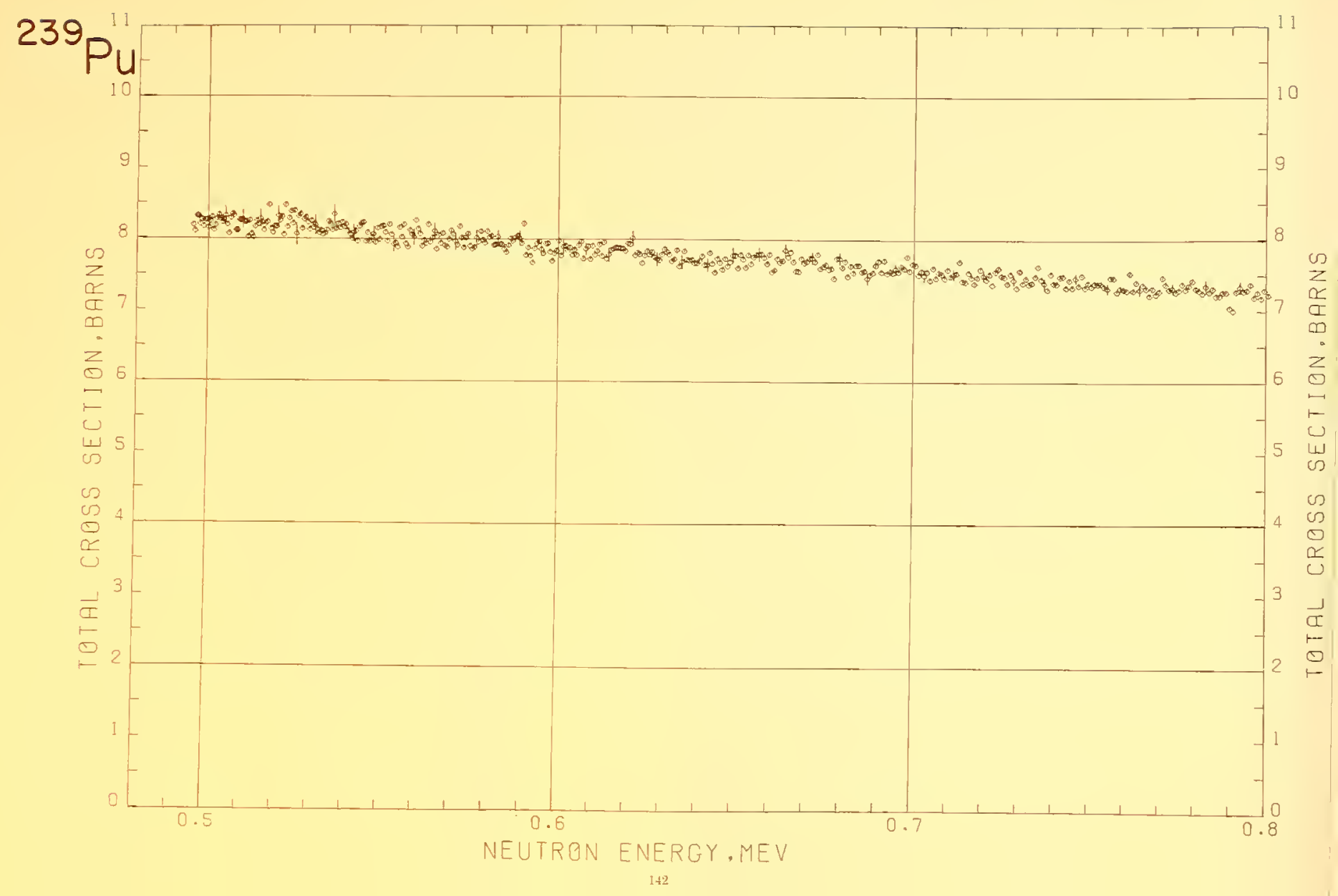




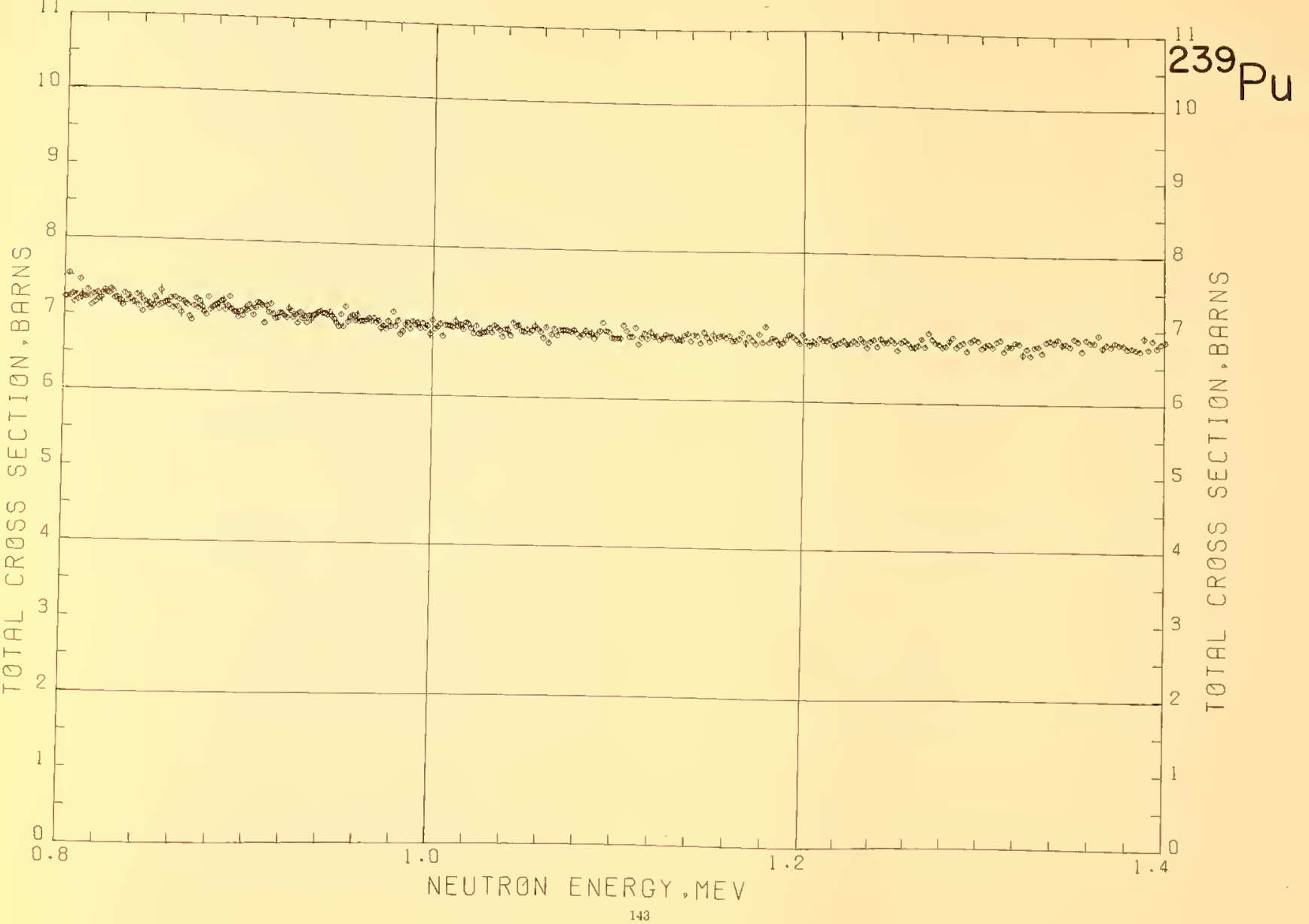




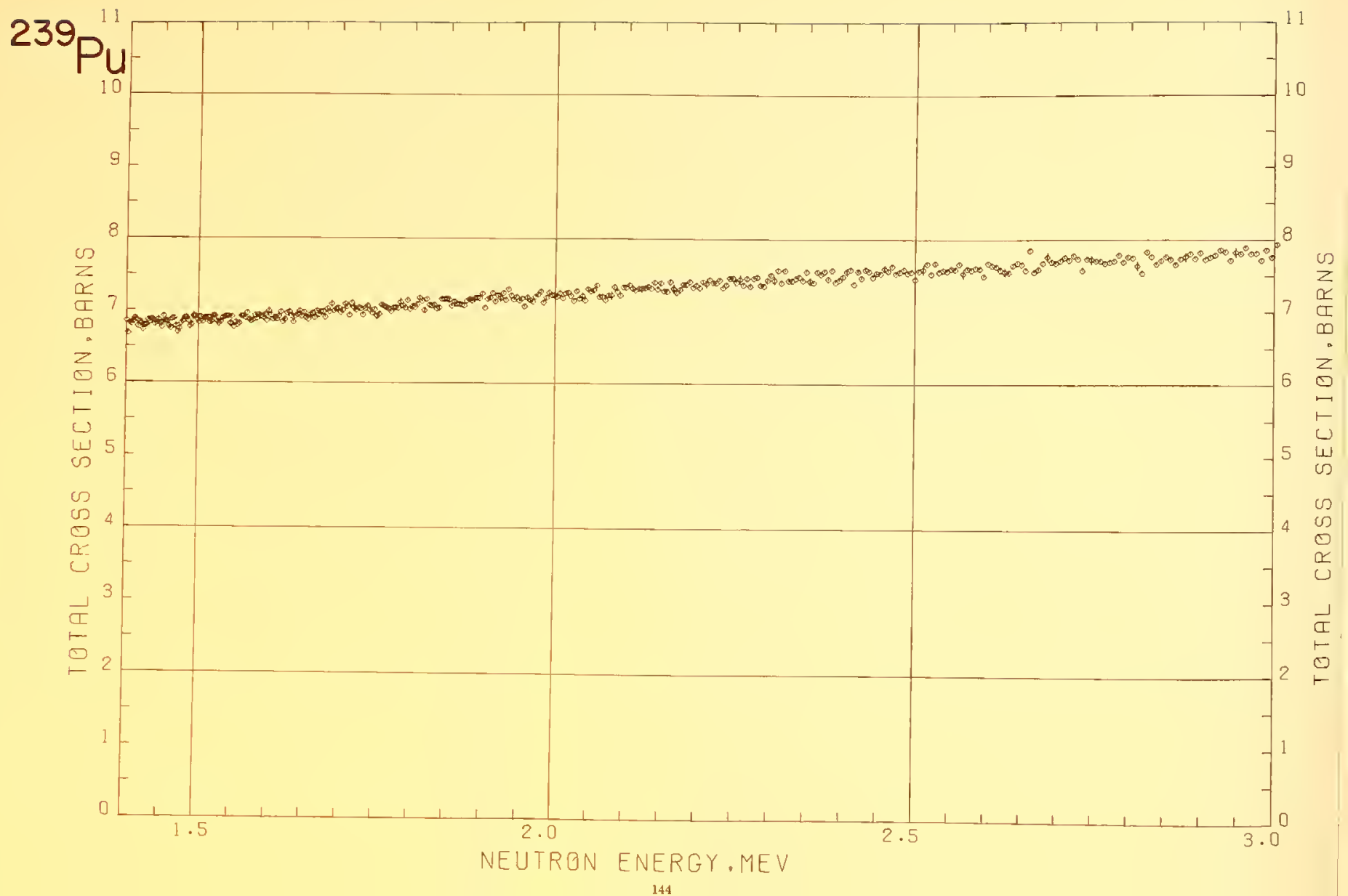




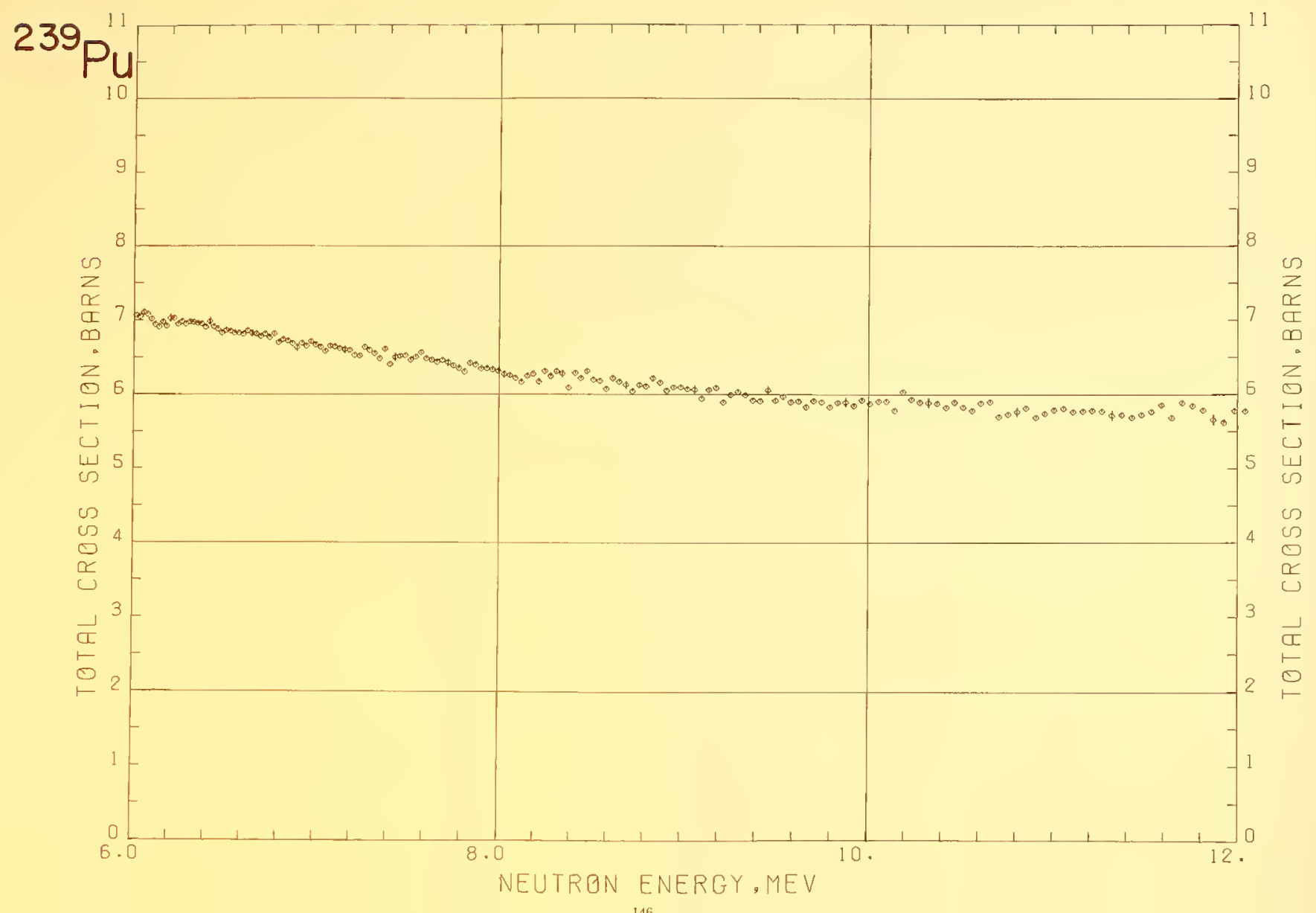





\section{Appendix-Experimental Techniques}

A brief account of our experiment has been given earlier [1] 1 . This will be expanded
brought up-to-date here.

\section{A1. Experimental Arrangement}

Figure 1 is a bird's eye view of our target area. We use the pulsed beam of the NBS electron linear accelerator as a source of neutrons. The beam enters from the bottom monitor. Since this neutron cross section mothes spectroseopy as well as For cross section measurasents a our equipment also inces a dumping magnet. For cimply turned off and serves magnet. tion The electron beam emerges from the magnet vacuum chamber into air an funcour neutron producing target.

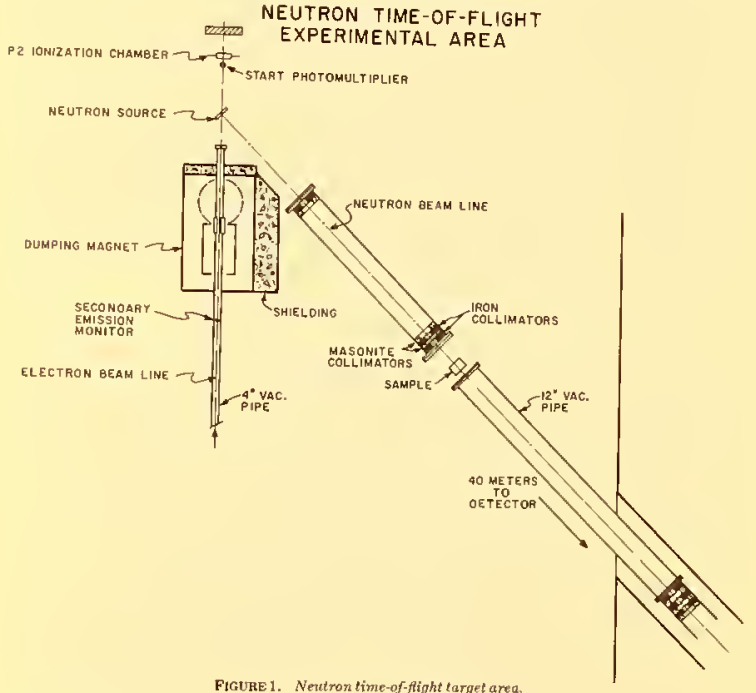

FIGURE 1. Nentros time-of-fight target ared.

Figures in brackets indicate the literature references at the end of the appendix.
The resulting neutrons are observed at $135^{\circ}$ over a $40 \mathrm{~m}$ evacuated flight path. The transmission samples are placed three meters from the neutron source.

\section{A2. Electron Linear Accelerator}

The NBS electron linear accelerator has been described previously [2], and hene only the characteristics of particular importance to the time-of-flight experiment

For neutron total cross section measurements the linac is generally run at abou $60 \mathrm{MeV}$. The exact energy is, of course, rather arbitrary, as long as it is considerably higher than the highest energy neutrons to be measured. On the other hand once the energy is chosen, it must remain stable over the course of a measurement (sever days) in order that the high-energy part of the neutron spectrum remains the same. The beam is therefore energy analyzed through 2 percent energy rlits before bittin the neutron producing target.

Since the electronics for this system can only process one count per beam burst and since the yield of neutrons is fairly high, only very low beam currents are required, average currents being of the order of $100 \mathrm{nA}$. Approximately currents are required, is available in a $2 \mathrm{~ns}$ wide pulse.

The linac injector has a fairly conventional triode gun, ${ }^{2}$ driven by a special pulser which allows a wide range of pulse widths: from several microseconds down to than 2 ns. We normally run with a $1 \frac{1 / 2}{2}$ to 2 ns wide pulge, at a repetition rate les pulses per second.

The average dark current is generally held to 0.01 percent of the average beam current, and hence causes no problem.

The beam spot size is $\sim 3 \mathrm{~mm}$ in diameter.

Once tuned up, the linac is generally quite stable in operation. Specifically, the beam spot is stable in size and position, the beam nercent, the energy remains within the 2 percent limits and the pulse shape reman 10 nercent, the energy remains within the 2 percent limits and the pulse shape remains taking.

\section{A3. Neutron Producing Target}

To some extent, it is possible to "tailor" the neutron spectrum by the choice of neutron producing target. Very generally, in the $\mathrm{MeV}$ energy range, higher $\mathrm{Z}$ targets produce more neutrons, but of low energy and lower $\mathrm{Z}$ materials will give $\mathrm{z}$ targets trons, but of higher energy. The observed spectrum will, of course, be modified by the variation in the detector efficiency as a function of will, of course, be modified by the (which only went to $~ 5 \mathrm{MeV}$ neutron function of energy. In our early measurements used. The went to $\sim 5 \mathrm{MeV}$ neutron energy), cadmium targets 1 to $2 \mathrm{~cm}$ thick were used. The yield from cadmium falls off sharply above about $6 \mathrm{MeV}$, however, so a combination of $\sim 0.1 \mathrm{~cm}$ tungsten, backed by $\sim 3 \mathrm{~cm}$ beryllium is now used. The tungsten provides the low energy neutrons and also acts as an efficient bremsitraturen

'Applied Radistion Corporation Model 10. (This particular piece of equipment, and certain other commercial equipment, instruments and materials are identified in this Bonegraph in order to adequately ment by the perimental procedure. In no case does such ids necessarily the best available for the purpose. 
for the beryllium which, in turn, supplies the higher energy neutrons. The difference in thickness between the $W$ and the $B e$ is typical of the difference in yields between high $\mathrm{Z}$ and low $\mathrm{Z}$ materials. The use of a target which is mainly low- $\mathrm{Z}$ is also important in solving some of the problems associated with the gamma flash, as will be discussed in section $\mathrm{A} 4.3$.

\section{A4. Instrumentation}

A4.1. Detector and Fast Timing Electronics

The main function of the fast electronies is simply to provide a "start" signal, related in time to the production of the neutrons, and a "stop" signal, similarly related in time to the detection of a neutron at the end of the flight path. These signals are then analyzed and encoded by a Time Interval Counter. (sec. A4.3)

A block diagram of the electronics is showl in figure 2. Not included are such an cillary units as fanouts, pulse shapers, and delay cables, nor do we show the slow electronics necessary to produce the logic signals for the on-line data handling system.

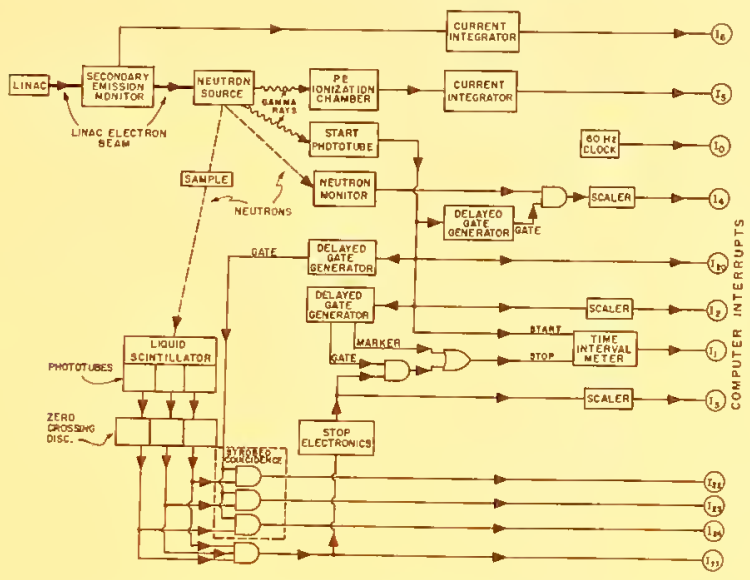

FTGURE 2. Block diagram of electronicos.

The shower developed when the electron beam strikes the neutron producing target impinges upon a bare RCA $931 \mathrm{~A}$ phototube (i.e., no scintillator is used). The phototube anode signal is fed to a zero crossing discriminator [3] whose output furnishes the "start" signal. The start signal performs several functions. It is fed to the Time
Interval Counter, initiates delayed gates and a marker generator, and is scaled by the computer.

The neutron ("stop") detector is a 13 in. diam. by 5 in thick NE $211^{3}$ liquid scintillator, viewed by 3 Amperex type 58AVP photomultipliers. The anode signals are fed to zero cross-over discriminators [3]. The outputs of the zero crossing discriminators go to a Two-Out-of.Three [4] coineidence gate and an OR gate.

The Two-Out-of-Three coincidence requirement reduces the noise counts.

The actual "stop" timing is derived from the output of the OR circuit. Before each run, the delays among the three phototubes and zero crossing discriminators are carefully matched so that the centroids of the timing distributions for the three tubes are exactly coincident in time (i.e., total spread less than $200 \mathrm{ps}$ ) at the input to the OR circuit. For each individual event, however, there will generally be some spread in the time of arrival of the three pulses. Since the Time Interval Counter is triggered by the leading edge of its input pulse, timing from the output of the OR circuit means that the timing is actually determined by whichever of the (nominally coincident) pulses arrives first. This procedure makes the best use of the timing information from the scintillator.

Signals from dynode 14 of each phototube are summed in a fast adder-discriminator. Since the gains of the phototubes are carefully matched, this provides a convenient method for setting the overall bias level, which is usually set at about 160 keV energy neutrons.

The outputs of the Two-Out-of-Three coincidence, the "OR" and the fast adder. discriminator are suitably shaped and delayed, and applied to the inputs of an AND circuit, along with the output of a delayed gate generator which is used to define the timing range and hence the energy range. If no neutron is detected during the time the delayed gate is open, the marker pulse generator provides an artificial stop pulse which resets the Time Interval Counter.

\section{A4.2. System Response Function}

We have used two approaches in determining the response function of our system: s.ynthesis and analysis. In the synthesis approach, we fold all the known contribution to the response function to obtain the final overall response function. We have used contributions from the following sources:

1. Electronic response function

2. Neutron detector thickness

3. Neutron source thickness

4. Electron beam pulse width

5. Timing channel bin width

The electronic response function was determined by a coincidence technique usin ${ }^{22} \mathrm{Na} \gamma$ rays. For $\gamma$ rays whose pulse height was approximately equal to that of $0.5 \mathrm{MeV}$ neutrons, the response function was 3.5 ns FWHM. The detector and source respons functions are truncated exponentials determined by the mean free path of the neutrons and their flight time in the medium. The electron bean pulse shape was assumed to be a 2 ns wide Gaussian, as determined from measurements of the eamina fash thape through thick absorbers.

Janufactured by Nuclear Enterprises, inc. 
RESPONSE FUNCTION COMPONENTS AT .5 MeV

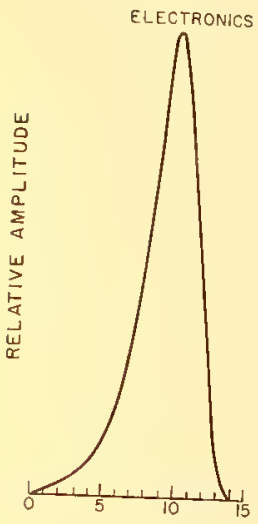

NEUTRON
DETECTOR

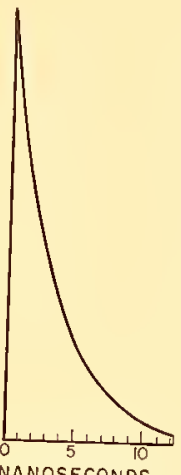

NANOSECONDS
NEUTRON ELECTRON
SOURCE

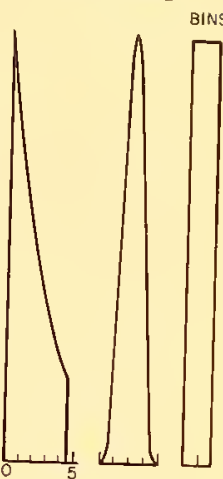

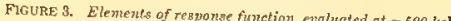

All of these contributions, evaluated at approximately $500 \mathrm{keV}$ neutron energy, are shown in figure 3 . The synthesized overall response function is shown in figure 4 and has a width of $8 \mathrm{~ns}$ or $2.2 \mathrm{keV}$ at $530 \mathrm{keV}$

The response function was also determined by analysis of the $534 \mathrm{keV}$ line in Si. The natural width of this line is considerably less than the response funetion of the system so that the shape of the transmission line is a good indication of the resp the function shape. To improve the analysis, the natural Breit-Wiener of the respons by area analysis of the transuission) was unfor sponse function thus obtained has a width of 24 ilovolts the transmission. The retion used at 530 kilovolts is the compromise shown by

It should be noted that the respone fun the dashed hine in igure

$600 \mathrm{keV}$ neutron noted that the response function improves rapidly above about $600 \mathrm{keV}$ neutron energy, since the electronie response function as well as effects due to source and detector thicknesses all improve at higher energies. The measured (analyzed) response function is about $5.5 \mathrm{~ns}$ (11 keV) at $2.1 \mathrm{MeV}$ and about $3.4 \mathrm{~ns}$ $(120 \mathrm{keV}$ ) at $14 \mathrm{MeV}$. Figure 5 shows the width of the response function about $3.4 \mathrm{~ns}$ of neutron energy. The points are from an lyses of narrow resonanes. (The pointon $14 \mathrm{MeV}$ is the measured direct response to $14 \mathrm{MeV}$ neutrons Van de Graaff.

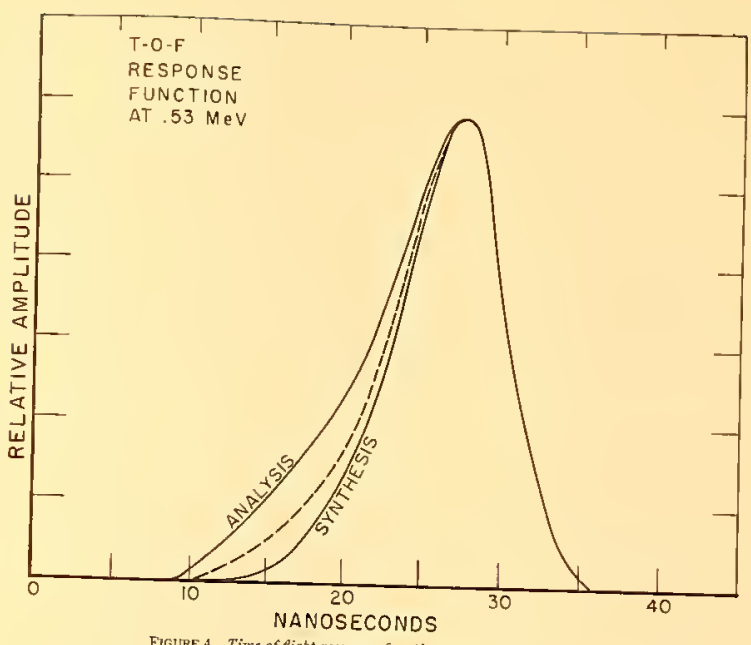

FłGURE 4. Time-of ffight reapouse function at 5 so $\mathrm{keV}$.

A4.3. Gramma Flash

When the linac electron beam strikes the neutron-producing tareet, an interse burst of gamma rays (the " three undesirable effects in the detector:

1. A very large primary pulse, which may cause over-load and baseline shift problems;

2. An after-pulse, oecurring approximately $600 \mathrm{~ns}$ after the main pulse; and

An enornous increase in phototube noise for approximately $750 \mathrm{~ns}$ after the gamma flash pulse.

ing the after-pulse is caused by the photoelectrons from the gamma-flash pulse ionizing the residual gas in the region between the photocathode and the first dynode the phototube [5]. The ions are isochronous]y accelerated back to the photoeade is causing the observed after-pulse.

Since the problem occurs in the "front end" of the phototube before the photoelectrons even reach the first dynode, pulsing off the phototube in the usual way, i.e., pulsing off the first few dynodes, will not help. It was pointed out by Farinelli and Malvano [6], however, that a phototube can be just as well turned off by pulsing its 


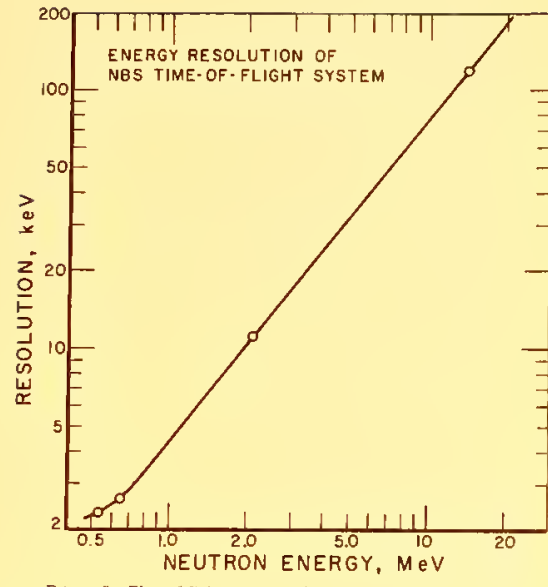

FlGURE b. Time-off-fight energy renohution as a finction of entergy.

focus electrode. In our case, we are not really concerned with turning off the phototube per se: our object is specifically to reverse the electrostatic field near the photoeathode so that the enormous number of photoelectrons generated by the gamma flash are not accelerated down the photocathode-first dynode space. We do this by applying a 600 volt negative pulse to the focus electrode of the 58AvP during the gamma flash.

Figure 6 shows the electrostatic field lines in the front end of a 58AVP as mapped out on an analog electrostatic field plotter. (For clarity, we show the field lines which would exist with the photocathode at ground and +2600 volts on the anode; in actual practice the anode is at ground and -2600 volts is applied to the cathode.) Figure $6 a$ shows the field lines during normal operation; figure $6 \mathrm{~b}$ shows the field lines with -600 volts applied to the focus. Note the reversal of the field at the photocathode so that photoelectrons are not accelerated down to the first dynode.

After the applied pulse, the photomultiplier gain recovers as rapidly as the pulse decays, which in our case is about $100 \mathrm{~ns}$ (caused mainly by the stray capacity of the leads and the phototubes.)

This method of eliminating the after-pulse also, of course, essentially eliminates most of the primary gamma flash pulse itself. Further details of the phototube pulsing as well as a circuit diagram of the pulser, have already been published [7].

While the phototube becomes rather noisy for several microseconds after the applied pulse, the Two-out-of-Three coincidence requirement eliminates this as a
58 AVP FIELD DISTRIBUTIONS

-600 Volt Pulse
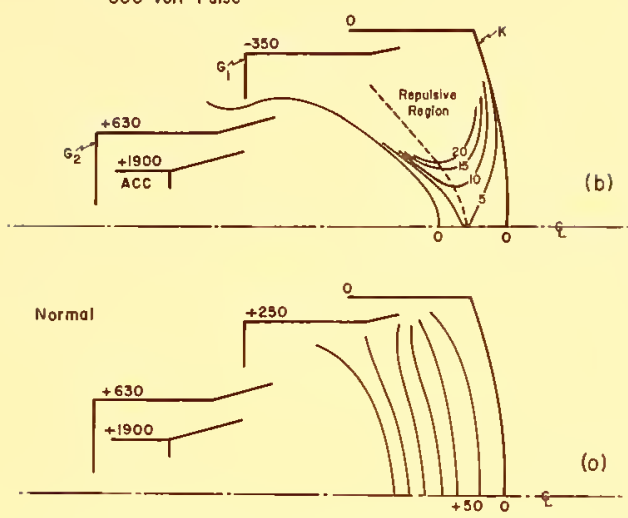

FIGURE 6. Elcetrastatic field tines in the type 58 AVP photomultiplien.

The upper part of the figure shows the field lites when the -800 volt pulse is applied to the focus electrode, $G_{1}$. The lower part of the figure shows the applied voltages and resultant field lines during normal operation. For clarity, the voltapes ahown are tho which would exist with the photocathade at ground and +2600 volts on the anode. In actual use, the anode is run at dc ground and -2600 volts is applied to the cathode. The field lines are, of course, the same in either case.

problem. A much more serious noise proble $m$ is caused by the gamma flash itself. While the noise from the gamma flash pulse decays after about $750 \mathrm{~ns}$, it is so intense during this period that a significant number of accidental coincidences are recorded. Requiring a three-fold (rather than 2/3) coincidence helps, but results in an appreciable loss of smaller pulses. In addition to pulsing off the phototube, it was also found neces sary to reduce the intensity of the gamma flash by using a $\mathbf{l}$ inch thick tungsten filter in the beam and by using a neutron-producing target consisting largely of low-z material (see sec. A3). In this way, we are able to make aceurate med about $20 \mathrm{MeV}$, or $500 \mathrm{~ns}$ af ter the gamma flash pulse.

\section{A4.4. Time Interval Counter}

As indicated earlier, the "start" and "stop" signals are analyzed by the Time Interval Counter. This is a commercial digital timing device with one nanosecon

* Manufactured by Eldorado Electrodata Corporation 

resolution and accuracy. The integral linearity of the device is easily checked by means
of an accurate frequency standard or a marker and is within one ns.

The differential linearity is checked in the usual way: The is started by a pulse generator, and stopped usual way: The Time Interval Counter source. When properly adjusted the differentiol random pulses from a gamma ray which cancels out in a transmission differential nonlinearity is $\leq 3$ percent, most of

\section{A4.5. Energy Calibration}

Our system allows convenient, absolute energy calibration. (By "absolute" we mean that the energy scale is determined in terms of measured distances and times, rather than by comparison with other measurements.) The procedure is simply to record the position of the $y$-flash using the Time Interval Counter, and then correct back for the flight time of the gamma rays down the $40 \mathrm{~m}$ flight path. This accurately determines the time of arrival of the electron pulse at the neutron producing target, flight are thene (arbitrary) zero time on the Time Counter. The neutron times-offight are then measured using exactly the same electronics in exactly the same physical location, and hence are measured with respect to the same (arbitrary) zero. Since the widths of the timing channels on the counter are known, this gives an zero. lute measurement of the neutron time-of-flight. then gives a direct measurement of the neutron. A mear The uncertainty in the

tainties in the timing measurem from uncerCounter, long-term (i.e., a few days) drifts in the include nonlinearities of the Time ences between ences between neutrons and gamma rays. The non-linearitieg and long term drifts have both been carefully checked, and are less than $1 \mathrm{~ns}$ and $1 / 2 \mathrm{~ns}$, respectively. While it is difficult to measure directly the difference in the timing response of the scintillator-phototubes-discriminators between neutrons and gammas, it is of the scintilla211 does not show any difference in response between neus, it is known that NE slewing between small pulses (due to low energy netron gamma flash) is approximately $1 \mathrm{~ns}$.

The path length has been measured with a geodimeter ${ }^{5}$ to an accuracy of 0.02 percent; this contributes a negligible error to the energy scale uncertainty. A minor problem arises due to the detector thickness. The detector is approximately 4 mean free paths thick at $0.5 \mathrm{MeV}$, and 0.3 mean free paths at $20 \mathrm{MeV}$. Therefore, the low energy neutrons effectively stop near the front face of the average, the high energy neutrons stop nearer the length is greater for high-energy than for low energy neutrons, the efrective path path length (amounting to almost $0.1 \%$ ) can, however, easily be calculated and is corected for.

The final energies are all calculated relativistically.

Taking all the above factors into consideration, the over-all uncertainty in the energy scale determination is $0.04 \mathrm{~ns} / \mathrm{m}$ (e.g., $\pm 3 \mathrm{keV}$ at a neutron energy of $2 \mathrm{MeV}$ )

Below about $2 \mathrm{MeV}$ this compares very favorably with the best work reported from Van de Graaff accelerators. At higher eneris, some high-acuracy Van te Grom experiments [8] have smaller errors, but, in any case, the time-of-flight method has

We are gratefui to Mr. George Lestey of the U.S. Coast and Geadetic Survey for making this the great virtue of allowing a direct measurement. It is worth noting that there is excellent agreement, even at the higher enerement. It is worth noting that there is reported by the Wisconsin group [8] (i.e., agreem, between our energy scale and that energy).

\section{A4.6. Data Handling}

The data from the Time Interval Counter, as well as the counts from the monitors, various scalers, clocks, etc. are all handled by the NBS on-line data handlin system. The general features of this system have been described previou handling a detailed report of our use of the system has been published previously [9], and major features will be reviewed here.

The on-line data handling system has been construeted around an XDS $920 \mathrm{com}$ puter. ( $16 \mathrm{~K}$ core memory, 24 bit word, and $8 \mu$ s cycle time). The modular concept ha been applied to both the software and hardware design of the system. Associated with the 80 levels of priority interrupts are programs used to record the experimental data The priority hierachy insures that the nost important data will be recorded first after which time the computer can do more routine functions, such as present ars display, output the data ete.

\section{A5. Monitoring}

Two monitors are used: a secondary emission monitor (SEM) to monitor the electron beam, and an NBS P2 ionization chamber [11] which monitors the shower create in the neutron producing target. The ratios among the monitor counts and the neutron counts are printed out periodicnlly during an experiment. The constat these ratios during the course of the experiment is a meare

It is important to note, however, that the spread in value of these ratios only represents an upper limit to the error caused by any errors in monitoring. This is because in our transmission measurements the samples are cycled in and out eyery twenty minutes. Hence drifts, with time constants long compared to twenty minutes, wil minutes.

\section{A5.1. Secondary Emission Monitor}

The secondary emission monitor (SEM) consists of three aluminum foils, each approximately $1 \mathrm{mg} / \mathrm{cm}^{2}$ thick. $A$ thin layer of platinum $\left(\sim 25 \mu \mathrm{g} / \mathrm{cm}^{2}\right)$ is evaporated on the aluminum surfaces to reduce ageing effects. Although work $\left.{ }^{2}\right)$ is evaporated indicates that an SEM may not give very reproducible results fork high this laboratory indicates that an SEM may not give very reproducible results for high $(\geq 20 \mu \mathrm{A})$ elec
tron beam currents, the SEM is satisfactory for the low currents $(-100$ nanoamps used in this experiment. The ratio of neutron counts to SEM readings show RMS fluctuations of $-1 \frac{1 / 2}{2}$ percent during the course of an experiment (i.e., two to three days).

\section{A5.2. Ionization Chamber}

The more stable of our two monitors is a conventional NBS P2 ionization chambe [11]. The $\mathrm{P}_{2}$ is placed immediately behind the neutron producing target, and hence effectively monitors the shower produced in this target. Although the P2 may over load (due to recombination effects) at high currents, again, as in the case of the SEM, at the low currents used in these experinents there is no sign of overloedin. neutron-to- $\mathrm{P} 2$ ratios fuctuate by $\pm 1 / 2$ percent during the course of an experiment. 


\section{A6. Sample Thickness Considerations}

It had been customary to use fairly thin samples-50 percent to 70 percent aver. age transmission-in total cross section measurements. In a low background situa. tion, however, there are two factors which argue for the use of thicker samples-say, $\leq 15$ percent transmission.

First, Rose and Shapiro [13] long ago showed that where the background is low, the optimum sample for minimum statistical error is approximately two nean free paths thick; i.e., transmission $\sim 15$ percent.

Secondly, the over-all cross-section accuracy (as opposed to the statistical preci. sion) may be improved by the use of a thick sanple. This is easily seen: since $T=e^{-i u r}$ where $T$ is the neasured transmission, $n$ is the areal density of the sample (in units, of, say, atoms/barn) and $\sigma$ is the total cross section,

$$
\frac{d \sigma}{\sigma}=\frac{1}{n \sigma} \frac{d T}{r}
$$

(We call the dimensionless quantity no the "sample thickness."

Thus, for example, an error in normalization will give a constant fractional error in the transmission. Equation (1) shows that for this case, the resultant errar in the cross section may be reduced by simply running a thick snmule. Equntion (1) also explains why a particular cross section measurement may be accurate where the cross section $\sigma$ is high, but have large fractional errors where $\sigma$ is low.

On the other hand, eq (1) does not, of course, mean that one can achieve arbitrarily small errors in the final measured cross section by using arbitrarily thick sanples. In addition to losing statistical precision for samples whose thicklless is far from optimum, for very thick samples ( $n \sigma \geq 5 ; T<1 \%$ ) the in-scattering correction (see sec. A7.3) becomes large and difficult to calculate, even in good geometry. More im. portant, for thick samples, the background correction becomes large, and the everpresent uncertainties in the background can become the dominant error.

In addition, if the instrumental resolution width is wider than the natural width of any structure to be measured, the observed peak cross sections will be higher for thinner samples. In other words, a thick sample worsens the apparent resolution. This is sometimes referred to as a "beam hardening" effect.

A final complication derives from the simple fact that cross sections vary with energy, hence a particular sample which is "thick" at one energy may be very "thin" at another energy.

Thus, while it is clear that the sample thickness has an important function in determining the quality of a total cross section measurement, the procedure for choosing the " $r$ " value of the sample is much less clear. Careful consideration must be given to all the sources of error in a particular experiment, as well as the use to which the final data will be put, before the optimum sample thickness can be sensibly chosen. In our case, the backround is very low and well-behaved (see can be sensibly chosen. In our case, the background is very low and well-behaved (see sec. A7.1). In addition, an important use of our data was to be as input in neutron transport calculations; for deep-penetration calculations the minima in the cross section are most important. Thus, relatively large " $n$ " values seem to be called for. Such samples might, however, be too thick to give any useful information in regions where the cross section is high hence we generally ran with two different samples. The " $z$ " value for the thicker Bample was commonly $\geqslant 1 ;$ " $n$ " for the thinner sample was a factor of 2 to 4 less.
We thus had samples appropriate to cover a wide range of cross section values and in addition, the data from the two samples provided an important chect on internal consistency. (The exact " $n$ " values used are listed for each element in the main body of this report. It will be seen that even the "thin" samples are rather thicker than has been customary in this type of measurement.)

\section{A7. Corrections to the Data \\ A7.1. Background}

The background is measured by simply inserting a "shadow bar" (32 $\mathrm{cm}$ of copper plus $15 \mathrm{~cm}$ of polyethylene) in place of the transmission sample. The background count ing rate is generally less than 0.3 percent of the open beam counting rate. About half of the background is due to cosmic rays and natural room background, and the other half is associated with the linac beam. The background is flat and structureless, and quite constant during the course of a run.

We have investigated the question of whether the true background is adequately determined by this simple shadow.bar measurement. We have, for example, measured counting rates with the detector off-axis, at "long" times-of-flight between machine bursts, with the beam purposely missteered, with various combinations of shielding and beam stops, etc. We find no significant background beyond that measured with the shadow bar technique. We note that our cross section measurements tend to be rather immune to background caused by neutrons which scatter off the walls of the measurement room and return to the detector, since such an event must occur within $4 \mu \mathrm{s}$ of the beam burst (at which time our gate closes) and must give a pulse larger than a $160 \mathrm{keV}$ recoil proton.

The "black resonance" technique commonly used to measure backgrounds in the $\mathrm{eV}$ and $\mathrm{keV}$ regions can not be used in the same way in the $\mathrm{MeV}$ region, simply because the peak heights are so much lower. Nevertheless, a measurement with black (or almost black) resonances does provide a valuable check on backgr'ounds determined from shadow bar measurements. This was generally the case in our "thick" sample measurements and the results (albeit often with rather poor statistics) were consistent with our assumed background. The $2.95 \mathrm{MeV}$ resonance in carbon, for example, was studied with a quite thick sample $(n=1.2)$ for which the transmission $T$ was 2.4 pereent, and with a thinner sample $(n=0.48)$ with $T=23$ percent. The final value for the peak cross section was the same for the two samples, despite the factor of ten difference in transmission, indicating that the background was accurately known.

\section{A7.2. Dead Time}

With a low duty cycle machine (maxinum rep. rate $=720$ pulses per second) and an electronic system which will only record one count per pulse, it is difficult to and good counting statistics in each of several thousand channels in a reagonate amoun of running time. In addition to optimizing the sample thickness (sec. necessary to run at high counting rates, which unfortunately, means that large dead time corrections are required. In practice we anfortunately, means that large dead the "ore" the "open" runs, an average of one neutron per burst is detected by the "stop" detector. For this case, Poisson statisties show that the average number of neutrons actually recorded by the electronics is (1-1/e) per burst, and in the last timing channel (lowest nergy neutrons) the ratio of true counts to recorded counts is equal to $e$.

For a "one-shot" electronic systen which completely recovers between pulses, it has been shown, [14] however, that to first order the dead-time correction is a sim. 
ple, exact, analytical function which only involves explicitly measured quantities.
Specificaliy,

$$
T_{1}=\frac{R_{\mathrm{l}}}{\mathrm{I}-\left[\sum_{c=1}^{L_{1}^{-1}} \mathrm{R}_{\mathrm{d}} / S+R_{\sqrt{ }} / 2 S\right]}
$$

where $T_{1}$ is the true number of counts in channel $i ; R_{i}$ is the number of recorded counts in channel $i: S$ is the total number of start counts; and $\Sigma R$ is of recorded counts recorded counts from channel 1 to channel $(i-1)$

This is, however, only a first-order correction and is exact only to the extent that 20 minutes, as noted in section A5.) If the the course of a run. (A "run" is generally order correction which must be made nuning rate fuctuates, there is a secondminimized by taking data only when the beamerically. The second order correction is is within \pm 10 percent of a meter-relay from the ou a predetermined value. This is accomplished by driving a the the beam current varies from its original value by more than 10 percent the relay turns off the counting equipment. In practice, the linac beamerrent is meter stable enough in intensity so that it remains well within the 10 percent is generally these conditions, the second-order dead time corretion is

We have verified these expectations experime

jifferent neutron counting rates and by rexperimentally, primarily by running at active sources at counting rates and by recording "flat" timing spectra from radioctive solires at counting rates equivalent to those obtained under actual runnin trodue large corrections can be made very accurately and in roduce negligibly small errors in the final result. This is further verified by the good agreement between thick and thin sample measurements.

By using thick samples and counting at relatively high rates, in $\sim 50$ hours of

running time the statistical errors are approximately 2 percent over most of the 3500 channels.

\section{A7.3. Inscattering}

The good geometry which is intrinsic in a time-of-flight experiment almost automatically insures that the inscattering correction will be small.

The fractional change in the total cross section, $\frac{\Delta \sigma_{i}}{\sigma_{t}}$, due to inscattering is given by [15]:

where

$$
\frac{\Delta \sigma_{i}}{\sigma_{\mathrm{s}}}=\left[\frac{r_{1} r_{2}}{r_{3}}\right]\left[\frac{\sigma(0)}{\sigma_{i}}\right][f(n \sigma)]
$$

$r_{1}$ is the sample-to-source solid angle,

$r_{2}$ is the detector-to-sample solid angle,

$r_{3}$ is the detector-to-source solid angle,

$\sigma(0)$ is the scattering cross section at $0^{\circ}$, in $\mathrm{b} / \mathrm{s} x$.
In our case, the first term in brackets (called the "inscattering index" by Foster and Glasgow [16]) equals $2 \times 10^{-1}$ for our $5 \cdot \mathrm{cm}$ diameter samples. The second term is generally 0.5 or less. The last term, which is essentially a multiple scattering corre tion to the in-scattering varies betwe which is essentially a multiple scattering correc these measurements. 1 and 3 for the sample thicknesses used in mately $10^{-4}$ and mately $10^{-4}$, and is, therefore, generally ignored.

\section{A8. Summary}

In the appendix we have described the NBS system for making accurate total nts in the MeV energy region, the main body of this Mono graph consisting of detailed curves of the cross sections measured with this system. disc some of these measurements in detail, and comparisons with results from other Iaboratories.

We should like to thank Julian Whittaker for his inestimable contributions to the electronics and instrumentation. It is very doubtful that this promram succeeded without his active assistance.

\section{A9. References}

(1) Schwartz, R. B., Schrack, R. A, and Heaton, H. T., II, Proc. Symp. Neutron Standards and Flux Normalization, AEC CONF-701002, Argonne, 1llinois, p. 377 (Oct. 21, 1970).

(3) Whitt.

(4) Whitter

(5) $M$ (4)

Y.M, G. A., Smith, H. M, and Wagserman, R., IEEE Trans. Nuci. Sci. NS-14, No. 1, 443 (1967); Shin, [6] Farinelli, U., S., Glavina, C., and Rawlins, J. A., Nucl. Instr. and Meth. 58, 363 (1968).

(7) Schrack, R. A, Heaton H.

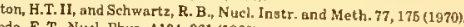

[8] Davis, J. C., and Node, F. T., Nucl. Phys. Al34, 361 (1969).

[10] Heor,

(11) Peaton, H. T, I1, Nat. Bur. Stand. (U.S) Tech, Note 516, 31 pages (Jan. 1070).

[12] Miller, D. W., Fast Neutron Physics, Part Stand, (U.S.) Monogr. 48,18 pakes (June 1952), (Interscience Publishers, New York, 1963).

(131 Rose, M. E., and Shapiro, M. M., Phys. Rev. 74, 1853 (1948) Bollinger, L. M., and Thomas, G. E., Rev. Sci. Instr. B2,
Crandall, D. G., Nucl. Instr. and Meeh. 52, 29a (1967).

1044 (1961); Kirkbride, J., Yates, E. C., and

[16] Bratenahl, A., Peterson, J. M., and Stoering, J. P., Phys. Rev. 110, 927 (1957).
(16] Foster, D. G., Jr., and Glasgow, D. W, Phys. Rev. C3, 576 (1971). 


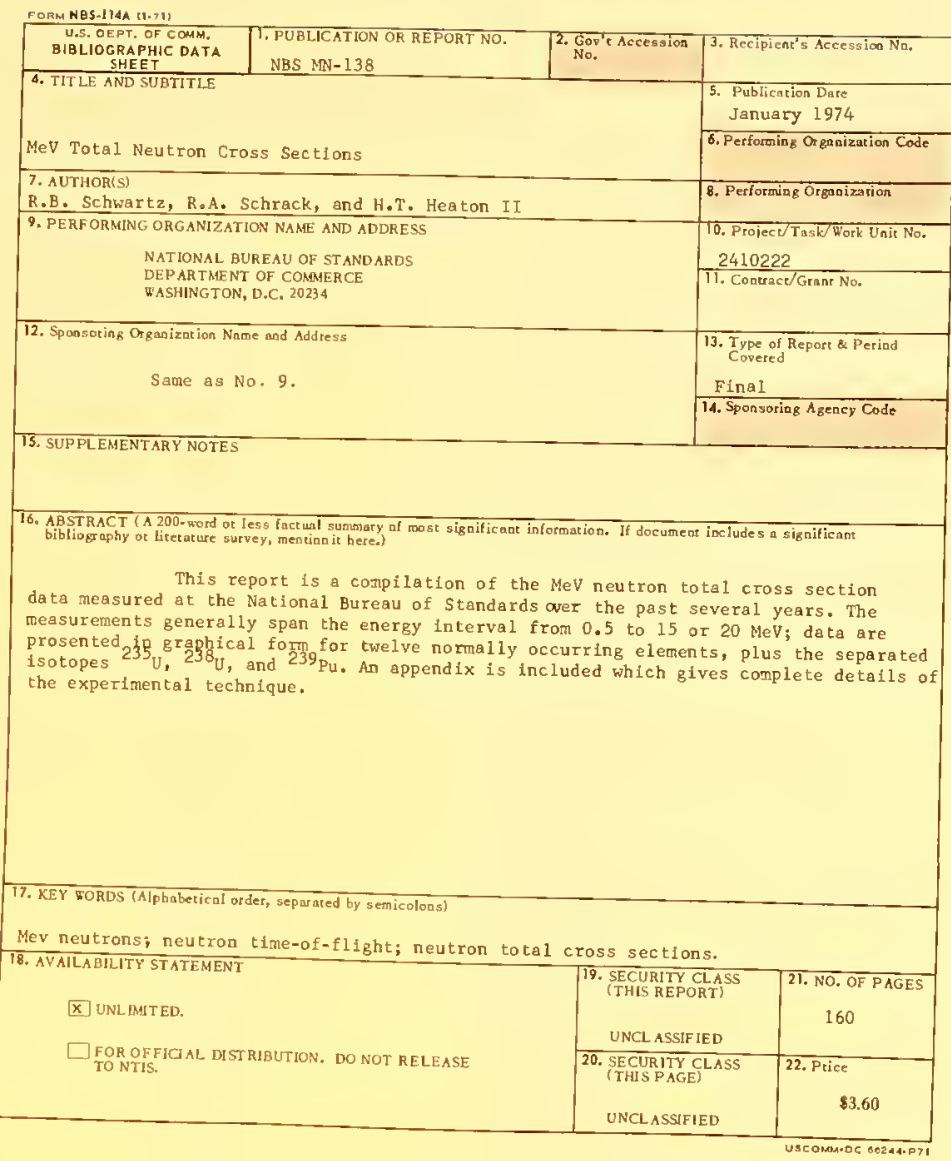




\section{NBS TECHNICAL PUBLICATIONS}

\section{PERIODLCRLS}

JOURNAL OF RESEARCH reports Nation: Burrat of Standards research and development in plyysics, mathrmatics, and chemistry. Comprehensive including laboratory data, experimental the work, and theoretical and mathematical analyses procedures with photographs, drawings, and charts Includes listings of other NBS papers as issiled.

Published in two scclions, available seprarately:

- Physics and Chemistry (Section A)

Papers of interest primarily to scientists working in playsical and This section covers a broad range of on standards of physical measurement, fuzd pon constants, and properties of matter. lssued six times a year. Aunual subscription. Domestic s17.00. For

\section{- Mathematical Sciences (Section B)}

Sundies and compilations designed mainly for the mathematician and theoretical physicist. Topics in numerical analysis theotetic theory of experiment design, borical design and programming of and chemistry, computer sysit'ms. Short numerical on coniputers and erly. Annual subscription: Domestic, $\$ 900$. Fomim, $\$ 11.25$.

\section{DIMENSIONS, NBS}

The best single source of information concerning the Bureau's measurement, rescarch. developnental, co operative, and publication activities, this montlly pubtication is dissigned for the layman and also for Chie industry-oriented individual whose daily wark - for sominate contacr with science and lechnology agers, products, chemuts, phystrists, research manexecuevivas. Annual subscription: Donestic, $\$ 6.50$; Foreign, \$8.25.

\section{MOHPERIDOIGALS}

Applicd Mathematics Series. Mathematical tables

Buildittg Seience Series. Research results, les methods, and performance eriteria of building maHals, components, systems, and structures.

Handbooks. Rrcommended codes of engineering and industrial practice (including safery condes) de veloped in conperntion with inerested industrica, prolessional oryanizations, and regulatory bodies.

Special Publications. Proceedings of NBS conierenees, bibliographies, annual report5, wall charts, pamphlets, etc.

Monographs. Major contriluntions 10 the technical literature on various subjects related to the Bureau's scientific and technical activitics.

National Standard Reference Data Series. NSRDS provides quantutative dati on the series and chemical jropertics of malerials come physical the morld's litcrature and critically evaluated.

Product Standards. Provide requirements for sizes, types, quality, and methods for testing various indusoperacivelycis. These standards are deweloped cogroups and provide ing of product characteristics for both buyers and Thes. Their use is voluntair.

Technical Notes. This series consisss of communicastions and rteorts teovering hoth otluer-arence and NBS-sponsored work) of limited or transiton inierest. Federal Information Processing Standards within the Frdernl Gosetnment for inforicheation standards adopted and promulgated undor the Public Law 89-306, and Bureare of the Budget Circular A-85 entitled, Standardization of Data Elements and Codes in Data Systems.

Consumer Information Series. Praclical informa tinn, bastd on NBS research and experience covering arcas of interest to the consumet. Fasily understandable language and illinstrations pravide uscful background knowledge for shopping in today's tech-

\section{MIBLOGRaPHIC SUESCRIPTIOH SERVICES}

The following current-awareness and literaturesurvey bibliographies are issued periodically by the Bureau:

Cryogenic Data Center Current Awareness Service (Publications and Reports of Interest in Cryogenics). A literature survey issued weekly. Annual subscription: Domestic, $\$ 25.00$.

issued quatural Gas. A literature survey $\$ 20.00$. Superconducting Devices and Materials. A literature survey issued quarterly. Annual ubscrion: \$20.00. Send subscription orders and remittances for the preceding biblioCophiment of Service, National Technical Information

Electromagnetic Metrology Current Awareness Service (Abstracts of Selected Articles of Eleasurement Techniques and Standards of Electromagnetic Quantities from D-C to cial rates for subscription: $\$ 100.00$ (Spesubscription for multi-subscription). Send Electromarnetic Center, Electromagnetics Division Bureau of Standards, Boulder, Colo sonal 
